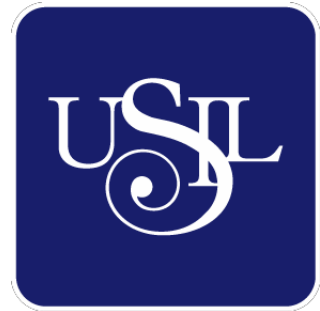

UNIVERSIDAD

SAN IGNACIO

DE LOYOLA

ESCUELA DE POSTGRADO

Maestría en Educación con Mención en Gestión de la Educación

\title{
ESTRATEGIA DE GESTIÓN PARA EL DESARROLLO DE LAS HABILIDADES INFORMÁTICAS EN LOS DOCENTES DE LA FACULTAD DE CONTABILIDAD DE UNA UNIVERSIDAD PRIVADA DE LIMA
}

Tesis para optar el grado académico de Maestro en Educación con Mención en Gestión de la Educación

\section{SOFÍA YVETTE CUBAS CERCADO}

Asesora:

Miriam Encarnación Velázquez Tejeda

Lima - Perú

2020 


\section{Dedicatoria}

A mis padres por haberme forjado como la persona que soy en la actualidad; muchos de mis logros se los debo a ustedes. La formación que me dieron con reglas y con algunas libertades, me hicieron una persona con valores. Sus motivaciones constantes me hicieron alcanzar mis anhelos. Gracias madre y padre. 


\section{Agradecimiento}

Primeramente, doy gracias a Dios, por permitirme ser un profesional en lo que tanto me apasiona, gracias a los maestros que hicieron realidad este proceso de formación.

Finalmente agradezco de manera especial, a mi asesora Miriam Encarnación Velázquez Tejeda, quien estuvo pendiente durante el proceso de investigación y redacción de mi tesis. 


\section{Índice}

Pág.

\section{Dedicatoria}

\section{Agradecimiento}

\section{Resumen}

\section{Abstract}

$\begin{array}{ll}\text { Introducción } & 1\end{array}$

Preguntas científicas 3

Objetivos 3

$\begin{array}{ll}\text { Categorías y subcategorías apriorísticas. } & 4\end{array}$

$\begin{array}{ll}\text { Justificación de la investigación. } & 4\end{array}$

Metodología de la investigación $\quad 5$

Tipo y diseño de investigación.

$\begin{array}{lr}\text { Población, muestra y muestreo. } & 6\end{array}$

$\begin{array}{ll}\text { Métodos de investigación. } & 6\end{array}$

$\begin{array}{ll}\text { Técnicas e instrumentos de investigación. } & 7\end{array}$

\section{Capítulo I}

$\begin{array}{ll}\text { Marco Teórico } & 9\end{array}$

$\begin{array}{ll}\text { Antecedentes internacionales y nacionales sobre las investigaciones } & 9\end{array}$

Fundamentación teórica sobre el aprendizaje y las habilidades 10

\section{Capítulo II}

Diagnóstico o trabajo de campo. 25

Análisis, interpretación y discusión de los resultados 25

$\begin{array}{ll}\text { Procesamiento de la información. } & 25\end{array}$

$\begin{array}{ll}\text { Proceso de categorización e interpretación. } & 31\end{array}$ 
Relaciones analíticas e interpretativas entre datos y categorías emergentes.

Conclusiones aproximativas de los análisis realizados en esta parte de la investigación

\section{Capítulo III}

Modelación, validación y aplicación de la propuesta 36

Propósito de la propuesta metodológica 36

Diseño gráfico funcional de la propuesta. 39

Desarrollo o implementación 41

Validación de la propuesta $\quad 58$

$\begin{array}{ll}\text { Conclusiones aproximativas } & 61\end{array}$

$\begin{array}{ll}\text { Conclusiones } & 63\end{array}$

$\begin{array}{ll}\text { Recomendaciones } & 65\end{array}$

$\begin{array}{ll}\text { Referencias } & 66\end{array}$

$\begin{array}{ll}\text { Anexos } & 74\end{array}$

Anexo 1. Encuesta a estudiantes

Anexo 2. Observación a clases a docentes

Anexo 3. Entrevista semiestructurada a docentes

Anexo 4. Fichas de validación

Anexo 5. Matriz de categorización

Anexo 6. Codificación y categorización de las entrevistas

Anexo 7. Ficha de validación de la propuesta metodológica

Anexo 8. Análisis estadístico de la encuesta a estudiantes 


\section{Índice de tablas}

Pág.

Tabla 1: $\quad$ Categorías y subcategorías apriorísticas $\quad 4$

Tabla 2: Componentes ejecutores e inductores de la actividad $\quad 14$

Tabla 3: Relación de expertos que validaron la propuesta 59

Tabla 4: $\quad$ Tabla de valoración de la validación 59

Tabla 5: $\quad$ Resultados de la validación integral por de los especialistas 60

Tabla 6: $\quad$ Resultado de la valoración interna y externa por criterio de expertos $\quad 61$ 


\section{Índice de figuras}

Pág.

Figura 1: $\quad$ Base gnoseológica de la actividad

Figura 2: Categorías emergentes generales resultantes del proceso del diagnóstico o trabajo de campo

Figura 3: Categorías emergentes influyentes en el problema

Figura 4: $\quad$ Esquema teórico - funcional de la propuesta metodológica modelada

Figura 5: Resultados de la validación integral 


\section{Resumen}

El objetivo de la investigación se orientó a diseñar una estrategia de gestión para contribuir al desarrollo de las habilidades de informáticas en los docentes de la Facultad de Contabilidad de la universidad privada de Lima. Es una investigación educacional de tipo aplicada realizada desde el paradigma socio crítico - interpretativo. El estudio se orienta a la búsqueda del conocimiento para hacer, para actuar, para construir, para modificar el problema objeto de estudio. En ella se destaca el carácter dialéctico al sistematizar las categorías apriorísticas y se contrasta con los datos obtenidos a través del diagnóstico de campo, que permitió analizar las categorías emergentes que originan el problema. La muestra seleccionada mediante el muestreo por conveniencia está conformada por cuatro docentes y 25 estudiantes universitarios. Como parte del estudio se emplearon diversas técnicas e instrumentos: entrevista semiestructurada, guía de observación a clases a los docentes y cuestionario a los estudiantes que permitió identificar las categorías emergentes en general y las que inciden en el problema objeto de estudio. Como conclusión general se aporta a la práctica pedagógica una estrategia de gestión para contribuir al desarrollar de las habilidades de Informáticas en los docentes y de esa manera alcanzar un mejor desempeño al dirigir el proceso de enseñanza-aprendizaje de las distintas disciplinas curriculares.

Palabras clave: Estrategias de gestión, habilidades de Informáticas, didáctica desarrolladora 


\begin{abstract}
The objective of the research was to design a management strategy to contribute to the development of computer skills in teachers of the School of Accounting of the private university of Lima. It is an educational research conducted from the socio-interpretive critical paradigm, which is oriented to the search for knowledge to do, to act, to build, to modify the problem under study. It highlights the dialectical nature of its method, given that the theoretical references are systematized, the causes that cause the problem were analyzed and a management strategy is proposed that enables the development of computer skills; in that sense, the role of practice is revalued as an evaluation criterion of knowledge. The study sample was selected through intentional non-probabilistic sampling, and is made up of four teachers and 25 students. As part of the study, various techniques and instruments were used: semi-structured interview, teacher observation guide for teachers and student questionnaire that allowed characterizing the problem. In conclusion, it is contributed to the pedagogical practice with a proposal of management strategy to develop computer skills in teachers and thus contribute to its performance to effectively facilitate the teaching-learning process that directs in its classroom with university students.
\end{abstract}

Keywords: Management strategies, computer skills, educational development 


\section{Introducción}

El mundo actual está viviendo un tiempo que se denomina "sociedad del conocimiento" y se constituye como paradigma emergente en el siglo XXI. Bajo esta óptica aparecen dos elementos que fundamentan el desarrollo estructural de las organizaciones y la sociedad: el conocimiento y la información. Al respecto, Terrazas y Silva (2013), plantean:

Entendemos el conocimiento como la apropiación y generación de un conjunto de ideas manejadas por el ser humano y que le proporcionan datos preliminares, que estructurados lógicamente permiten construir información para que se pueda tomar decisiones y actuar en consecuencia para transformar la sociedad (p. 147).

Esa perspectiva ha ganado en posición porque el conocimiento le permite al sujeto tener acceso a la información, procesarla y asumir posiciones críticas. Hoy la sociedad del conocimiento ha llevado al mundo hacia un funcionamiento más tecnológico, donde los desafíos discurren en torno al proceso de la globalización, la competitividad que ha influido en los cambios de la sociedad, donde los ciudadanos en ocasiones muestran incapacidad para producir conocimiento y asumir posiciones loables (Morín, 2011).

Es ese sentido, la educación cobra relevancia especial como fuerza emancipadora de la personalidad, al decir de Álvarez (1999) y Peñaloza (2003). Ello requiere poner en práctica los métodos, procedimientos y estrategias que revolucionen las formas de socialización y educación donde se adquieran los conocimientos y se desarrollen las habilidades de manera consciente por los estudiantes, de manera que contribuya al desarrollo de las personas para una vida social armoniosa, equilibrada, y productiva en un marco de la equidad y la justicia como ciudadano

Los estudios de La Organización de las Naciones Unidad para la Educación, La Ciencia y la Cultura (Unesco, 2013), refieren que la educación de la época actual, afronta el desafío del acceso, la integración y la calidad de la educación desde que se incorpora las TIC, al proceso de enseñanza- aprendizaje como elemento mediador para hacer más atractiva e interesan el proceso de aprendizaje a los estudiantes como un medio de enseñanza potente del que se vale el docente para hacerle más asequible el contenido y construyan los conocimientos (Alvarez, 1999 y Addine, 2013).

Al respecto, las investigaciones de Díaz (2009), Oltolina (2015) y Vega (2017), revelan que el uso de las tecnologías en la enseñanza promueve nuevos espacios y formas de orientar el aprendizaje de manera que el contenido se torna más asequible, objetivo y le permita al educando, acceder en menos tiempo a un volumen de información que debe 
asimilar. Ello lo alcanzará con la orientación del docente, al entrenarlo en cómo procesarla, asumir posiciones críticas que le ayuden a resolver los problemas de la realidad.

Se comprende que la inclusión de las TIC en la clase, no depende solo de ellas en sí, sino de otros factores como las habilidades comunicativas, científicas y didácticas, que deberán ser desarrolladas antes de incorporarlas a la docencia. Son habilidades profesionales que permiten acceder al conocimiento en condiciones favorables, al trabajar en colaboración donde todos se ayudan y aprenden a través de comunidades de aprendizaje de discusión y toma de acuerdos útiles para el bien común (Martínez, 2009).

Desde esa visión, se privilegia el uso de las TIC para mejorar la calidad educativa. como asevera la Unesco (2013), en su publicación titulada "Enfoques estratégicos sobre las TICS en educación en América Latina y el Caribe", la implementación de las TIC se debe realizar desde las políticas públicas, para facilitar las prácticas educativas y se atiendan las necesidades de aprendizaje de los estudiantes. Desde estas perspectivas, el docente deberá desarrollar las habilidades de informática en el uso de las TIC como parte de su capital intelectual y dirigir la enseñanza- aprendizaje con eficiencia.

En el Proyecto Educativo Nacional al 2021 (Consejo Nacional de Educación, 2016), se propone un programa integral para promover el uso de tecnologías como una vía para complementar la función cultural del docente en su desempeño. Asimismo, en el Plan Nacional Estratégico de Ciencia, Tecnología e Innovación para la Competitividad y el Desarrollo Humano 2006 - 2021 (Consejo Nacional de Ciencia y Tecnología, 2006), se precisa la importancia de actuar de manera coordinada con la Agenda Digital, impulsar la investigación científica, el desarrollo tecnológico y la innovación con base en las prioridades nacionales de desarrollo.

En el perfil profesional del docente universitario se precisa como exigencia profesional, el conocimiento y las habilidades para la aplicación de las Tecnologías de la Información y las Comunicaciones como herramienta y medio de enseñanza en el desempeño de su práctica pedagógica; propiciar su utilización en los entornos educativos, informáticos y tecnológicos en cualquier modalidad educativa, así como dominar las técnicas audiovisuales como vía para optimizar el aprendizaje de los estudiantes (Álvarez, 2011).

Sin embargo, en la práctica pedagógica se observa que no todos los docentes universitarios conocen o tienen la habilidad para el uso de TIC ya sea como herramienta y como medio didáctico en el proceso de enseñanza - aprendizaje, a fin de estimular la motivación y el interés en la observación, asimilación y procesamiento del contenido por los estudiantes a fin de lograr un aprendizaje de calidad en los profesionales en formación a través de las diferentes asignaturas que reciben en sus respectivas carreras. 


\section{Preguntas científicas}

\section{Pregunta general.}

¿Cómo contribuir al desarrollo de las habilidades de Informáticas en los docentes de la Facultad de Contabilidad de una universidad privada de Lima?

\section{Preguntas específicas.}

¿Cuáles son los referentes teóricos que sustentan el tema de las estrategias de gestión y las habilidades de Informática en los docentes de la Facultad de Contabilidad de una universidad privada de Lima?

¿Cuál es el estado actual del desarrollo de las habilidades de Informáticas en los docentes de la Facultad de Contabilidad de una universidad privada de?

¿Qué criterios teóricos y metodológicos se tendrán en cuenta al modelar una estrategia de gestión para contribuir al desarrollo de las habilidades de Informáticas en los docentes de la Facultad de Contabilidad de una universidad privada de Lima?

¿Cómo validar la efectividad de la estrategia de gestión modelada para contribuir al desarrollo de las habilidades de Informáticas en los docentes de la Facultad de Contabilidad de una universidad privada de Lima?

\section{Objetivos}

Objetivo general.

Diseñar una estrategia de gestión para contribuir al desarrollo de las habilidades de Informáticas en los docentes de la Facultad de Contabilidad de una universidad privada de Lima.

\section{Objetivos específicos.}

. Sistematizar los referentes teóricos que sustentan el tema de las estrategias de gestión y las habilidades de Informáticas en los docentes de la Facultad de Contabilidad de una universidad privada de Lima.

- Diagnosticar el estado actual del desarrollo de las habilidades de Informáticas en los docentes de la Facultad de Contabilidad de una universidad privada de Lima.

. Determinar los criterios teóricos y metodológicos que se tendrán en cuenta al modelar una estrategia de gestión que contribuya al desarrollo de las habilidades de Informáticas en los docentes de la Facultad de Contabilidad de una universidad privada de Lima. 
- Validar por criterios de expertos la pertinencia de la estrategia de gestión modela para contribuir al desarrollo de las habilidades de Informáticas en los docentes de la Facultad de Contabilidad de una universidad privada de Lima.

\section{Categorías y subcategorías apriorísticas.}

Tabla 1 Categorías y subcategorías apriorísticas

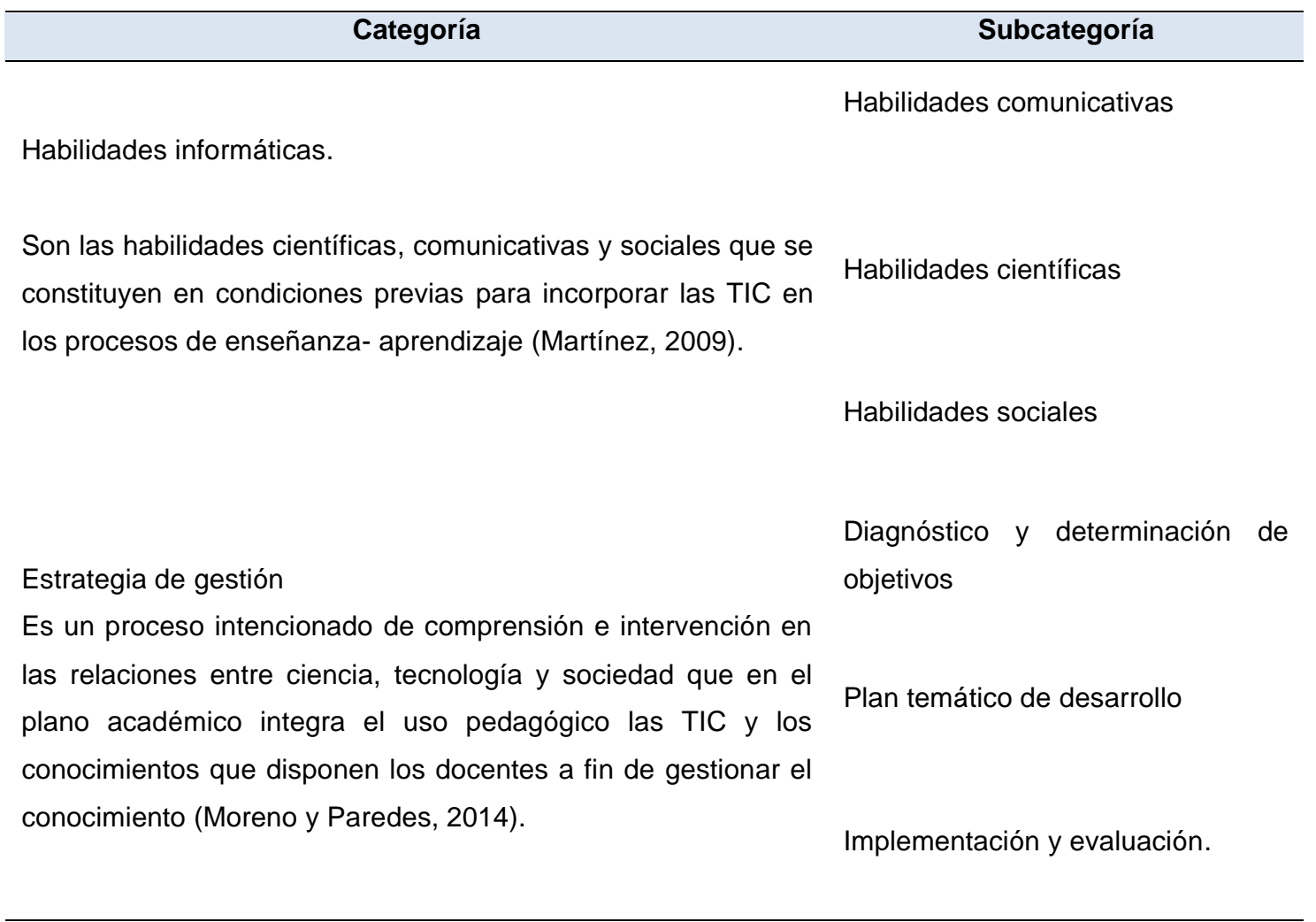

Fuente. Elaboración propia (2019).

\section{Justificación de la investigación.}

\section{Justificación teórica.}

El proceso de investigación sistematiza teóricamente los conocimientos y las habilidades de informática en genera y las que deben desarrollar los docentes como herramienta tecnológica y como medio de enseñanza para emplearla en la enseñanzaaprendizaje. El proceso de sistematización de las categorías apriorísticas servirá a la comunidad científica y pedagógica para modelar sus proyectos de gestión de las TIC en las clases. La comprensión de estas categorías abrirá camino a investigaciones posteriores que permitirán incrementar el conocimiento asociado a las herramientas tecnológicas en la educación desde las fuentes teóricas consultadas (Martínez, 2009); Moreno y Paredes (2014). 


\section{Justificación metodológica.}

El proceso investigativo llevado a cabo permitió modelar y proponer una estrategia de gestión que se sustentan en las Ciencias de la Educación y que se pone a disposición de la comunidad educativa de los docentes. La misma prioriza y contribuye al desarrollo de la capacitación del profesor para tener un mejor desempeño al orientar la enseñanzaaprendizaje utilizando las TIC y de esa manera incidir en el nivel de calidad del aprendizaje integral de los estudiantes universitarios.

\section{Justificación práctica.}

El producto resultado de la investigación consistente en la estrategia de gestión modelada que por su pertinencia se convierte en un modelo teórico- práctico pertinente donde se ponen en práctica los fundamentos de las ciencias y se incorporan como medio de enseñanza, el uso de las TIC por los docentes. La propuesta se convierte en una guía para el desempeño del docente en el aula en cuanto al cómo usar los medios audiovisuales como vía para activar el interés y se potencien los conocimientos y las habilidades informáticas al dirigir la enseñanza- aprendizaje, lo cual favorecerá el desarrollo de las competencias en los estudiantes universitarios.

\section{Metodología de la investigación}

Tipo y diseño de investigación.

La investigación responde al paradigma socio- crítico interpretativo, el enfoque es cualitativo y se concreta en una investigación educacional de tipo aplicada. El estudio se orienta a la búsqueda y exploración del conocimiento para hacer, para actuar, para construir, para modificar el problema objeto de estudio (Cisterna, 2005). El proceso investigativo partió de la observación, e interpretación de la problemática por la investigadora en su práctica docente del aula, y mediante el método científico busca la respuesta para contribuir al cambio. En ella destaca el carácter dialéctico al basarse en las funciones metodológicas de los niveles del conocimiento en su relación entre el ser y el pensar, en la objetividad de la verdad y el papel de la práctica como criterio valorativo del conocimiento.

Mediante la aplicación del método científico se sistematizan los referentes teóricos, se analizaron las causas que originan el problema y se propone una estrategia de gestión del docente sobre el uso de las TIC en la enseñanza- aprendizaje para contribuir al rol protagónico de los estudiantes en la asimilación activa, analítica y reflexiva que los lleva a un aprendizaje de calidad que incide en las formas de pensar, sentir y hacer. 


\section{Población, muestra y muestreo.}

La población objeto de investigación está conformada por 35 docentes de distintas especialidades y 567 estudiantes de la Facultad de Contabilidad y Finanzas de una universidad privada de Lima.

La muestra seleccionada por muestreo no probabilístico por conveniencia la integran cuatro docentes de distintas especialidades y 25 estudiantes de la Facultad de Contabilidad y Finanzas de una universidad privada de Lima.

Las unidades de análisis la conforman los docentes de distintas especialidades de la carrera de Contabilidad, los estudiantes, las fuentes teóricas especializadas y de los documentos normativos de la Facultad de Contabilidad y Finanzas de una universidad privada de Lima.

\section{Métodos de investigación.}

Los métodos teóricos para emplear en el presente estudio son:

\section{Método analítico-sintético.}

El análisis y la síntesis funcionan como una unidad dialéctica; el análisis se produce mediante la síntesis de las propiedades y características de cada parte del todo, mientras que la síntesis se realiza sobre la base de los resultados del análisis (Rodríguez y Pérez, 2017). Se aplicó para analizar las distintas fuentes teóricas y al procesar los instrumentos del proceso del diagnóstico de campo.

\section{Método histórico lógico.}

Este método estudia el objeto investigado de forma lógica, los antecedentes relacionados con el objeto de estudio y de esa manera facilitar la identificación de supuestos teóricos y conceptuales con respecto a ella (Díaz, 2009). Se empleó para conocer los antecedentes del problema relacionado a las habilidades informáticas a fin de elaborar los fundamentos teóricos y metodológicos de la propuesta de solución al problema.

\section{Método inductivo-deductivo.}

Es un método de inferencia basado en la lógica y relacionado con el estudio de hechos particulares (Rodríguez, 2005). Se usó durante la observación de la práctica pedagógica a los docentes, al analizar la información recogida y al hacerlas inferencias y deducciones para comprobarlas o explicar sus consecuencias lógicas y comparar la teoría con los datos empíricos.

\section{Método de modelación.}

Según Valle (2007), la modelación debe tener cierta analogía estructural y funcional con el objeto de investigación a fin de constituirse en fuente de adquisición de nuevos 
conocimientos. Se empleó para modelar la estrategia de gestión a partir de los fundamentos teóricos y el análisis de las categorías emergentes que inciden en el problema y contribuir a su transformación.

\section{Método estadístico.}

A través de este método se organiza la información cuantitativa del estudio, específicamente aquellos datos obtenidos mediante las encuestas de tipo cuestionario. Este método consiste en una secuencia de procedimientos para el manejo de los datos cuantitativos, ya que permite interpretar datos cuyo carácter esencial es la variabilidad de los datos tratados (Hernández, 2012).

\section{Técnicas e instrumentos de investigación.}

Durante la investigación se emplearon distintas técnicas e instrumentos de investigación que permitieron acopiar la información requerida, entre ellos se encuentran:

\section{Observación a docente en clase.}

La observación tuvo el propósito de recopilar información acerca de las estrategias de gestión de la TIC que utiliza el docente durante el desarrollo de su sesión de enseñanza. La observación conduce al registro de respuestas tal y como se presentan en los sentidos, motivando los problemas y llevando a la necesidad de sistematizarlos (Rodríguez, 2005). Para ello se empleó como instrumento una guía de observación.

\section{Encuestas a los estudiantes.}

Se aplicó a los estudiantes un cuestionario para conocer las estrategias de gestión de los docentes para desarrollar habilidades informáticas. Como señala Martínez (2004), el propósito de la entrevista de investigación cualitativa es obtener descripciones del mundo vivido por las personas entrevistadas, con el fin de obtener interpretaciones fidedignas del significado que tienen los fenómenos descritos.

\section{Criterio de expertos.}

De acuerdo con Escobar y Cuervo (2008), el criterio de expertos o juicio de expertos es un método que se define como "una opinión informada de personas con trayectoria en el tema, que son reconocidas por otros como expertos cualificados en este, y que pueden dar información, evidencia, juicios y valoraciones. Con este fin se utilizó para validar la efectividad de estrategia de gestión propuesta para contribuir a desarrollar de las habilidades de informáticas en los docentes de la Facultad de Contabilidad de la universidad privada de Lima.

La tesis se estructura en tres capítulos.

Capítulo I comprende la sistematización teórica de las categorías y subcategorías apriorísticas desde posiciones holísticas para dar sustento y empoderar al investigador en 
los aspectos cognitivos relacionados a la investigación.

Capítulo II se encuentra el diagnóstico o trabajo de campo para conocer el estado actual de las habilidades informáticas de los docentes y las estregáis de gestión utilizadas para desarrollar el proceso de enseñanza. A partir de los resultados de los instrumentos se identificó las categorías emergentes.

Capítulo III se modeló la estrategia metodológica, desde los fundamentos científicos: socioeducativo, psicológico, pedagógico y curricular; se ponen ejemplos de las exigencias de las actividades de aprendizaje, la dosificación de una unidad didáctica, ocho talleres, formatos de evaluación formativa, la implementación de talleres de capacitación docente. La validación de la misma por el método de criterios de expertos para su puesta en práctica.

Aspectos finales: Se presentan las conclusiones como resultado del proceso de investigación, las recomendaciones, las referencias y los anexos. 


\section{Capítulo I \\ Marco Teórico}

\section{Antecedentes internacionales y nacionales sobre las investigaciones}

Al revisar las investigaciones internacionales y nacionales sobre el desarrollo de las habilidades informática como medio de enseñanza, se constató el siguiente resultado.

\section{Antecedentes internacionales.}

En el campo internacional, Díaz (2009) realizó una tesis de maestría titulada, Las competencias TIC y la inclusión de estas por los docentes de la Universidad Católica del Maule, con el objetivo de determinar la relación del nivel de competencias TIC de los docentes y el grado de integración del aprendizaje. El estudio es cuantitativo, de diseño correlacional. La muestra la integraron 207 docentes de la Universidad Católica del Maule, a quienes les aplicaron un cuestionario con respuestas Likert. Concluyó el estudio indicando que en medida que las competencias en el uso de estas tecnologías aumentan, también lo hacen la integración de estas en la enseñanza de los docentes.

Por su parte, Oltolina (2015), realizó una tesis de Maestría titulada, La formación de competencias digitales de estudiantes de profesorados universitarios, cuyo objetivo se orientó a demostrar las competencias digitales. La investigación es de tipo aplicada con diseño pre experimental. La muestra constituida por 24 estudiantes, a quienes se les aplicaron distintos cuestionarios que reveló una información objetiva. Los resultados hacen concluir que las actividades con el uso de esos recursos permiten mejorar en calidad del aprendizaje en los estudiantes y el nivel de logro educativo.

Mora (2014), desarrolló una tesis doctoral titulada, Habilidades en el uso de herramientas informáticas en la investigación: estrategia didáctica para la unidad curricular proyecto el PNF en Mecánica, con el objetivo proponer una estrategia didáctica para el desarrollo de habilidades en el uso de herramientas de informáticas de apoyo a la investigación. La investigación es de tipo mixta, iniciando con un estudio transversal exploratoria para luego pasar a otra de tipo evaluativo. Concluyó que la propuesta presentada es efectiva al estimular el desarrollo de la reflexión, como vía para autorregular la construcción de conocimientos y habilidades particulares en torno al objeto que se estudia. En ese sentido consideró que toda propuesta que busca aplicar la tecnología en la práctica docente debe ser siempre flexible y contextualizada.

\section{Antecedentes nacionales.}

Coronado (2015), llevó a cabo una tesis de maestría titulada Uso de las TIC y su relación con las competencias digitales de los docentes de la Institución Educativa № 5128 del distrito de Ventanilla - Callao, cuyo objetivo se orientó a determinar la relación entre uso 
de las TIC y competencia digital de profesores de escuela elemental. El estudio es cuantitativo, diseño correlacional, la muestra integrada por 91 docentes y estudiantes. Los resultados al concluir revelaron que existe relación entre el uso de las TIC y las competencias digitales demostradas por los profesores, es decir, a medida que el docente utiliza los recursos tecnológicos en la clase, aumentaron sus competencias digitales.

Gonzales (2015), realizó una tesis de maestría titulada, Eficacia del uso de herramientas informáticas básicas en el aprendizaje significativo de estudiantes del programa de estudios básicos de la Universidad Ricardo Palma. El objetivo es determinar la influencia del uso de herramientas informáticas básicas en el aprendizaje significativo de los estudiantes. La investigación es cuantitativa de nivel explicativa, siendo la muestra 119 estudiantes del programa de estudios básicos de la universidad, a quienes se les aplicaron cuestionarios para medir las variables. Los resultados permiten concluir que si existe influencia de los conocimientos de las herramientas informáticas básicas (uso del ordenados e internet), en el aprendizaje significativo de los estudiantes.

Otro estudio realizó Vega (2017), al desarrollar una tesis de maestría titulada. Uso de las TIC y su influencia con la enseñanza - aprendizaje del idioma inglés en los estudiantes del I y II ciclo de la Escuela Académico Profesional de la Facultad de Educación Universidad Mayor de San Marco-Lima, tuvo como objetivo explicar la influencia de las tecnologías de la información y la comunicación en la enseñanza-aprendizaje. El estudio es cuantitativo de nivel descriptivo y diseño correlacional. La muestra la conformaron 30 estudiantes a quienes les aplicaron un cuestionario para constatar el nivel de desarrollo de los conocimientos y sus habilidades. Las conclusiones determinaron que los medios didácticos y tecnológicos influyeron en la calidad de la enseñanza-aprendizaje.

El análisis de las investigaciones revisadas ha permitido corroborar que el dominio y empleo por el docente de las TIC estimula el desarrollo de las capacidades y las competencias profesionales al dirigir la enseñanza- aprendizaje y en consecuencia se eleva el nivel de conocimientos y el desarrollo de las habilidades en los estudiantes.

\section{Fundamentación teórica sobre el aprendizaje y las habilidades}

Diversos teóricos que han estudiado el aprendizaje lo han descrito como sinónimo de cambio o transformación, diferenciándose más en aquellos aspectos que describen el objeto de dicha transformación o la manera como se producen.

Al respecto, Gagné (1965), hace alusión al cambio que se produce a nivel aptitudinal aislando procesos de orden madurez en dicho proceso. Por su parte, (Hilgard, 1979), sostiene que lo que cambia son las actividades externas mediante las cuales el individuo reacciona a esos estímulos que proceden del medio 
Desde un panorama más cognitivo, Piaget (1981), sostiene que aprender es construir conocimientos, ya sea por medio mecanismos internos (asimilación, acomodación y organización), o externos (interacción sujeto-objeto), siendo la condición que el sujeto se halle enfocado en las actividades que realiza. Nótese que estas concepciones alcanzan solo al sujeto que aprende y a la conexión que establece con el objeto y los procesos implicados, obviando la esfera motivacional y la influencia del medio.

Otra posición aporta, Ausubel (1983), con su teoría del aprendizaje significativo. Con ello enfatiza que este es un proceso individual activo, en el que el sujeto aprende al relacionar los saberes previos con la nueva información, si está bien organizada para ser asimilada y entendida. En esa interacción el sujeto conoce qué es lo que aprende, cuál es su valor, su importancia, lo relaciona con la realidad, asume posiciones, lo aplica y le da sentido y por ello es un aprendizaje significativo.

Estos autores asumen posiciones cognitivistas, al referir que el aprendizaje se produce debido al conflicto cognitivo, cuando contrasta los conocimientos previos con la nueva información. Enfatizan que al aprender se realizan estas operaciones, a fin de organizar la información, asimilarla y entenderla y transformar las estructuras. Es así que se produce, el aprendizaje significativo, al poder valorar lo aprendido, evaluar su pertinencia, utilidad, aplicarla y sobre todo hallarle sentido. En todo caso, la condición es que el sujeto active los saberes previos, le dé importancia a lo que aprende, sabe cómo manejar la información, la integra, descubre y la aplica a la realidad en la solución de la tarea (Bruner, 1988).

En tal sentido, Jarvis (2006), refiere que el aprendizaje es el proceso donde los individuos interpretan y transforman su pensamiento, la experiencia en conocimientos, destrezas, actitudes, valores, creencias, emociones y sensaciones. Como se puede observar, se define el aprendizaje bajo la estructura de procesos, por lo que es necesario insumos previos, que en este caso viene a ser la experiencia sensible, las cuales serán sometidas a una serie de operaciones o actividades de orden cognitivo a fin de obtener resultados, los cuales vendrían a ser los conocimientos, lo cual es comparten (Addine, 2004; Castellanos, García y Reinoso, 2007; González, 2008; Ortiz, 2015 y Tobón, 2013).

Una posición teórica integral aporta, Vygotsky (1987), al aseverar que el aprendizaje es un proceso social (interpersonal) e individual (intrapersonal); es a través de la relación del sujeto con el objeto y con los otros sujetos donde se da la apropiación activa y consciente del conocimiento, desarrollándose habilidades y actitudes en un contexto sociohistórico concreto.

En ese orden de ideas, (Castellanos et al. 2007), precisa que el aprendizaje es un proceso dialéctico en el que, como resultado de la práctica, se producen cambios 
relativamente duraderos y generalizables, y a través del cual el individuo se apropia de los contenidos y las formas de pensar, sentir y actuar construidas en la experiencia sociohistórica con el fin de adaptarse a la realidad y transformarla.

Desde estas perspectivas, Parra (2006), González (2008) y Ortiz (2015), enfatizan que el aprendizaje no solo se da a partir de los procesos internos en la mente del individuo cuando se interrelaciona con el objeto, sino que también con los otros sujetos que comparten el mismo espacio social. En esa interrelación los sujetos amplían y enriquecen los saberes y las formas de pensar, sentir y actuar construidas en la experiencia sociohistórica con el fin de adaptarse a la realidad y transformarla para el bien común.

En resumen, el aprendizaje es un proceso complejo y dialéctico como afirman: Gonzales (2003), Castellanos et al. (2007), Froufe (2011), Rico, Santos y Martín (2013 y Ortiz (2015), que no debe maximizar lo cognitivo, lo intelectual, lo informativo, los saberes, lo afectivo- emocional, lo ético y lo vivencial, y el saber hacer en la medida que el sujeto que aprende transforma la realidad, influye en su propia transformación. Con ello se producen cambios a nivel cognitivo, conductual y procedimental al interactuar con la realidad expuesta. Según Parra (2006), esto se produce a través de los procesos de construcción y reconstrucción de la actividad, por lo que el aprendizaje nunca concluye.

\section{La actividad de aprendizaje y el desarrollo de las habilidades.}

Acerca de la actividad, Vygotsky (1987), expresó que es una categoría psicológica que expresa la síntesis de lo ideal y lo espiritual del sujeto. Aseveró que, en la interacción entre el sujeto y el objeto, media la actividad y la comunicación como elementos esenciales en el desarrollo de la personalidad.

Al respecto, Pupo (2006) refiere, la actividad alude el modo de existencia, cambio y transformación de la realidad social. Por lo tanto, la actividad es un proceso mediante el cual el sujeto interactúa con el medio que lo rodea incluyendo a otros sujetos, incidiendo en él, transformando y al mismo tiempo recibiendo sus influencias que en mayor o menor medida también transforman al propio sujeto.

El sujeto en su interacción social realiza distintos tipos de actividades, como es la actividad de aprendizaje. Al respecto, Brito y González (1987) y Silvestre y Zilbersteins (2002), refieren que es el proceso mediante el cual el educando, respondiendo a sus necesidades, se relaciona con la realidad con determinada actitud hacia ella como pueden ser sus intereses y motivaciones.

Al respecto, Alonso, Gallego y Honey (1999) asevera que este tipo de actividad es específica en el ámbito educacional y se orienta a la transformación de la personalidad integral de los estudiantes, en función de los objetivos previstos. 
En ese sentido, Solórzano y García (2013), manifiestan que la actividad de aprendizaje es social, se potencia con la interacción en redes de aprendizaje y la conexión a nodos de esas redes. los contextos ricos en interacciones requieren de marcos conceptuales, por esa razón, en este trabajo se conciben las comunidades virtuales desde el marco conceptual de la teoría de la actividad y el modelo del aprendizaje expansivo como fenómeno histórico que supone un cambio cultural, un movimiento histórico de lo simple a lo complejo y de lo abstracto a lo concreto, y que tiene un carácter social (Froufe 2011; Ortiz 2015).

Desde esta óptica, el proceso de enseñanza - aprendizaje es la vía esencial para el tratamiento del contenido y para lograr en los estudiantes el desarrollo de los conocimientos, las habilidades, los hábitos, las normas, las relaciones interpersonales y la práctica de los valores actitudinales que debe formar parte del contenido u objeto de estudio, en estrecho vínculo con el resto de las actividades docentes que se realizan en la clase (Feo, 2010; Rico et al, 2013 y Addine, 2013).

De este modo la enseñanza- aprendizaje es un proceso organizado, planifica y dirigido a formar y desarrollar al educando a través de la comunicación asertiva y una actividad exigente como un proceso dinámico y complejo de ejercicios de análisis y diálogo en el que debe darse el tránsito del nivel logrado en el estudiante hacia el que se aspira, vinculando el contenido del aprendizaje con la práctica social, las experiencias y vivencias para estimular la valoración axiológica del estudiante.

Para lograr la eficiencia en el aprendizaje es preciso que el docente identifique las necesidades y potencialidades del estudiante, estructure el proceso de enseñanzaaprendizaje de forma que promueva su protagonismo. Para ello deberá concebir un sistema de actividades exigentes, que partan de lo conocido a lo desconocido, que se conozca el objetivo a lograr, cómo lograrlo y para qué.

De esa manera se potenciará en los estudiantes la motivación y los intereses para promover el tránsito del nivel real, al potencial para estimular su desarrollo integral (Vygotsky 1987; Collazo y Puentes, 2001; Castellanos et al; 2007; Pimienta 2012; Rico et al. 2013).

El docente debe tener en cuenta estructura de la actividad de estudio según sus componentes ejecutores e inductores (Leontiev, 1989). 
Tabla 2

Componentes ejecutores e inductores de la actividad

\begin{tabular}{lll}
\multicolumn{1}{c|}{ Componentes ejecutores } & \multicolumn{1}{c}{$\begin{array}{c}\text { Componentes inductores } \\
\text { (motivos, intereses, } \\
\text { necesidades) }\end{array}$} \\
\hline $\begin{array}{l}\text { Actividad } \\
\text { Acciones }\end{array}$ & $\longrightarrow$ & $\begin{array}{l}\text { Objetivo principal } \\
\text { Objetivos subordinados } \\
\text { Operaciones }\end{array}$ \\
& $\longrightarrow \begin{array}{l}\text { No tienen objetivo, dependen de } \\
\text { las condiciones existentes en el } \\
\text { contexto o sujeto. }\end{array}$ \\
\hline
\end{tabular}

Fuente. Elaboración propia (2019).

Como se puede apreciar, lo que diferencia una actividad de otra es el objetivo que guía la misma, la materia, el contexto y las características de los estudiantes como es la motivación, el interés, la orientación que posea para su realización y las necesidades del educando.

En la interacción del sujeto con la actividad emergen las habilidades como resultados de las acciones que debe aplicar de manera permanente. Se hace necesario que los estudiantes realicen distintos ejercicios en interacción colaborativa con sus compañeros donde socialicen ideas, puntos de vistas, se ayudan mutuamente y se potencian los saberes conceptuales, procedimentales, actitudinales y en general la formación integral como precisó Vygotsky (1987), Castellanos et al; 2007; Aguilera y Ortiz, 2008).

Al desarrollar la clase, el docente debe aplicar métodos, procedimientos problematizadoras y heurísticos, así como medios de enseñanza audiovisuales variados que propicien la observación, el análisis, la síntesis, la reflexión crítica del contenido, de manera que estimule en el estudiante el desarrollo de las habilidades a través de la actividad cognoscitiva, práctica y valorativa del contenido a fin de que traduzca en el saber hacer de forma integral (Silvestre y Zilbersteín, 2002; Castellanos et al; 2007; Díaz y Hernández, 2010; Tobón, 2013 y Addine 2013).

\section{¿Qué es la habilidad?}

Uno de los especialistas clásico en los fundamentos de las habilidades es, Leontiev (1989), quien precisa que estas son formaciones de corte psicológico a través del cual el sujeto manifiesta concretamente una actividad. Congruente con ese punto de vista, Pino, (2012), añade que la habilidad es el resultado de la ejecución de una acción con alto nivel de dominio por el sujeto.

En ese orden de ideas, Marqués (1999), sostienen que los estudiantes pueden evidenciar las habilidades de diferentes modos, ya sea aplicando los conocimientos por medio de las acciones conocidas y que al operacionalizarla y ejercitarlas activamente a 
través de una actividad variada, experimentan, extrapolan o elaboran nuevas combinaciones sobre la base de las experiencias adquiridas al ejecutar la tarea.

En tal sentido, Álvarez (1999) refiere que, la habilidad forma parte del contenido o el saber teórico del contenido y se expresa en un lenguaje didáctico a partir de un sistema de acciones y operaciones que debe demostrar y orientar el docente, para que el educando las pueda poner en práctica para alcanzar un objetivo.

Distintos especialistas, como Marqués, (1999), Zilbertein y Silvestre (2002), Froufe (2011) y Rico et al. (2013), aseveran que las habilidades son formaciones psicológicas que se manifiestan concretamente durante el desarrollo de la actividad, y de esa forma se elaboran, transforman, crean, resuelven circunstancias y problemáticas de forma autorregulada por el sujeto.

Desde la perspectiva psicológica la habilidad tiene su estructura que se relaciona con la estructura de la actividad. Al respecto Leontiev (1989) precisa que: Lo más importante que distingue una actividad de otra, es el objeto de la actividad que parte de la necesidad; sea el objeto de la actividad material o ideal, es el que motiva al sujeto a incidir sobre él para lograr un objetivo; y las acciones mediante las cuales se realiza la actividad constituyen sus componentes inductores y ejecutores.

De ese modo se comprende que la habilidad tiene una estructura conformada por un sistema de acciones y operaciones, mediante las cuales se manifiesta el dominio de determinados conocimientos, con un objetivo definido ya sea resolver un problema o sencillamente ejecutar una tarea. Por otro lado, es necesario considerar que toda acción, sea cual fuere el contexto en el que se ejecute, es y será siempre un hecho de naturaleza psíquica (Zilbertein y Silvestre, 2002 y González, 2008).

En ese orden de ideas, Marqués (1999) y Bernardo (2007) coinciden en que la habilidad es el grado superior de asimilación de los procedimientos para resolver las tareas o ejercicios de aprendizaje por el estudiante durante el proceso de aplicación de los conocimientos.

Desde esas perspectivas, la estructura de la habilidad está conformada por componentes ejecutores y componentes inductores sustentados en la base gnoseológica, referida a los conocimientos asociadas a cualquier habilidad y la integran las experiencias previas, conceptos científicos, o la combinación de ambos con otros elementos gnoseológicos. Lo relevante es destacar que dominar una habilidad implica utilizar conocimientos, cuya organización pueda ser simple o compleja matizada por funciones psicológicas de carácter afectivo-volitivas; las emociones, los sentimientos, los intereses, las actitudes y las decisiones (Marqués, 1999 y Ortiz, 2015). 
Según el análisis realizado, los componentes ejecutores de la habilidad, hacen referencia a las acciones y las operaciones, que se organizan en distintos niveles de complejidad y puede ser de naturaleza simple cuando se atienden operaciones; medianamente complejas, cuando se atienden acciones complejas en la actividad. Dependiendo de su naturaleza la habilidad, puede estar expuesta a cambios sobre todo si en ella influye el contexto.

En los componentes inductores (motivo, objetivo) se insertan matices de formaciones afectivo-volitivos, como se indicó anteriormente (González, 2008 y Ortiz, 2015). Debido a ello, en la ejecución de la habilidad no solo se manifiesta la asimilación de conocimientos, lo cual es esencial, sino también diversos rasgos psicológicos intelectuales tales como la disposición, decisión, seguridad, entre otras.

\section{Base gnoseológica}

(Conocimientos)

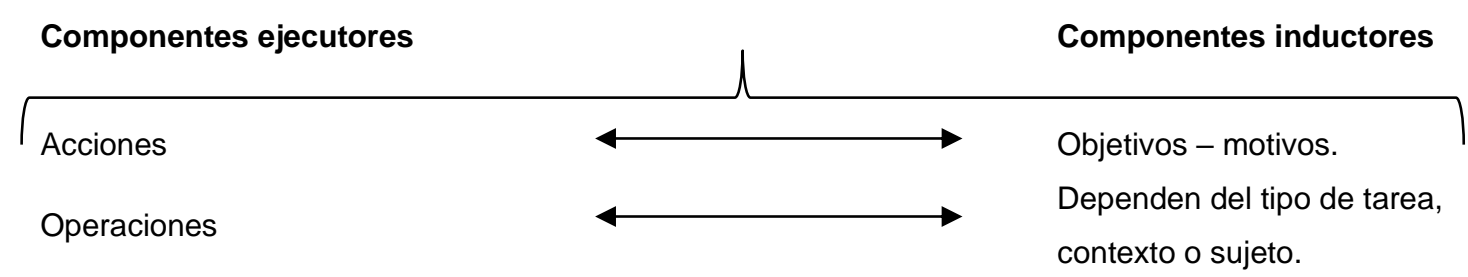

Figura 1. Base gnoseológica de la actividad. Fuente. Elaboración propia (2019).

El conocimiento de la estructura de la habilidad por el docente es uno de los requerimientos esenciales para su desempeño efectivo en el proceso de enseñanzaaprendizaje. Al ejercitar las acciones y las operaciones de una habilidad, conduce a la asimilación integral del contenido y el desarrollo de la habilidad que debe responder al saber, saber hacer y al cómo actuar de forma integral propios de la competencia (Leontiev, 1989; Marqués, 1999; Zilbertein y Silvestre, 2002; Castellanos et al; 2007; Tobón, 2008).

En resumen, la estructura de la actividad sirve como fundamento a la estructura de habilidades, al poseer el conocimiento como base gnoseológica, la acción y la operación como factores ejecutores y los motivos y objetivos como componentes inductores; la actividad se manifiesta en dos planos: el externo en el cual se enmarcan las habilidades prácticas y el interno para las habilidades intelectuales; ambas poseen la misma estructura, partiendo de que la actividad es su fundamento (Álvarez, 1999, Marqués 1999; Gonzales, 2008 y Pino, 2012). 


\section{Reflexiones teóricas sobre las habilidades de informáticas.}

Con el desarrollo de la Informática, se hace necesaria la superación permanente sobre esta herramienta tecnológica que cada día se perfecciona más y surgen nuevos avances que minimiza el tiempo, reduce los espacios y permite acceder a la información en milésimas de segundo. Para usarla con eficiencia se deben desarrollar las habilidades de informática en el uso de las Tecnologías de la Información y las Comunicaciones, sobre todo en el campo educativo, donde la integración de estas en los procesos de enseñanza y aprendizaje es uno de los mayores desafíos educacionales (Valencia, et al., 2016).

En tal sentido, se hace necesario abordar tres posturas para poder definir la Informática como disciplina científica: es considera da como un campo o ciencia emergente donde concurren distintas disciplinas; otro punto de vista la identifica con la computación; y una tercera, la define como una ciencia de la información (Cañedo, Ramos y Guerrero, 2005).

Al considerar su uso social, es la primera fundamentos la que cobra mayor relevancia, pues la concepción de la informática siembre la ubicará como ciencia que permite transformar la información, bien sea por parte del procesamiento en las tecnologías de información como por los efectos de la comunicación. En efecto, la relación que existe entre sociedad de la información y sociedad del conocimiento crea escenarios propicios que permiten emprender investigaciones y producir conocimiento con el fin de lograr mejores estándares de calidad que promuevan el desarrollo tecnológico y la innovación para el bienestar y progreso de la humanidad (Pérez, Mercado, Martínez y Mena, 2018).

Desde esta óptica, Leiva (2006) define Informática como un cuerpo de conocimiento que trata el análisis, diseño, implementación, eficiencia y aplicación de los procesos que transforman la propia información, evidenciando así una perspectiva dialéctica.

En ese entendido, las investigaciones de Oltolina (2015) y Vega (2017), revelan que estos procesos tienen carácter automático y racional, en vista que son las máquinas quienes recopilan, procesan y presentan la información, aunque ese procesamiento se lleva a cabo bajo la lógica de la razón humana. De esta manera, a través de la informática se obtiene información por medios automáticos, razón por el cual estas competencias involucran habilidad para recopilar, procesar y presentar la información a través de la computadora.

Como se aprecia, la asunción de esta competencia implica cambios en la concepción curricular para potenciar en el estudiante los modos de actuación del profesional informático y en los profesores de las distintas disciplinas que deben hacer uso de este recurso audiovisual para fortalecer el proceso de aprendizaje y elevar la eficiencia (Addine, 2013 y González, 2016). 
De ese modo se requiere desarrollar las competencias profesionales en el campo de la didáctica para saber cómo usarlas en la clase. Al respecto, los estudios revelan que, las competencias de informáticas forman un conjunto de conocimientos, habilidades, disposiciones y conductas que capacitan a los individuos para saber cómo funcionan las TIC, para qué sirven y cómo se pueden utilizar para conseguir objetivos constructivos (González, 2016, Santiesteban y Molina, 2018).

Al respecto, Martínez (2009), expresa que, es un proceso que implica el saber, cómo funcionan las TIC y sobre todo, conocer cuál es su uso ante las diversas situaciones de aprendizaje. Enfatiza que las habilidades informáticas se constituyen en habilidades comunicativas, científicas y sociales (Santiesteban y Molina, 2018).

Como se aprecia en el análisis realizado, desarrollar las habilidades de informáticas no solo supone el conocimiento en sí, sino de otras habilidades de orden cognitivo, afectivo, motivacional y de gestión del conocimiento para determinar en qué momento usarla y con qué objetivo. En ese sentido, Maldonado (2006) señala que las habilidades de informática están relacionadas con:

. El desarrollo del pensamiento instrumental: habilidades cognoscitivas, la capacidad de comprender y manipular ideas y pensamientos.

. Capacidades metodológicas para organizar procesos: ser capaz de organizar el tiempo y las estrategias para el aprendizaje, tomar decisiones o resolver problemas

- Destrezas tecnológicas relacionadas con el uso de maquinaria, destrezas de computación y gerencia de la información y, destrezas lingüísticas tales como la comunicación oral y escrita o conocimiento de una segunda lengua.

No se puede perder de vista que las habilidades de informática se adquieren a partir de la apropiación de un conocimiento teórico y de las actitudes que posibilitan a las personas o grupos a utilizar de manera eficiente y eficaz la crítica y ética, las tecnologías de la información y la comunicación como un medio para acceder a información con fines académico, científico, profesional, laboral, cultural, político, social, de entretenimiento, etc. y a recursos/espacios de aprendizaje mediados por estos medios de enseñanza(Uribe,2008).

Por otro lado, Romero (2006), señala que las habilidades informáticas con fines específicos de la Informática, se consideran como un conjunto de destrezas enfocadas en el manejo de la información, uso y aplicación de las herramientas informáticas, el dominio de las herramientas, el manejo semántico adecuado, la identificación y operación de patrones y el reconocimiento de ambientes de trabajo.

De ese modo, las características de las habilidades informáticas, según (UribeTirado, 2010) son las siguientes: Se componen de conocimientos y actitudes que posibilitan 
a las personas o grupos a utilizar de manera eficiente y eficaz, crítica y ética, las TIC. Es un medio para acceder a información de carácter académico, científico, profesional, laboral, cultural, político y social; Facilita el acceso a los recursos o espacios de aprendizaje mediados por TIC.

Su desarrollo implica el uso de computadores, programas de software, herramientas y servicios de Internet, redes, plataformas virtuales de aprendizaje, entre otros y. E desarrollo de estas habilidades implica unos procesos de enseñanza-aprendizaje que buscan facilitar lo que se ha denominado alfabetización digital.

Al concluir el análisis de la categoría apriorística, habilidades de informática, ha permitido asumir como autor de base a Martínez (2009), por considerar su definición integradora y ser coherente con los objetivos de la investigación que se presenta. Desde esta concepción teórica de identificaron las subcategorías apriorísticas: habilidades comunicativas; habilidades científicas y habilidades sociales.

Habilidades comunicativas. Es el proceso mediante el cual el docente expresa el pensamiento con coherencia para utilizar de forma óptima las competencias comunicativas: vocabulario en función a la temática, capacidad de recursos expositivos y de redacción (Batista, 2011). La competencia comunicativa, implica el dominio del contenido, las habilidades y el discurso acorde al contexto comunicacional, así como una actitud apropiada que garantice la eficacia de la comunicación (Moyá, 2016). Su desarrollo, integra un permanente aprender para poder proyectar su enseñanza estratégica en diversas situaciones y contextos de interacción humana (Arnao, Aguilar y Santisteban, 2013), lo cual condiciona el clima escolar que favorece los aprendizajes (González, Vicent, San Martín, Martínez, 2018). Por su parte Cassany (2009), precisan que las habilidades comunicativas básicas son escuchar, hablar, leer y escribir como destrezas que un usuario de la lengua, debe dominar para poder comunicarse con eficacia en todas las situaciones posibles.

Los indicadores: Usa vocabulario relacionada a la informática. Describe el cuidado que debe tener el docente para utilizar términos relacionados a la intencionalidad de lo que trata; Evidencia capacidad de redacción en procesadores de texto; y señala la capacidad para la producción escrita respetando reglas gramaticales, ortográficas y semánticas.

Habilidades científicas. Las habilidades científicas se organizan en función a cuatro dimensiones: conceptual, para utilizar el conocimiento para describir, explicar y predecir fenómenos naturales; metodológica, para identificar problemas científicos y diseñar estrategias para su investigación; y actitudinal, para interesarse por el conocimiento, indagación y resolución de problemas científicos y problemáticas socioambientales (Cañal, 2012). El docente desarrolla en los estudiantes el pensamiento lógico que incluye un 
conjunto de habilidades como la formulación de hipótesis, inferir, predecir y obtener conclusiones, entre otras y para ello debe desarrollar en él mismo estas habilidades que le cuanto facilitan el acceso y procesamiento de la información (Reyes y García, 2014).

Los indicadores: Usa el conocimiento en la explicación de fenómenos. Implica conocer, comprender y saber relacionar entre sí, con el propósito de describir, explicar o predecir fenómenos de la realidad cotidiana; Diseña estrategias para abordar problemas científicos. Implica la identificación de problemas que se puedan investigar desde los fundamentos y metodologías científicas, así como plantear las estrategias necesarias para llevarla a cabo; y muestra interés por el conocimiento científico. Implica la expresión de actitudes valorativas que predisponen hacia la acción indagatoria y la resolución de problemas socioambientales.

Habilidades sociales. Las habilidades sociales favorecen las relaciones interpersonales y la socialización del sujeto. En el trabajo pedagógico en entornos TIC son: la habilidad de conversación, las habilidades de aceptación asertivas, y las habilidades de oposición asertiva (Villasana y Dorrego, 2007). Las habilidades sociales son esenciales para el desempeño de los docentes, por lo que es necesario incorporar su desarrollo desde la formación inicial, sobre todo haciendo relevancia a las habilidades empáticas solidarias y las habilidades de comunicación (Tapia y Cupo (2017).

En ese sentido, Barrientos (2016), existe relación entre comunicación interactiva de los estudiantes y las capacidades del docente para promover habilidades de pensamiento y de lenguaje tanto formales como informales a partir de promover el debate, la discusión constructiva y al realizar las actividades con determinado nivel de exigencia en el aula, con la finalidad de fomentar el aprendizaje, el conocimiento, el desarrollo del pensamiento, la amplitud del vocabulario y resolver problemas.

Los indicadores: Emplea la comunicación asertiva. Es la capacidad que permite comunicar eficazmente a otros, puntos de vista, pensamientos, cogniciones o emociones; sin sentir incomodidad al hacerlo; Evidencia relaciones interpersonales adecuadas. Es la habilidad para establecer comunicación informal con otros; Señala un vocabulario suficiente para salir airoso en las interacciones sociales; Manifiesta seguridad, empatía y responsabilidad en sus actos. Es la capacidad para manifestarse seguro y empático en las relaciones sociales y responsable por los propios actos. 


\section{Conceptualización de la categoría estrategia de gestión de las TIC.}

El término estrategia es antiguo cuyas bases conceptuales datan de la Grecia antigua y su uso estuvo ligado al campo militar y describe el proceder del mando superior quien es denominado estratega. La concepción del término, guarda dos acepciones una dinámica y otra genérica; en el primer caso, se alude a la razón de uso, lo que supone la existencia de un propósito para dicha estrategia; y la segunda, atañe al sujeto que la usa, quien deberá tener capacidad de maniobra, pericia, competencia; entendida en su acepción formativa más que competitiva (Tobón, 2013).

En el campo educativo, el docente emplea estrategias a fin de mejorar el aprendizaje de los estudiantes. En general, la identificación de una estrategia supone un cómo, y para ello es necesario tener una conceptualización con respecto al que, por qué, para qué, con quien, con qué, cuanto, donde, cuanto, etc. pues en medida que cuente con estas respuestas tendrá mayor éxito la estrategia que use.

Por su parte, García (1996), refiere que por estrategia se entiende el diseño de intervención en un proceso de enseñanza con sentido de optimización. La didáctica es organizar método y recursos para la enseñanza, pero la estrategia amplia esta noción hacia la mejora.

Por otro lado, el vocablo, gestión fue usado inicialmente en el ámbito empresarial como un conjunto de decisiones y acciones que llevan al logro de objetivos previamente establecidos (Salgueiro, 2001). De hecho, el termino al alude a la acción imperativa de lograr algo que representa una necesidad para alguien; no obstante, debe quedar claro que estas acciones no son improvisadas, sino que obedecen a una planificación previamente establecida y cuya ejecución requiere de verificación. Ya en el campo educativo puede hablarse de gestión educativa y gestión pedagógica.

La gestión educativa lleva una mirada institucional, pues la realiza el directivo y sus acciones se dirige hacia toda la organización y se concibe como el conjunto de procesos, de toma de decisiones y realización de acciones que permiten llevar a cabo las prácticas pedagógicas, su ejecución y evaluación (Botero, 2009). Esto supone la gestión de todos los procesos que signifiquen mejora de la práctica pedagógica: recursos educativos, infraestructura y desempeño docente, siendo su propósito alcanzar calidad.

Por su parte, la gestión pedagógica alude al docente y su quehacer en el aula para conseguir los aprendizajes esperados para sus estudiantes. Al respecto, López (2017), expresa que la estrategia de gestión pedagógica es un proceso que facilita la orientación y coordinación de las acciones que despliegan los docentes para administrar la enseñanza a fin de alcanzar con eficiencia los objetivos propuestos para la formación integral. En ese sentido, gestionar, desde el punto de vista educativo, significa planificar la enseñanza, 
ejecutar los procesos didácticos y evaluar los logros alcanzados en función a las metodologías utilizadas.

Desde esta mirada, la estrategia de gestión hace referencia a la competencia del docente para usar las TIC como medio de enseñanza en el aprendizaje. Es un modelo teórico- metodológico que supone organización de los recursos disponibles hacia la mejora de la enseñanza considerando las realidades específicas. En la gestión se planifica, ejecuta y evalúa el proceso y estas herramientas audiovisuales devienen en un medio potenciador de la motivación para alcanzar un aprendizaje cualitativamente superior. Esto supone que no basta con dominar las TIC, sino que es necesaria saber usarla con maestría para ponerla al servicio del aprendizaje activo y consciente en los estudiantes.

Por su parte, Moreno y Paredes (2014), afirman que las estrategias de gestión en el campo tecnológico, se debe considerar su carácter intencional, pues esta no es una acción intuitiva sino razonada sobre evidencias previas. De esa manera, el docente gestiona el conocimiento; es decir, usa la ciencia, los recursos tecnológicos y las organiza en función a una necesidad social.

Estos son procesos intencionados de comprensión e intervención en las relaciones entre ciencia, tecnología y sociedad, que en el plano académico integra el uso pedagógico las TIC y los conocimientos que disponen los docentes, a fin de gestionar el conocimiento como recurso pedagógico que facilita el aprendizaje. La incorporación de estos recursos digitales en los centros de educación se da en dos niveles: gestión y práctica docente, a través de dos formas: nuevas vías de comunicación y novedosas formas de comunicación de materiales didácticos (Lanuza 2018).

Desde esas posiciones teóricas, las estrategias tienen como objetivo la integración curricular, pues va de la mano a los procesos de planificación curricular; así como de la ejecución de acciones que buscan obtener calidad en la enseñanza. Precisamente las TIC, ofrecen las aplicaciones necesarias para que el aprendizaje tenga una característica dinámica, inclusiva y efectiva (Aguirre, 2018).

Por otra ha que aseverar que, la estrategia de gestión favorece la integración de los objetivos curriculares al privilegiar la preparación docente sobre cómo emplearla y de esa manera se logra que el profesor pueda transitar de una enseñanza tradicional, a una más efectiva que responde a las necesidades integrales de los estudiantes y es congruente con el desarrollo de las ciencias, la tecnología y de la sociedad del conocimiento. Ello supone comprender en qué consiste el currículo, la didáctica, la enseñanza- aprendizaje y el rol del docente al emplear las TIC de modo contextualizado evitando la prescripción (Illán y Molina, 2011). 
La investigación realizada por Cubillos y Díaz (2012), asevera que al usar adecuadamente las estrategias de gestión de las TIC, se mejora la comunicación, pues las restricciones temporales y espaciales desaparecen, dado que los estudiantes pueden tener acceso de manera permanente y flexible a los recursos que los docentes ponen a su disposición Por otro lado, facilita la interacción mediante diversas herramientas informáticas de los diferentes actores que participan en una actividad de aprendizaje.

Al concluir la sistematización teórica de la categoría apriorística, estrategia de gestión, se asume como autor de base a Moreno y Paredes (2014), por la manera objetiva que define la categoría apriorística, estrategia de gestión sobre el uso de las TIC por los docentes en la enseñanza- aprendizaje, por adecuarse a los objetivos de la investigación. Desde esta posición teórica se identificaron las subcategorías apriorísticas y los indicadores:

Diagnóstico y determinación de objetivos. Es un ejercicio fundamental de aproximación del docente para con su labor y se lleva a cabo con la finalidad de conocer aspectos cognitivos, actitudinales y aptitudinales que permitirán asegurar su eficacia en el proceso de enseñanza aprendizaje (Arriaga, 2015). De esa manera, el diagnostico no se realiza desde un plano unilateral, sino que exige un proceso colaborativo pues solo así se puede conocer su realidad y los aspectos situaciones que favorecen o restringen su desempeño (Castillo y Cabrerizo, 2006). Teniendo claro las características que lo describen y el contexto en donde se desarrolla, se le hace posible formular objetivos pertinentes que guíen el proceso de su mejora (Meléndez y Gómez, 2008). Cabe indicar que por objetivo se hace referencia a un término de carácter didáctico que expresan en forma clara y precisa los cambios de conducta que se han de operar en el como efecto del proceso de cambio al que podría exponerse, Salcedo (2011).

Los indicadores: Determina fortalezas y debilidades. Describe las acciones del docente para identificar sus fortalezas en el escenario pedagógico; ello incluye el dominio de estrategias de identificación y el involucramiento en acciones colaborativas que le permitan conocerse mejor; Caracteriza la realidad educativa. Supone las acciones que realiza el docente para conocer las características de sus estudiantes e identificar sus necesidades y demandas; Formula objetivos a corto, mediano y largo plazo. Implica la capacidad para formular objetivos pedagógicos en función a un diagnóstico concreto, proyectando su plan de enseñanza en base a objetivos de corto, mediano y largo plazo. Plan temático de desarrollo. Hace referencia la tarea de programar acciones que permitan resolver dificultades halladas en el diagnóstico. En este caso, las acciones se encaminan a fortalecer desempeños para fortalecer el uso pedagógico de las TIC, la cual es utilizado al medio para favorecer el aprendizaje pues son herramientas que condicionan o influyen 
en la creación de contextos específicos de enseñanza-aprendizaje (Chumpitaz y Rivero, 2012). Se precisa que son herramienta pedagógica que puede ser utilizada para apoyar los procesos didácticos y comunicativos, por lo que resulta ser más un medio que un fin. Perera y Torres (2005), expresan que los conocimientos del docente sobre TIC son incluso recurso didáctico que facilitan los aprendizajes (Fremio y Andrade, 2017).

Los indicadores: Sustenta los conceptos, principios y enfoques teóricos de las TIC. Describe el uso adecuado de conceptos necesarios para comprender las TIC en el ámbito educativo, lo cual se sustenta en enfoques teóricos vigentes; Fundamenta las distintas herramientas para desarrollar el aprendizaje. Implica el conocimiento y dominio las herramientas virtuales para desarrollar el proceso de enseñanza-aprendizaje, cuya didáctica en entorno virtual posee fundamentación teórica; Aplica métodos variados con el uso de las TIC; y Señala el conocimiento de diversos métodos de enseñanza con aplicación de esos recursos y sus respectivas aplicaciones.

Implementación y evaluación. Implica la puesta en marcha de las actividades planificadas y su consecuente evaluación, bajo una perspectiva de calidad a través de la mejoría continua. Se desarrollan acciones que conducen a la optimización de aspectos susceptibles a cambio. Por otro lado, la evaluación supone el trazo de una línea de orientación en base a indicadores que permita saber el nivel de cumplimiento de actividades, así como de los resultados obtenidos, lo que deviene en un nuevo diagnóstico y por tanto un nuevo plan (Arnaiz, Azorín y García, 2015).

La idea es generar una línea auto formativa capaz de dar respuesta a las exigencias de las demandas sociales con una sólida formación teórico-práctica (Pérez, Enrique, Carbó y González, 2017), que permita a los docentes mejorar su práctica pedagógica en aula, sobre todo mediante la aplicación de herramientas TIC.

Los indicadores: Crea condiciones para su aplicación. Describe resultados que describen al docente creando espacios propicios para su formación y la creación de estrategias TIC. Ello supone la preparación de materiales y recursos para implementar estas estrategias; Transforma el desempeño del docente. Autopercepción del docente que le afirma y evidencia mejora en el desarrollo y aplicación de estrategias TIC para ser usados en su práctica pedagógica; y Provoca cambios en la enseñanza- aprendizaje. El docente observa que sus estudiantes se encuentran más motivados para aprender y que el desempeño de éstos mejora, aduciendo que todo ello es resultado de la aplicación de estrategias de gestión. 


\section{Capítulo II \\ Diagnóstico o trabajo de campo.}

\section{Análisis, interpretación y discusión de los resultados}

El diagnóstico de campo se llevó a cabo en una universidad privada de Lima con el fin de constatar el nivel de desarrollado de estrategias de gestión para el desarrollo de habilidades informáticas por parte de docentes universitarios, específicamente en la Facultad de contabilidad.

Durante el proceso de investigación se aplicaron diferentes métodos empíricos para el recojo, procesamiento y triangulación de la información recabada. Entre las técnicas e instrumentos: entrevista, observación a clases y cuestionario, siendo los instrumentos de estudio: la guía de entrevista, la guía de observación y el cuestionario que fueron validados a través del método de criterio de expertos, quienes luego de analizarlos y valorar su efectividad dictaminaron su pertinencia para su aplicación en la práctica (Anexo № del3 al 9validación).

Los datos obtenidos son de orden cualitativo y cuantitativo: los primeros fueron procesados por medio de tablas de reducción de datos y los cuantitativos se procesaron con tablas de frecuencias. Las tablas de reducción de datos posibilitaron la identificación de categorías emergentes, mientras que las tablas de frecuencia permitieron determinar algunas tendencias y regularidades.

\section{Procesamiento de la información.}

Resultados de la entrevista aplicada a los docentes.

Se aplicó una entrevista a 4 docentes de la Facultad de Contabilidad, cuyo proceso de codificación se presente en el (Anexo $\left.N^{\circ} 4\right)$, y los resultados interpretativos se exponen a continuación:

Al indagar sobre la capacidad para manejar y gestionar herramientas tecnológicas, tres docentes la identificaron como importante para desarrollar las habilidades informáticas, aunque uno de ellos manifestó que para que ello sea posible es necesario que exista capacitación previa en el uso de las TIC para la gestión pedagógica en aula.

En referencia al dominio de la informática, tres docentes indicaron que esto es concretado en el nivel de destreza desarrollado por las personas para operar las TIC en función a sus necesidades. Uno de los mencionados a su vez indicó que no usa estas herramientas, no solo por qué no la domina, sino que aduce que es por la falta de tiempo, aunque reconoce que solo la práctica hace que se domine estas herramientas.

Sobre las TIC como recurso expositivo, se tiene que tres docentes manifiestan que el uso de las TIC mejoraría sus exposiciones en clase; adicionalmente uno de ellos revela 
que es necesario una mayor capacitación, pues el uso discursivo solo se mejoraría si se tiene cierto nivel de dominio, pues se podría ser más eficaz al diseñar las sesiones de aprendizaje con ayuda de imágenes, video y audio, lo que redundaría en el fortalecimiento de las capacidades profesionales.

Con respecto a la motivación y actitudes positivas para el aprendizaje, un docente manifestó que el uso de las herramientas tecnológicas permite mayor nivel de concentración y expectativa de los estudiantes; dos docentes indican que las TIC despiertan el interés y motivan a los educandos haciéndolos más participativos y que la práctica del uso de las TIC en las sesiones de aprendizaje les proporciona mayor solidez al explicar el contenido.

Sobre las TIC como facilitadora de la comunicación y retroalimentación, dos docentes refieren que estas herramientas permiten mantener una comunicación fluida, a todo nivel, y en tiempo real con los estudiantes, lo que no solo facilita el seguimiento académico, sino que asegura que se realice la retroalimentación necesaria que el aprendizaje demanda.

Respecto al acceso a la información para alcanzar aprendizajes significativos, un docente, indicó que los medios audiovisuales facilitan el intercambio de información y el acceso a una mayor posibilidad de encontrar herramientas que permitan lograr y alcanzar aprendizajes significativos; dos profesores añadieron no poseer el dominio necesario para hacer esto posible, y que su práctica solo se reduce al uso de internet para la búsqueda de información.

En cuanto a las TIC como facilitadores de la enseñanza -aprendizaje, dos docentes indicaron que estas potencian la comprensión del aprendizaje, porque despierta y fomenta el interés de los estudiantes por las asignaturas, sea cual sea sus características y el último docente indicó que se constituyen en importantes estrategias pedagógicas que el docente dispone, aunque para ello se debe preparar o actualizar.

En cuanto al aspecto curricular, tres docentes indicaron que el docente debe caracterizar a sus estudiantes tomando en cuenta su realizada académica, a fin de conocer sus fortalezas y debilidades. Uno de los docentes indicó que el mayor problema que tiene los estudiantes es su redacción lo cual se trasluce cuando hacen uso de procesadores de texto; por otro lado, a un nivel más intrapersonal, se tiene estudiantes poco motivados y dispuestos a aprender; se añade responsabilidad familiar y limitado conocimiento de TIC.

En referencia a los niveles de planificación pedagógica, dos docentes la conciben en función al corto plazo (sesión), mediano plazo (unidad) y largo plazo (plan), formulando objetivos para cada etapa; otro añade que la formulación de estos objetivos debe ir en concordancia con el perfil de egreso planteado por la universidad y el último manifestó que 
estos objetivos son formulados por los responsables de elaborar las mallas y los sílabos, autoexcluyéndose de este proceso.

Sobre los conocimientos y uso de herramientas informáticas en la enseñanzaaprendizaje, ninguno, los cuatro docentes conocen sobre algún modelo o referente teórico que fundamente esta práctica. Uno de ellos aduce conocer y usar herramientas Word, Excel y PowerPoint durante el desarrollo de sus sesiones de aprendizaje; otra señala que solo usa el Excel y otro que solo el PowerPoint. Asimismo. Se constata que los cuatro docentes tienen la convicción de que el uso de estas herramientas facilita el proceso de aprendizaje y eleva el desempeño de los docentes.

Sobre los métodos de enseñanza - aprendizaje que realizan con apoyo de las TIC es diverso; uno de los docentes refiere que las utiliza para facilitar el recojo de saberes previos, la práctica expositiva y las tareas grupales; otro refiere que las usa en el desarrollo del método de casos y la resolución de problemas; y otro para la para la metodología participativa, interrogativa y activa.

En cuanto a los entornos TIC facilitadoras de las habilidades, uno de los docentes hace referencia la infraestructura como condición ya que es necesario contar con aulas condicionadas tecnológicamente; otros dos docentes aducen que es la capacitación, pues es muy importante tener dominio en el manejo de las TIC para potenciar el proceso enseñanza-aprendizaje.

En resumen, se observa que las estrategias de gestión de habilidades informáticas encuentran sus puntos críticos en tres aspectos: En la falta de conocimientos y habilidades para gestionar las herramientas tecnológicas, dado que los docentes sienten que poseen limitado dominio en el uso de estas herramientas, dada la baja capacidad de manejarlas y gestionarlas dentro del ámbito educativo, pese que reconocen que les sirve como recurso expositivo.

En resumen, se aprecia en los docentes falta de dominio de estas herramientas tecnológicas y su aplicación en el proceso de enseñanza-aprendizaje por las carencias que presentan en los conocimientos y las habilidades acerca de sus fundamentos y el uso de estas herramientas tecnológicas como medio didáctico que facilita la dirección del proceso de enseñanza- aprendizaje y como vía para activar la motivación, la comunicación y el aprendizaje en los estudiantes. 


\section{Resultado de la observación a clase a los docentes.}

Se observaron las clases de cuatro docentes de la especialidad de Informática, cuyo procesamiento se presenta en el Anexo $\mathrm{N}^{\circ} 4$, y los resultados interpretativos se exponen a continuación:

Con respecto a la motivación y orientación hacia los objetivos, se observa que un solo docente se presenta de manera activa y expresiva al momento de iniciar la clase generando una conversación relacionada al tema de estudio, los otros tres lo hacen de manera apática ingresando directamente a la temática. El docente que exploró los conocimientos previos alcanza fácilmente participación de todos los estudiantes, generándose un intercambio de ideas no solo con el docente sino también entre estudiantes. Por otro lado, solo dos de los cuatro docentes señalaron el objetivo de la clase, los otros dos iniciaron inmediatamente al tema programado.

En referencia al proceso de enseñanza-aprendizaje, se observó que los cuatro docentes realizaron sus clases con apoyo de Presentación Power Point, solo dos de ellos se dieron pausa para entablar un dialogo con los estudiantes con respecto a la temática planteada, manifestando situaciones reales vinculadas a ella; ello denotaba gran dominio del curso y del contenido que desarrolla. Los otros dos, solo siguieron con lo expresado en el PPT, incluso uno de ellos solo dedico a leer el contenido, sin detenerse a averiguar el nivel de compresión y contacto con los estudiantes.

Tres docentes se detuvieron durante su exposición para lanzar preguntas que permitan recoger sus inquietudes sobre lo mostrado en las imágenes y permitiendo la participación de los educandos y el uso de la informática al explicar el contenido de la enseñanza. Sin embargo, uno de ellos sí hizo preguntas, pero las contestaba el mismo.

Dos profesores presentaron ejemplos sobre cómo proceder al emplear las TIC y las habilidades comunicativas para estimular el pensamiento y la libre expresión de los estudiantes. Uno de ellos sí las emplea hábilmente, pero no las utiliza para incentivar la comunicación de los estudiantes y uno de ellos no las usas ni estimula la libre expresión en los estudiantes.

Los cuatro docentes se orienta las actividades de aprendizaje de manera tradicional en forma individual, evitan el trabajo colaborativo o en grupo ni emplean las TIC como recurso didáctico en sus clases.

No se apreció a los docentes explicarles a los educandos las acciones que debían realiza en la actividad de aprendizaje, no se programaron actividades para ellos, no expusieron ni se llevó a cabo la heteroevaluación ni la autoevaluación

Se constató que los docentes solo utilizaron en sus clases la presentación del contenido en las PPT como medio de enseñanza, no hubo guía de trabajo ni indicaciones 
adicionales para el trabajo con la tarea, la mayor parte de la clase fue expositiva por el profesor. No se orientó ni precisó producto a entregar, los indicadores de evaluación ni orientaciones de trabajo en clase.; tampoco se pusieron en práctica variedades de tareas de aprendizaje para estimular el pensamiento y la iniciativa en los participantes. Dos docentes hicieron preguntas al final de la sesión, pero de manera muy general. Todos usaron la PPT como medio de enseñanza.

Ningún docente utilizó métodos y procedimientos TIC que promueven la búsqueda reflexiva, valorativa e independiente del conocimiento por los estudiantes.

Al no orientar actividades de aprendizaje a los estudiantes, no trabajaron en equipos lo que les impidió la socialización, el diálogo y la colaboración que estimula el debate, el intercambio y la construcción del conocimiento y la ejercitación de las habilidades.

Los docentes emplean las PPT como medios de enseñanza, y se observó que no aprovechan las potencialidades reales de estos medios digitales ni de la temática expuesta para potenciar la observación, el análisis, la síntesis y la producción del conocimiento y la aplicación en la resolución de problemas.

Con respecto a las conclusiones de la clase, se observó que todos los docentes terminan la clase sin ofrecer las orientaciones claras y precisas del nuevo contenido a trabajar ni se llevaron a cabo acciones orientadas a la evaluación participativa y formativa del aprendizaje, por lo que los estudiantes difícilmente se autorregulan.

Al no conformarse equipos de trabajo, ni espacio para que expongan sus trabajos o productos no hay oportunidad para que los mismos estudiantes evalúen las acciones de sus compañeros ni para que los docentes cierren la temática con ideas-fuerza esenciales o emita valoración sobre los niveles de eficacia de los estudiantes al realizar y exponer sus trabajos.

En genera se constató que los docentes usan en sus clases las diapositivas o PPT, y tiene la idea de que este es un recurso para emplear en la clase, más no saben argumentar que por ser un medio audiovisual favorece la observación, la comprensión y el aprendizaje en los estudiantes. Tal vez por ello, no todos los docentes se detienen a explorar conocimientos previos o explicar los objetivos de la clase.

Como deficiencia se comprobó que en las clases prevalece el empleo de los métodos expositivos, se hacen algunas preguntas como parte del discurso, pero no se propicia el debate ni el diálogo entre los estudiantes; las actividades de aprendizaje no promueven el trabajo colaborativo en grupos y no se aplica la evaluación del aprendizaje con el fin de que los estudiantes analicen de forma crítica el proceso y el producto de la actividad. 


\section{Resultado del cuestionario a estudiantes.}

El cuestionario se aplicó a 25 estudiantes de contabilidad del IX ciclo una universidad privada, los cuales fueron elegidos de modo no aleatorio y cuyos resultados cuantitativos figuran en el anexo N. Y su interpretación es la siguiente:

Los resultados indican que 21 estudiantes para un (84\%) consideran que las TIC son importantes para el desarrollo de las clases y $4(16 \%)$, refieren que solo es a veces es importante. Ello, pone en evidencia la necesidad de que el docente enfatice en la importancia del uso de TIC en las sesiones de aprendizaje por cuanto eleva los niveles de preferencia de los estudiantes con respecto al curso que se imparte.

Asimismo, 14 (56\%) de los estudiantes, manifiestan que el docente aplica las TIC en sus clases, $3(12 \%)$ no lo hace y $8(32 \%)$, lo hace a veces. Ello indica que no es usual que el docente aplique TIC en sus sesiones de aprendizaje, por lo que existe aún una tendencia del docente por el método tradicional de enseñanza.

En cuanto a la aplicación de estas tecnologías en la clase por el profesor los 25 estudiantes refieren que el docente explica el contenido de la clase utilizando sistemas de preguntas que hacen comprender mejor el contenido y pone ejemplos del contexto de la profesión. Se comprende que si bien las clases tienden a cumplir los objetivos propuestos no siempre se hace uso de la TIC para conseguir ello.

Al preguntárseles sobre los métodos que utilizan los profesores al desarrollar sus clases los 25 (100\%) respondieron la exposición de contenidos. Lo que denota una tendencia de enseñanza tradicionalista, pues se enfocan a la exposición del conocimiento y no tanto en las competencias.

Con respecto a otros métodos, un estudiante (4\%) refiere que el docente aplica continuadamente la problematización del contenido de la clase; $15(60 \%)$ que no lo hace y $9(36 \%)$ que es aplicado a veces. Se infiere que el docente no dirige su sesión a la aplicación de los conocimientos que se van adquiriendo, cabe decir, el uso del conocimiento para resolver situaciones del contexto.

Sobre el método de proyectos, los 25 educandos expresaron que nunca se aplica, $14(56 \%)$ indican que el docente utiliza el trabajo en grupo durante el desarrollo de su clase, $8(32 \%)$ no lo hace, y $3(12 \%)$ lo hace a veces. Ello demuestra que los docentes no explotan el trabajo colaborativo como un procedimiento adecuado para favorecer el aprendizaje.

En cuanto al método orientado a la realización de trabajos por internet, 20 estudiantes $(80 \%)$ refieren que el docente lo hace, $2(8 \%)$ no lo hace y $3(12 \%)$ que lo hace a veces. La labor investigativa que hace uso de TIC es de suma importancia siempre y cuando la identificación de la información vaya a acompañada del procesamiento respectivo. 
Respecto a la evaluación del aprendizaje utilizando las herramientas tecnológicas, solo un estudiante (4\%) indica que el docente la realiza; 18 (72\%) que no lo hace y $6(24 \%)$ que lo hace a veces. Se comprueba así que la mayor parte de docentes no usan las TIC con el objeto de implementar la evaluación formativa en aula, lo que indica que aún desconoce de las posibilidades de estas herramientas para facilitar dicha labor.

Los 25 estudiantes manifestaron que les gustaría que el profesor utilice en sus clases las diferentes herramientas TIC existentes, que las use cotidianamente en sus labores académicas o creen que el uso de estas herramientas les provee de mayor posibilidad de construir un aprendizaje integral. Se aprecia que las TIC son cercanas al estudiante por lo que demandan su uso en la enseñanza- aprendizaje para incidir en la calidad de su formación profesional.

En cuanto al uso de las TIC en otras asignaturas 17 (68\%), refirieron que las utilizan en el desarrollo de la clase y 8 (32\%) que no lo hacen. Ello indica que existen docentes que ya están usándolas en sus clases, lo que supone una mayor aceptación de los estudiantes y mayor facilidad para que el proceso de enseñanza- aprendizaje se lleve a cabo de manera eficaz.

Según refleja el análisis realizado, los estudiantes esperan que los profesores utilicen estas herramientas TIC durante las sesiones de aprendizaje, pues aducen que de ese modo comprenden mejor, se facilita su aprendizaje y desarrollan las habilidades. Ello refleja la necesidad de los docentes en el dominio teórico de estas herramientas audiovisuales y su aplicación en las clases para activar el protagonismo del estudiantado en el aprendizaje.

\section{Proceso de categorización e interpretación.}

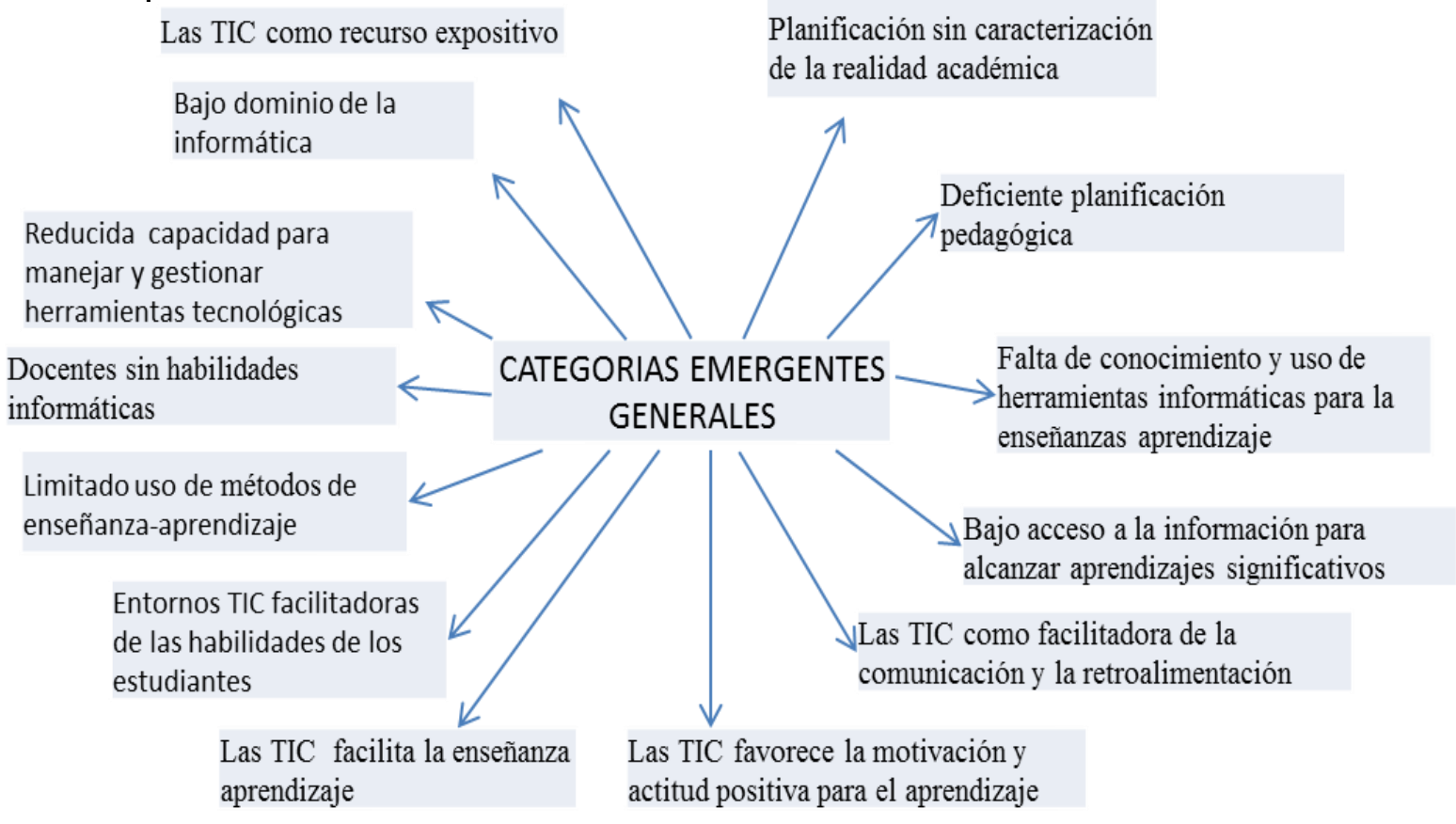


Figura 2. Categorías emergentes generales resultantes del diagnóstico de campo.

Fuente. Elaboración propia (2019).

El proceso de triangulación permitió analizar las coincidencias y las discrepancias de la información obtenida a partir de la información obtenida de los diferentes instrumentos aplicados. Ello permitió identificar las categorías emergentes generales como se presentan a continuación

El análisis holístico realizado de las categorías emergentes generales, permitió identificar las categorías emergentes que inciden negativamente en el problema investigado, tales como: Falta de conocimientos y habilidades para gestionar herramientas tecnológicas; Deficiente planificación con la inclusión de las TIC; Falta de aplicación de las TIC en el proceso de enseñanza-aprendizaje.

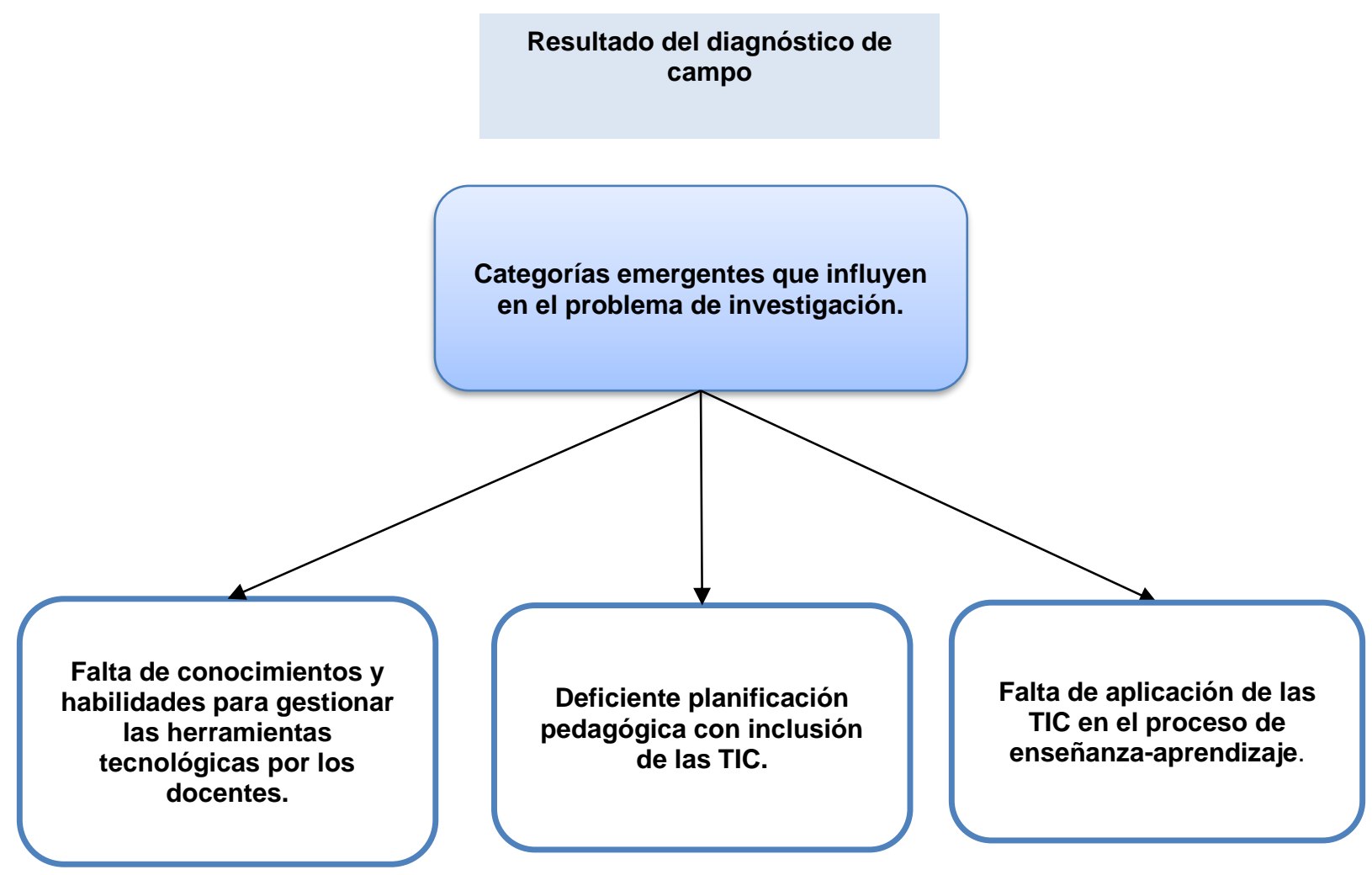

Figura 3. Categorías emergentes influyentes en el problema

Fuente. Elaboración propia (2019).

\section{Relaciones analíticas e interpretativas entre datos y categorías emergentes. \\ Conocimientos y habilidades para gestionar herramientas tecnológicas.}

Toda estrategia de gestión que busque contribuir al desarrollo de las habilidades de informáticas en docentes universitarios debe iniciarse fortaleciendo capacidades de estos 
para utilizar herramientas informáticas en el espacio educativo. Esto implica cambio de paradigmas no sólo en el funcionamiento de las instituciones educativas, sino también en el quehacer de los profesionales de la educación. No se trata solamente de adquirir tecnologías o de conocerlas, sino de administrarlas debidamente, adquiriendo capacidades para aplicarlas y adaptarlas en beneficio de la comunidad universitaria que se atienden (Agudelo, Niebles y Gallón, 2005).

Al respecto, Duart y Lupiánez (2005) manifiestan que la decisión más relevante que pueden asumir la institución educativa superior, aparte de implementar infraestructura tecnológica moderna y recursos pedagógicos TIC, es disponer de acciones que permitan que la docencia tenga un carácter más dinámico, motivador y centrado en el aprendizaje autorregulado, siendo la ampliación de capacidades para gestionar herramientas tecnológicas el desafío más próximo de todo docente.

Para Aguirre (2018), la verdadera implementación de la TIC en la enseñanza es un asunto de política pública integral, aparte de infraestructura y recursos. Adicionalmente hace falta una gestión efectiva que permita que los actores educativos participen de este proceso. Se requiere que existan posibilidades de formación e iniciativas que amplíen el acceso a la TIC en entornos colaborativos bajo una plataforma que posibilite comprensión crítica de sus ventajas (Hanna y Silver, 2005; Bou, Trinidad y Huguet, 2003; Uribe-Tirado, 2010). Al mismo tiempo, el uso de estas facilita el reforzamiento de la colaboración multidisciplinar y del desarrollo profesional de grupos de trabajo interuniversitarios (Kehm y Wit, 2005; Uribe -Tirado, 2010 y Lanuza 2018).

\section{Planificación pedagógica con inclusión de las TIC.}

La relevancia de las TIC en el contexto universitario, específicamente en el ámbito de la planificación curricular se circunscribe no solamente a la actividad académica, sino además en la gestión de los aprendizajes. Todo ello supone la creación de un entorno de aprendizaje adecuado, cabe decir, un espacio o comunidad organizados con el propósito de lograr el aprendizaje, y que para que éste tenga lugar requiere ciertos componentes ya señalados: una función pedagógica (actividades de aprendizaje, situaciones de enseñanza, materiales de aprendizaje, acciones de tutoría puestos, procesos de evaluación); la tecnología apropiada (herramientas seleccionadas en conexión con el modelo pedagógico) y los aspectos organizativos (que incluye la organización del espacio, del calendario, la gestión de la comunidad ( Uribe-Tirado, 2010 y Lanuza. 2018).

La inclusión de las TIC en la gestión de la escuela debería generar un cambio significativo en la planificación y desarrollo de los procesos de enseñanza-aprendizaje, constituyendo una herramienta eficaz para el aprendizaje. De ahí que el profesor debe 
planificar acciones para acompañar, orientar, evaluar y apoyar al estudiante, mientras sea necesario, para que este finalmente sea capaz de aprender a aprender. Ello sobre todo con la ampliación de las aplicaciones de internet, que incursionado en el campo educativo a través de sus diversas plataformas que principalmente permiten desarrollar mayor autonomía del estudiante durante su proceso de aprendizaje dejando de lado la idea que el docente es la única fuente de conocimiento (Lugo, 2010; Uribe-Tirado, 2010 y Lanuza. 2018).

\section{Aplicación de las TIC en el proceso de enseñanza-aprendizaje.}

El avance de las TIC obliga a las universidades a que adopten nuevas formas de enseñar, dado que reconfigura elementos básicos como espacio, recursos y funciones docentes. La potencialidad de las TIC no solo descansa en sus atributos, en la bondad o calidad tanto técnica como pedagógica de su diseño, sino en el marco del método pedagógico bajo el cual se insertan y se utilizan didácticamente. En esta dinámica, los conocimientos, las percepciones y actitudes que tenga el profesorado sobre los medios se convertirán en factores determinantes para su integración en los procesos curriculares (García-Valcárcel, 2007)

Hablar de la incluir las TIC en el currículum supone al menos reflexionar sobre tres grandes dimensiones de innovación o cambio que, a su vez, van a repercutir en la cultura institucional, la capacitación, el desarrollo profesional de los docentes y el apoyo explícito a la administración educativa: cambios en los objetivos educativos y en la concepción de los procesos de enseñanza-aprendizaje; cambios en los roles del profesor y del alumno y cambios en la estructura organizativa y relacional universitaria (Cabero y otros, 2006; Uribe-Tirado, 2010 y Lanuza, 2018).

Uno de los ejes centrales del mencionado cambio afecta a la finalidad del proceso de enseñanza-aprendizaje que se sitúa en el desarrollo de competencias tanto específicas como genéricas, de un alumnado que se convierte en el protagonista de su propio proceso de aprendizaje. Se reconoce que en la docencia potencia: Facilita el acceso a la información; propicia mayor comunicación entre profesores y alumnos; permite una adaptación más flexible, mejor entorno para elaborar recursos de aprendizaje; estimula una mejor comunicación entre docentes para intercambiar opiniones o recursos.

\section{Conclusiones aproximativas de los análisis realizados en esta parte de la investigación}

En general, en el proceso de análisis seguido durante el proceso investigado permitió constatar que el nivel de los conocimientos y habilidades de los docentes para gestionar las herramientas tecnológicas se hayan por debajo del requerido para alcanzar una idónea 
práctica pedagógica. Entre las causas se halla el bajo dominio que tienen estos docentes en el uso de estas herramientas y el poco interés por generar a cuenta propia de mayor competencia, esperando que sea la institución donde labora la instancia que se la proporciones.

La planificación pedagógica de por sí ya es deficiente e incluso nula, dado que no contempla la caracterización de los estudiantes para especificar objetivos de aprendizaje y llevar a cabo una planificación curricular acorde con sus necesidades, a lo que se suma la no inclusión de las TIC en este proceso.

Otro aspecto es la falta de aplicación de las TIC en el proceso de enseñanzaaprendizaje, dado que no conoce la fundamentación teórica necesaria que le brinde base en su práctica. A ello se suma el reducido uso de estrategias y recursos didácticos, en menor media aún se encuentra la posibilidad de uso de las TIC en estas circunstancias.

Se concluye que a través del análisis de los resultados obtenidos y el proceso de sistematización teórica, el diagnóstico de campo y la triangulación de la información se logró de una comprensión holística del problema científico y se identificaron las categorías emergentes influyentes en el problema que se tendrán en cuenta en la modelación de una estrategia de gestión que contribuya al desarrollo de las habilidades informáticas en los docentes en los docentes de la Facultad de Contabilidad de una universidad privada de Lima. 


\section{Capítulo III}

\section{Modelación, validación y aplicación de la propuesta}

El proceso de investigación desarrollado permitió contrastar los fundamentos teóricos con los resultados del diagnóstico de campo y analiza la objetividad de las categorías emergentes incidentes en problema con el fin de modelar la estrategia de gestión orientada a la transformación del problema investigado.

\section{Propósito de la propuesta metodológica}

El propósito de la investigación se concretó en el diseño de una estrategia de gestión para contribuir al desarrollo de las habilidades informáticas en los docentes de la Facultad de Contabilidad de una universidad privada de Lima, a fin de elevar la calidad educativa.

\section{Fundamentos de la propuesta.}

\section{Fundamento socioeducativo.}

La propuesta diseñada está dirigida a los docentes de la Facultad de Contabilidad de una universidad privada de Lima Metropolitana ubicada en el distrito de Los Olivos.

El servicio educativo beneficia a las de 3000 estudiantes en las 34 carreras profesionales que se llevan a cabo en sus diversas sedes de la ciudad capital. El trabajo académico se orienta a la formación integral de los profesionales, con un perfil de emprendimiento y competitivos que generen impacto positivo en la sociedad al responder a las demandas socioeconómicas del país y las exigencias internacionales. La población beneficiada con la propuesta son 65 académicos de las diversas asignaturas curriculares que desarrollan la enseñanza- aprendizaje en los diferentes ciclos de la Facultad de Contabilidad.

De manera general, la institución universitaria ofrece una apertura a la investigación científica y brinda las facilidades necesarias para ello. Por su parte, los docentes se muestran con buena actitud y compromiso por mejorar su labor pedagógica y comprender la necesidad de implementar estrategias y acciones novedosas para mejorar su nivel de gestión en los conocimientos sobre las TIC y sus habilidades para usarlas en la práctica y tener un fortalecimiento en su desempeño profesional en las aulas.

\section{Fundamento psicológico.}

Los docentes universitarios de la Facultad de Contabilidad se hallan en proceso de adaptación al enfoque curricular del aprendizaje por competencias y las demandas de la sociedad acerca de la formación integral de los profesionales en formación por el camino ético en su desenvolvimiento. Esto alcanza mayor relevancia para la universidad porque 
muchos de ellos provienen del campo y su trayectoria profesional ha sido amplia desde un modelo práctico, por lo que sus niveles de seguridad, autoconcepto, autoestima y solidez se hayan sustentado en esos paradigmas que requiere de nuevos retos.

El punto de partida es que el profesional de la educación debe estar en constante superación para potenciar nuevas perspectivas y actuaciones pedagógicas con lo que establece un proceso de trasformación que trae consigo ampliar los fundamentos teóricos sobre las teóricas del aprendizaje y la didáctica actual que demanda una reestructuración cognitiva y afectiva para alcanzar el ajuste requerido para la nueva tarea que debe asumir acorde a la época.

En ese sentido, la propuesta facilita y promueve el cambio, dado que plantea un proceso de análisis, de capacitación y planificación pedagógica que cubre las necesidades de los agentes que participan en el estudio. Se orienta a que el docente se potencie en cómo lleva a cabo la enseñanza- aprendizaje con el uso de las TIC teniendo como centro al estudiante, sus intereses, emociones positivas, motivación por el qué y cómo hacer en el aprendizaje como refieren Vygotsky (1987), Ortiz (2015) y Mora (2017), y la concepción de la didáctica desarrolladora según los postulados de Castellanos et al. (2007), Ginoris (2011) y Rico et al. (2013).

\section{Fundamento pedagógico.}

La propuesta asume la pedagogía como ciencia, cuyo objeto de estudio es la formación integral del ser humano para la vida; el contenido de la enseñanza se basa en el conocimiento científico comprobado y validado por las ciencias. Se fundamenta en las categorías instrucción, educación y desarrollo a partir de las relaciones socializadoras, comunicativas, de responsabilidad, respeto y comprensión entre el pedagogo y los educandos y estos entre sí como precisan Álvarez, (1999), González (2003), Peñaloza (2003), Castellanos et al; 2007 y Addine (2013).

En este sentido, el docente al tratar el contenido científico de la clase se apoya en el uso de las TIC como medio de enseñanza-aprendizaje para activar la observación, el interés y la motivación para lograr la asimilación de la información por el estudiante hasta convertirla en conocimiento y aplicarlo en la solución de problemas.

Desde esa perspectiva, se requiere de la aplicación de métodos, procedimientos y estrategias problematizadoras para estimular la motivación, comprensión, activación de los saberes previos, provocación del conflicto cognitivo para lograr la construcción del conocimiento desde posiciones metacognitivas y autorreguladas y su aplicación a la realidad. Ese conjunto de acciones intersubjetivas se genera en el docente que aprende siempre y cuando exista una línea formativa que la promueva bajo una lógica de calidad 
de la enseñanza y los aprendizajes adquiridos, con miras a ampliar, fortalecer, mejorar, o crear mayor desempeño pedagógico y profesional del docente universitario.

Se identifica el proceso de enseñanza- aprendizaje como un proceso organizado, planificado, evaluado y dirigido por el docente con el fin de proyectar las tareas de aprendizaje de manera que hagan pensar al educando de su estado actual real a un desarrollo ascendente de manera que contribuya a transformar sus formas de pensar, actuar y sentir en al interactuar en la actividad teórica- práctica (Álvarez, 1999; Addine, 2013 y Ortiz, 2015).

\section{Fundamento curricular.}

Entre las funciones del docente universitario se halla la investigación y el mejoramiento continuo y permanente de la enseñanza (Ley $N^{\circ} 30220$, Ley Universitaria). Ello implica una comprensión más amplia del perfil específico para ellos, que más allá de los grados y la experiencia, requiere la explicitación de paradigmas en los procesos de enseñanzaaprendizaje. En principio, desde su atención a la enseñanza debe transitar hacia una mayor atención y centralidad en los estudiantes y sus aprendizajes; la aplicación de diseños curriculares modulares más que temáticos.

Ello requiere plantear los objetivos de aprendizaje en términos de competencias integrales donde se aprecie la información no como un componente adicional del proceso de aprendizaje, sino que debe estimularse los procesos lógicos del pensamiento del estudiante al interactuar con la tarea de aprendizaje bajo un marco metacognitivo y de autorregulación que los motive y oriente en el hacer y descubrir. Otro aspecto esencial del perfil docente es la investigación, no solo como alguien que la ejecuta, sino que la fomenta en los estudiantes; bajo ese escenario las clases se constituyen en fuente de incentivo y de formación para la investigación científica (Mas, 2011; Navio, 2005; Paquay, 2005).

El diseño de la propuesta guarda coherencia con los criterios de calidad de la Superintendencia Nacional de Educación Superior Universitaria, específicamente con el Criterio cinco, Disponibilidad de personal docente calificado; y las políticas de calidad de la universidad pues busca dentro del enfoque de mejora continua, la satisfacción de los estudiantes y la sociedad. Del mismo modo, apunta a fortalecer capacidades de los docentes para el idóneo cumplimiento de los propósitos establecidos en los sílabos de la carrera, pues plantea la incorporación de las TIC para una mejor gestión de los aprendizajes.

De este modo, el contenido curricular de la propuesta fomenta el desarrollo del aprendizaje significativo desde la competencia (Coll, Pozo, Sarabia y Valls, 1995; Tobón, 
2008; Díaz y Hernández, 2010 y Addine 2013), por lo que será descrito en términos de conocimientos, procedimientos y actitudes.

\section{Diseño gráfico funcional de la propuesta.}

El esquema teórico- funcional muestra la dinámica interna, abierta y transversal de la estrategia de gestión. En ella se representan los resultados del diagnóstico de campo (categorías emergentes influyentes en el problema) y los logros esperados a partir del proceso de enseñanza-aprendizaje orientado al desarrollo de las habilidades informáticas en los docentes de la Facultad de Contabilidad de una universidad privada de Lima. 


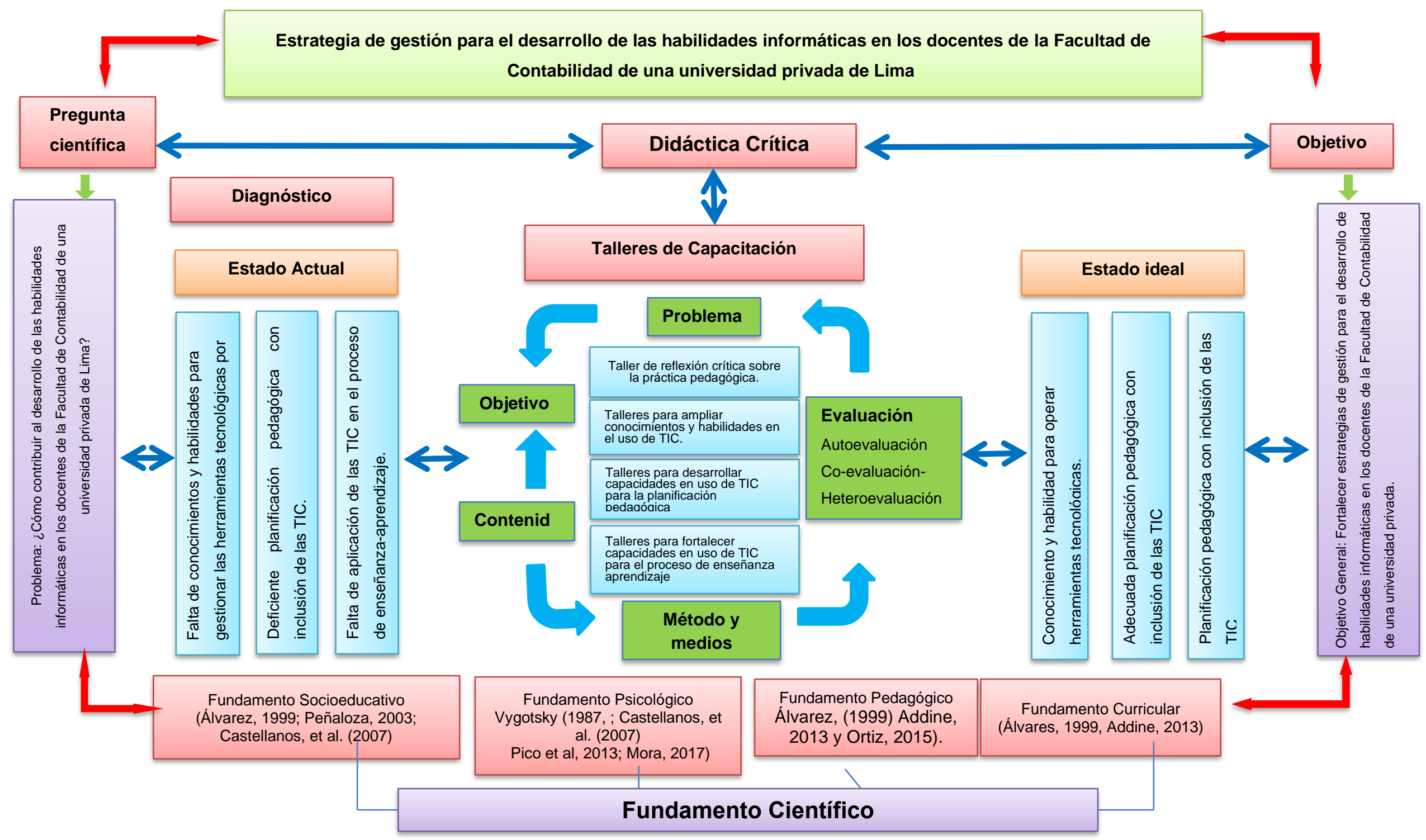

Fuente. Elaboración propia (2019).

Figura 4. Esquema teórico - funcional de la propuesta metodológica modelada. 
El esquema teórico - funcional muestra la dinámica interna, transversal y flexible del problema objeto de estudio, cuyo fin se orienta a su transformación a través de la estrategia de gestión modelada como producto de la investigación.

\section{Desarrollo o implementación}

\section{Fundamentos de la estrategia de gestión propuesta.}

La propuesta se sustenta en las bases científicas de la pedagogía, la que concibe la enseñanza- aprendizaje como un proceso planificado, organizado, conducido y controlado, integrado por categorías, principios y leyes didácticas. En la propuesta diseñada se toman en cuenta los principios didácticos planteados por Chávez (2002), Díaz y Hernández (2010) y Addine et al. (2015) y contextualizado al objeto de la investigación como se expresa a continuación:

Principio del carácter científico del proceso educativo: la propuesta metodológica se basa en la deficiencia reflejada en los instrumentos del proceso diagnostico relacionado en la falta estrategias de gestión para desarrollar habilidades informáticas. Por ello se propone activar el desarrollo intelectual a partir de una didáctica critica en las clases, para contribuir al desarrollo del pensamiento, la asimilación, y construcción del conocimiento de forma significativa.

Principio de sistematización de los contenidos: se presentan los contenidos organizados de una forma provechosa y con una secuencia lógica y psicológica para sobre la base de lo aprendido, aprendan el nuevo contenido de forma significativa.

Principio de la activación de conocimientos y experiencias previas: se debe activar los conocimientos previos del estudiante que posee en su estructura cognoscitiva acerca de los fundamentos de las TIC, esto posibilitara el proceso de aprendizaje significativo de los nuevos conocimientos que adquieran en la clase.

Principio de la vinculación de la teoría con la práctica: El conocimiento no solo se debe explicar, sino además señalar las vías para su transformación y su aplicación en la práctica. Este principio plantea el contacto directo de los conocimientos con la realidad, de la cual el estudiante directamente obtiene los conocimientos que se derivan o se obtienen de la práctica. Creadas las condiciones para ello, el docente debe procurar aprovechar en las clases esa experiencia obtenidas por ellos para guiarlos en la elaboración de conclusiones

Principio de la asequibilidad: la enseñanza del docente debe ser clara sobre los medios didácticos que utiliza y atender las particularidades individuales del estudiante. Se debe ir de lo simple a lo más complejo del curso y de lo conocido a lo desconocido. 
Principio del carácter audiovisual: se debe presentar los contenidos en forma de sistemas conceptuales, esquemas, graficas, mapas conceptuales, jerarquizar, interrelacionar y no presentar los datos desordenadamente y aislados y esto les va ayudar, por ejemplo, sobre todo en las gráficas como ejemplo, en el tema en la oferta y la demanda.

Principio de los contenidos aprendidos significativamente: la nueva información aprendida por descubrimiento o por recepción serán más consolidada, menos frágiles al olvido y permitirán el aprendizaje sobre todos en las nociones generales e integrados.

Principio de participación activa: puesto que el estudiante mediante ciertos mecanismos autorregulados puede llegar a controlar en su proceso de aprendizaje el ritmo de sus conductas y el proceso de estudio; el docente debe incitar la motivación y la participación activa del estudiante.

Estos principios didácticos contribuyen a que el docente propicie un tratamiento adecuado al contenido de la enseñanza para que los estudiantes asimilen consciente y activamente los conocimientos, y alcancen el desarrollo del aprendizaje significativo en la clase.

El modelo aportado, como producto de la investigación, promueve el aprendizaje significativo y desarrollador, sustentado por los aportes de Vygotsky (1987), González (2003), Castellanos et al; (2007), Crispín et al. (2011) y Mora (2017) que integrado dialécticamente a los fundamentos de Álvarez (1999), Díaz y Hernández (2010) y Pimienta (2012), en la enseñanza problémica privilegian iniciar la clase a partir de los problemas conocidos, de una comunicación asertiva, dialógica y reflexiva. La tarea de aprendizaje responde a un accionar consciente por el estudiante a partir de la aplicación de estrategias de aprender a aprender, el autoaprendizaje y la autoevaluación.

La estrategia propuesta, se orienta a la capacitación metodológica para fortalecer los conocimientos teóricos y didácticos de los docentes en las habilidades de informática para apoyarse de ellas en el tratamiento del contenido en la enseñanza- aprendizaje como vía para incidir en la motivación y la calidad del aprendizaje de los educandos. Ello reforzará las competencias profesionales de los profesores y tendrá como impacto, lograr un aprendizaje consciente e integral en los estudiantes.

En la concepción de la propuesta, el rol del docente es de un profesional competente y facilitador de los métodos y procedimientos para comprender el alcance de las TIC y sus beneficios al emplearlas como ayuda del docente en la clase que se erige como un espacio para que los profesores autorreflexionen sobre cómo usarlas, sus ventajas, importancia para la formación de los estudiantes, se capaciten de manera permanente para lograr los objetivos previstos en las distintas disciplinas docentes para contribuir a las exigencias digitales de la escuela en la época. 


\section{Misión de la estrategia didáctica propuesta.}

La estrategia propuesta tiene como misión: la capacitación teórica, didáctica y práctica de los docentes de las distintas especializados de la facultad de Economía en la gestión del conocimiento y las habilidades de informática para aplicarlas en el proceso de enseñanzaaprendizaje de sus disciplinas curriculares específicas a fin de contribuir al desarrollo de capacidad de pensar, construir el conocimiento y las habilidades integrales de los estudiantes como se expresa en el perfil profesional de sus respectivas carrera universitarias

La estrategia de gestión metodológica propuesta está conformada por un sistema de talleres pedagógicos, orientados a desarrollarse previa coordinación de un calendario de superación interna aprobado por los directivos de la carrera de la universidad privada referida.

\section{Características de los talleres de capacitación metodológica propuestos.}

Los talleres de capacitación que se proponen se orientan a los docentes de las distintas especializadas de la facultad de Economía y se caracterizan por su carácter.

Integrador. Esta característica se le atribuye desde su fundamentación teórico- práctico, pues los objetivos, actividades y las acciones se orientan como un sistema integrado de acciones con el fin de fomentar la competencia profesional en las habilidades de informática para usar las TIC en la enseñanza - aprendizaje con la aplicación métodos, procedimientos y tareas de aprendizaje que le exige aplicar la metacognición en los estudiantes.

Contextualizado. Se diseñaron las actividades, acciones y talleres metodológicos desde las fortalezas y debilidades de los docentes y del contexto de la carrera donde se potencia el autoanálisis y el autorreflexión en los docentes sobre sus necesidades en las habilidades de informáticas para utilizar herramientas digitales en la enseñanza.

Comunicación asertiva. Todas las acciones del proceso educativo se encauzan desde la comunicación asertiva y empática en un ambiente emocional de alegría lúdica para desarrollar estrategias metacognitivas desde una perspectiva optimista considerando las dificultades como fuerzas motrices para el desarrollo profesional del docente.

Carácter investigativo: por la naturaleza de las estrategias a desarrollar para fomentar la metacognición en el proceso educativo a partir de las TIC se precisa de la aplicación del método científico con fines pedagógico. Los ejemplos que se presentan se concretan en el proceso educativo de enseñanza -aprendizaje empleando las TIC en 
todas las asignaturas para contribuir a desarrollar los conocimientos y las habilidades integrales de los estudiantes.

\section{Objetivo de la estrategia de gestión.}

El objetivo de la estrategia es contribuir a desarrollar las habilidades informáticas de los docentes y su preparación teórico-didáctica y práctica pedagógica al impartir su clase. La mismas se sustenta en los conocimientos epistemológicos de Vygotsky 1987), González (2003), Aguilera y Ortiz (2008), Ortiz (2015), Sáez (2014), Moreno y Velázquez (2017) y Mora (2017), acerca del aprendizaje, la personalidad y la inteligencia emocional.

Como objetivo general del producto modelado por el proceso de investigación se analizaron las características de las habilidades informáticas, las especificidades de la gestión de las TIC por parte de los docentes que deberán dirigir el proceso formativo de sus estudiantes; se analizaron las alternativas para potenciar las capacidades referidas a las habilidades informáticas y para ello se definieron dos líneas de acción estratégicas teniendo en cuenta los siguientes lineamientos metodológicos:

La primera línea: tiene como fundamento, partir de la orientación y realización de diversas actividades de orden teórico práctico sobre los fundamentos de las estrategias de gestión y las habilidades informáticas, analizar los enfoques teóricos del aprendizaje en entornos TIC y sobre dicha base se consiga fortalecer sus habilidades informáticas en los distintos contextos de actuación pedagógica.

La segunda línea: se proyecta a la capacitación didáctica y metodológica dirigida a los docentes de la disciplina referida, con la finalidad de alcanzar la eficiencia requerida en su desempeño profesional al conducir la enseñanza- aprendizaje, desde un enfoque integral con la intención de sistematizar los conocimientos, las habilidades de pensar, analizar, reflexionar sobre el contenido y comunicar sus puntos de vistas, sentimientos y relacionarse asertivamente y con empatía con sus iguales al realizar las tareas de aprendizaje con el fin de contribuir a la formación integral de los estudiantes a su cargo.

Esto implica desarrollar la capacitación metodológica dirigida a los docentes. Para ello se diseñaron un conjunto de talleres teórico- práctico que aparecen al final de la propuesta.

El taller es una forma de organización del proceso de enseñanza- aprendizaje I que se basa en la relación entre la teoría y la práctica, se estimula el pensar con las experiencias y la ejercitación práctica. Los talleres propuestos se asumen como un espacio de superación, de reflexión teórica y de experiencias profesionales en el que se potencia la diversidad de criterios, las opiniones individuales y colectivas a través del diálogo, la comunicación, el respeto al criterio ajeno en la problematización del tema y la 
autorreflexión donde se integran todas las ideas que se fundamente en función de alcanzar un aprendizaje eficiente a fin de crear un saber colectivo profesional que incida en el desempeño profesional.

Desde esta posición metodológica el taller ofrece un marco de análisis teórico y de exposición de las experiencias como medio para ampliar, enriquecer los conocimientos y las habilidades que conduce a consensos en los docentes en cómo aplicar las TIC al guiar la enseñanza- aprendizaje a fin de contribuir a la calidad del aprendizaje de los estudiantes. Esa forma de capacitación profesional desde el puesto de trabajo, estimula el crecimiento, fortalece la autoestima, la socialización, la superación permanente e incide en la calidad del desempeño del docente, y el compromiso por la excelencia en la institución (Zegarra y Velázquez, 2016).

Cada taller se evaluará teniendo en cuenta los indicadores que responden a la superación del docente de acuerdo con las necesidades profesionales identificadas durante el proceso del diagnóstico de campo. Estos indicadores son:

Indicador Uno. Estudio previo de los temas orientados.

Nivel Alto. Los docentes evidencian haber leído sobre las temáticas propuestas. A lo largo de todo el taller realiza preguntas o responde las realizadas por el facilitador. Sus propuestas tienen base en fundamentos técnicos brindados o levantados por ellos mismos.

Nivel Medio. Los docentes evidencian haber leído parcialmente sobre las temáticas propuestas. A lo largo de todo el taller realizan preguntas, pero no responden las realizadas por el facilitador. Sus propuestas no tienen base en fundamentos técnicos, aunque se halla fundamentada por la lógica y la intuición.

Nivel Bajo. Los docentes no evidencian haber leído parcialmente sobre las temáticas propuestas. A lo largo de todo el taller no realizan preguntas ni responden las realizadas por el facilitador. Sus propuestas no tienen base en fundamentos técnicos, aunque ni se halla fundamentada por la lógica y la intuición. Requiere de seguimiento constante.

Indicador Dos. Realización de las actividades de estudio a realizar por equipos.

Nivel Alto. Los docentes se agrupan rápidamente por equipos de trabajo para ejecutar las actividades solicitadas mostrando predisposición para el trabajo colaborativo. Las interacciones son fluidas y con participación de todos. Los aportes brindados son equitativos en cuanto su contenido y expresión.

Nivel Medio. Los docentes se agrupan por equipos de trabajo con apoyo del facilitador a fin de ejecutar las actividades solicitadas mostrando parcial predisposición para el trabajo colaborativo. Las interacciones son fluidas y con 
participación de la mayoría. Los aportes brindados son no equitativos en cuanto su contenido y expresión.

Nivel bajo. Los docentes difícilmente se agrupan por equipos de trabajo esperando ser solicitado por algún grupo ya conformado o la indicación del facilitador a fin de ejecutar las actividades solicitadas mostrando nula predisposición para el trabajo colaborativo. Las interacciones son escasas y poco participativas. Los aportes brindados son limitados tantos en contenido como en expresión.

Indicador Tres. Participación y consciente en el estudio de los temas orientados.

Nivel Alto. Los docentes se hallan participativos y motivados durante el desarrollo de las actividades solicitadas. Se esfuerzan por elaborar y expresar aportes de manera voluntaria. Usan recursos TIC para hallar más información.

Nivel medio. Los docentes se hallan poco participativos y motivados durante el desarrollo de las actividades solicitadas. Se esfuerzan parcialmente para elaborar y expresar aportes de y lo hacen solo cuando se les solicitan. Usan recursos TIC para hallar más información, pero requieren apoyo para conseguir resultados.

Nivel bajo. Los docentes se hallan desmotivados y no participan durante el desarrollo de las actividades solicitadas. No se esfuerzan parcialmente para elaborar y expresar aportes de y lo hacen solo cuando se les solicitan. No usan recursos TIC para hallar información que facilite su participación.

Indicador Cuatro. Exposición individual y por equipos.

Nivel Alto. Los docentes exponen individual y grupalmente de manera eficaz. Los contenidos que expresan son coherentes y fundamentados. La voz es clara y fluida. Se evidencia coordinación entre los integrantes del grupo para la exposición ordenada del tema.

Nivel Alto. Los docentes exponen individual y grupalmente de manera eficaz. Los contenidos que expresan son coherentes y fundamentados. La voz es clara y fluida. Se evidencia coordinación entre los integrantes del grupo para la exposición ordenada del tema.

Nivel Medio. Los docentes exponen individual y grupalmente de manera poco eficaz. Los contenidos que expresan son coherentes, aunque no fundamentados. La voz es poco clara y medianamente fluida. Se evidencia coordinación entre los integrantes del grupo para la exposición ordenada del tema.

Nivel Bajo. Los docentes exponen individual y grupalmente de manera ineficaz. Los contenidos que expresan no son coherentes ni fundamentados. La voz es poco clara y fluida. Se evidencia descoordinación entre los integrantes del grupo para la exposición ordenada del tema. 
Indicador Cinco. Asistir a tiempo para ejercitar las habilidades

Nivel Alto. Solicita asistencia con tiempo cuando no logra realizar la actividad propuesta. El ejercicio de las habilidades corre paralelo a la asistencia constante del facilitador. Muestra seguridad y confianza para solicitar asistencia.

Nivel Medio. Solicita asistencia cuando no logra realizar la actividad propuesta, pero lo hace después de concluida la actividad. El ejercicio de las habilidades no siempre recibe asistencia del facilitador. Muestra poca seguridad y confianza para solicitar asistencia.

Nivel Bajo. Realiza la actividad propuesta de manera individual y no solicita asistencia pese a tener dificultades. El ejercicio de las habilidades recibe asistencia del facilitador. Muestra inseguridad y desconfianza para solicitar asistencia.

El control de estos se tendrá en cuenta en el desarrollo a nivel grupal e individual, teniendo presente la autoevaluación, coevaluación y la heteroevaluación.

Propuesta de talleres de capacitación teórico práctico orientado a los docentes.

La aplicación de estos indicadores referidos facilitará el control y la evaluación del proceso con el fin de hacer los reajustes necesarios en la marcha de su puesta en práctica. Por ello se prevé realizar un programa de talleres de capacitación teórico, didáctico y práctico orientados a los docentes con el fin de que se empoderen en los conocimientos y las habilidades de informática en el uso de las TIC para su inclusión en la enseñanza- aprendizaje de las distintas disciplinas curriculares a su cargo en el componente académico.

Taller № 1

Título: Retos y perspectivas de la Educación Universitaria en el siglo XXI.

Problema:

Comprender las exigencias en el siglo XXI en todas las ramas del saber humano y el reto que significa para los docentes universitarios contribuir a la formación integral de los profesionales para ayudar al desarrollo del país.

Objetivo.

Analizar la importancia de la inclusión de las TIC en el proceso de enseñanzaaprendizaje universitario a fin de contribuir a la formación de un profesional investigador, crítico, reflexivo que interactúa en la sociedad de la información, reflexiona y asume posiciones críticas para resolver problemas de la profesión y del contexto.

Introducción

¿Qué es la Educación? ¿Cuál es el objeto de estudio de la Pedagogía? 
- ¿Qué se entiende por sociedad de la Información?

- Ante esas exigencias, cuál es el rol de la universidad en el siglo XXI.

- Para poder responder a los retos de la época actual, qué competencias debe reunir el profesor universitario.

\section{Desarrollo}

Se les orienta a los participantes aplicar la técnica del conteo del uno al cuatro y luego se reunirán en equipo los números afines. Una vez organizados en los equipos de trabajo, el facilitador explicará el trabajo a realizar, y el método a seguir por cada grupo de trabajo y el logro esperado.

Se le entregará a cada equipo el material didáctico por equipo: La sociedad de la información y el uso de las TIC en la Educación Universitaria y la rúbrica de evaluación del trabajo.

Se les orienta que deben leer, analizar la información, debatirla y resumir las ideas relacionadas con el alcance de la información sobre las TIC a nivel global, el rol de la enseñanza universitaria frente ese reto y las competencias que deben asumir los docentes universitarios para dirigir el proceso de enseñanza- aprendizaje ante la formación del profesional. Ante ello deberán exponer atendiendo a:

Pegunta problémica: ¿Qué competencias profesionales debe alcanzar el docente universitario en el uso de las TIC para dirigir el proceso de enseñanza- aprendizaje universitario?

Cada equipo se prepara para exponer el siguiente tema.

Grupo Temas

Grupo 1: $\quad$ El proceso de globalización y la sociedad de la información

Grupo 2: $\quad$ Las TIC como herramienta y medios de enseñanza en la Educación Universitaria.

Grupo 3: $\quad$ Las competencias profesionales en las habilidades de Informática y su inclusión en el proceso de enseñanza- aprendizaje.

Grupo 4: $\quad$ El uso de las TIC en el proceso de enseñanza- aprendizaje y la calidad del aprendizaje.

\section{Evaluación}

Cada equipo expone el trabajo realizado ante la plenaria y se somete .al debate para llegar a un consenso democrático relacionado con la superación permanente para tener un desempeño profesional exitoso. 
Luego se propone la autoevaluación y la coevaluación por los participantes atendiendo a la rúbrica de evaluación y se otorga la evaluación que se corresponda con la calidad del trabajo presentado según la rúbrica de evaluación.

\section{Taller \# 2}

Título: Administración de entorno Windows.

Problema: Falta de preparación teórica y desarrollo de las habilidades para operar las herramientas tecnológicas.

Objetivo: Fortalecer los conocimientos y las habilidades en uso y manejo de las herramientas y entorno Windows para crear carpetas, copiar archivos, pegar archivos, comprimir y descomprimir archivos .zip o rar.

Introducción

Para dar comienzo al taller se propone las siguientes preguntas a los participantes:

¿Alguna vez han recibido capacitación en el entorno Windows?

¿Qué les ha parecido?

¿Cuál es la mayor dificultad que hallaron?

Después de las reflexiones y el debate se procede con la metodología de acuerdo con las etapas del taller.

\section{Desarrollo}

Se explica y demuestra qué es el entorno Windows: crear carpetas, copiar archivos, pegar archivos, comprimir y descomprimir archivos .zip o .rar.

El facilitador orienta cómo realizar los ejercicios, alcance, importancia y el logro esperado en la realización de cada uno. Seguido se orienta formar los cuatro grupos y a cada uno le asigna desarrollar una estrategia específica que deberán resolver atendiendo a una rúbrica de evaluación.
Grupo
Acción
Grupo 1:
Crear carpetas.
Grupo 2:
Copiar archivos.
Grupo 3:
Pegar archivos.
Grupo 4:
Comprimir y descomprimir archivos .zip o .rar.

Cada grupo expone su producto. Se ofrece espacio para preguntas de los estudiantes, los miembros de cada grupo contestan, pero el facilitador refuerza.

Evaluación 
Cada equipo expone el trabajo realizado ante la plenaria y se somete .al debate para llegar a un consenso democrático.

Deberán descargan información sobre entorno Windows; para luego copiar y pegar en una carpeta creada para dicho fin. Posteriormente comprimen la carpeta utilizando .zip o .rar. y envían el archivo al correo del facilitador.

Una vez concluido se sugiere aplicar la autoevaluación y la coevaluación por los participantes atendiendo a la rúbrica de evaluación y se otorga la evaluación que se corresponda con la calidad del trabajo según las exigencias de la rúbrica de evaluación y se estimula los mejores trabajos.

\section{Taller \# 3}

Título: Introducción al procesador de textos Word.

Problema: Desconocimiento teórico y desarrollo de habilidades para operar el procesador de textos Word.

Objetivo: Fortalecer los conocimientos teóricos y las habilidades de informática en la utilización del procesador de textos Word.

\section{Introducción}

Para dar comienzo al taller se propone las siguientes preguntas a los participantes:

- ¿Qué es el procesador de Word?

- ¿Qué importancia creen que tiene?

- ¿Cuál nivel de dominio del Word tienen ustedes?

- ¿Cuál es la mayor dificultad que tienen y cómo resolverla?

Después de las reflexiones y el diálogo se procede con la metodología de acuerdo con las etapas del taller.

Desarrollo

Se presenta el procesador de textos Word y se destaca la importancia de este procesador.

Se explican algunas funciones, específicamente en su configuración de página, encabezados y pies de página. Trabajarán con columnas, tablas de contenido, tablas de ilustraciones Combinar tablas, tablas de índices.

Se les demuestra cuáles son los procesos de configuración de página, encabezados y pies de página, columnas, tablas de contenido, tablas de ilustraciones, combinar tablas.

Cada equipo trabajará en su computadora el ejercicio que le corresponde con la orientación del facilitador. 
Se conforman cuatro grupos y cada grupo desarrolla una estrategia que luego explicará en plenaria cómo procedió en su realización:

Grupo Tema

Grupo 1: $\quad$ Configuración de página.

Grupo 2: $\quad$ Encabezados y pies de página.

Grupo 3: Columnas.

Grupo 4: Tablas de contenido e ilustraciones.

\section{Evaluación}

Cada grupo expone su producto a la sala de clase. Se ofrece espacio para preguntar, reflexionar y dialogar con los estudiantes ponentes que deberán responder y de ser necesario el facilitador refuerza.

A modo de conclusiones cada equipo presenta un tríptico sobre uso del procesador de textos Word, considerando tres columnas, tablas e ilustraciones para usarlos en su desempeño en el aula.

Una vez concluido se sugiere aplicar la autoevaluación atendiendo a la rúbrica de evaluación y el logro esperado.

\section{Taller \# 4}

Título: Introducción a la hoja de cálculo Excel para su aplicación en la planificación.

Problema: Deficiente uso de la hoja de cálculo Excel en la aplicación de la planificación pedagógica

Objetivo: Potenciar los conocimientos y las habilidades en la utilización de la hoja de cálculo Excel y su aplicación en la planificación pedagógica.

Introducción

Se realiza una dinámica, utilizando una aplicación (kahoot), donde los participantes interactúan antes las siguientes preguntas:

¿Qué es Microsoft Excel?

¿Cómo podría relacionar Excel en mi función docente?

¿De qué manera se podría usar el Excel en la planificación de las actividades pedagógicas?

Se produce una situación comunicativa activa a través de una dinámica de integración respondiendo preguntas simples y complejas de informática y formulando otras sobre sus necesidades e intereses.

Desarrollo 
El facilitador explica las potencialidades de estos recursos digitales y les demuestra los procedimientos:

Definición e importancia del programa Excel.

Entorno de trabajo

Estilos de celda

Formato de tabla

Operaciones básicas

Luego se procede a la orientación de las tareas a realizar por cada grupo de trabajo, se destaca que cada equipo deberá realizar su trabajo y exponerlo a los demás en el salón de clase atendiendo a los indicadores de la rúbrica.

$\begin{array}{ll}\text { Grupo } & \text { Actividad } \\ \text { Grupo 1: } & \text { Presentación del entorno de trabajo. } \\ \text { Grupo 2: } & \text { Estilos de celda. } \\ \text { Grupo 3: } & \text { Formato de tabla. } \\ \text { Grupo 4: } & \text { Operaciones básicas. }\end{array}$

Evaluación

Cada grupo expone su producto, se somete a la consideración del resto de los participantes que harán preguntas, observaciones o dudas que los miembros del grupo ponente contestarán y de ser necesario el facilitador refuerza.

Como producto realizan una tabla para organizar la evaluación permanente, considerando criterio conceptual, procedimental y actitudinal. Se configuran suma y promedios en dichas tablas. Una vez concluido se aplica la evaluación final atendiendo a la rúbrica de evaluación y el logro esperado.

\section{Taller \# 5}

Título: Gráficas, tablas y ordenamiento de listas en hoja de cálculo Excel para su uso en la planificación pedagógica.

Problema: Deficiente planificación y uso de Gráficas, tablas y ordenamiento de listas en hoja de cálculo Excel para su uso en la planificación pedagógica.

Objetivo: Fortalecer los conocimientos y el desarrollo de las habilidades para crear gráficas, tablas y ordenar listas en hoja de cálculo Excel.

Introducción

Se realiza una dinámica, utilizando una aplicación (kahoot), en donde ellos contestan las siguientes preguntas:

- ¿Qué es el Excel? 
¿Qué es un gráfico y qué valor tiene para la labor del profesor?

¿Qué es un filtro y para qué se usa?

Se establece un diálogo activo, abierto y flexible con los participantes a fin que se expresen y se refieran a sus necesidades y potencialidades en el uso y manejo de estos recursos con vista a que concientice el valor de su aplicación en la práctica pedagógica.

Desarrollo

El facilitador explica en qué consisten y el valor que tienen estos procedimientos para la labor pedagógica:

Creación y utilización de gráficos

Tabla de datos y ordenamiento

Listas

Filtros avanzados

Una vez analizador, el facilitador le asignará a cada equipo la actividad que deberá realizar, el logro esperado y una rúbrica del trabajo

Se conforman los cuatro grupos y cada uno desarrolla el siguiente ejercicio que luego expondrá ante el plenario:

$\begin{array}{ll}\text { Grupos } & \text { Temática } \\ \text { Grupo 1: } & \text { Creación y utilización de gráficos. } \\ \text { Grupo 2: } & \text { Tabla de datos y ordenamiento. } \\ \text { Grupo 3: } & \text { Creación de listas. } \\ \text { Grupo 4: } & \text { Operaciones básicas. }\end{array}$

Evaluación

Cada grupo expone su producto. Se ofrece espacio para preguntas de los estudiantes, los miembros de cada grupo contestan, aunque siempre el facilitador interviene para reforzar o aclarar cualquier punto de vista.

Como producto finar cada equipo realiza una lista de estudiantes y las organiza en una tabla según sexo, edad, ciclo de estudios y cursos, para luego presentarlas en una gráfica por cada criterio señalado. Se configuran suma y promedios en dichas tablas. Una vez concluido se aplica la evaluación final atendiendo a la rúbrica de evaluación y el logro esperado. 


\section{Taller \# 6}

Título: Manejo de herramientas en línea y uso de la aplicación Zotero.

Problema: Falta de aplicación de las TIC en el proceso de enseñanza-aprendizaje.

Objetivo: Fortalecer habilidades para crear gráficas, tablas y ordenar listas en hoja de cálculo Excel.

Introducción

Se realiza una dinámica, utilizando una aplicación (Padlet), en donde ellos contestan las siguientes preguntas:

¿Conocen el programa Zotero?

¿Cuál es la importancia de Zotero?

Se establece un diálogo activo, abierto y flexible con los participantes a fin de que se expresen y se refieran a sus necesidades y potencialidades en el uso y manejo de estos recursos con vistas a que concientice el valor de su aplicación en la práctica pedagógica.

Desarrollo

Se explican los siguientes procedimientos:

Se explica el entorno de trabajo de Zotero.

Uso de recursos en línea para detectar plagio en escritos

Uso de herramientas de alojamiento de archivos online: Google Drive, OneDrive Uso de herramientas para videoconferencias online (Zoom, Google Hangout).

Se procede al desarrollo de ejercicios con orientación del facilitador.

Se conforman cuatro grupos.

Cada grupo desarrolla una estrategia para enseñar al resto los cuatro contenidos expuestos con un ejercicio:

Grupo Actividad

Grupo 1:

Entorno de trabajo de Zotero.

Grupo 2:

Presentación de recursos en línea para detectar plagio en escritos.

Grupo 3: $\quad$ Uso de Google Drive, OneDrive.

Grupo 4: $\quad$ Uso de Zoom, Google Hangout.

Evaluación

Cada grupo expone su producto. Se ofrece espacio para preguntas de los estudiantes, los miembros de cada grupo contestan, pero el facilitador refuerza.

Realiza un ensayo y organiza referencias con Zotero, la escanea con un antiplagio online para luego alojar el archivo en Google Drive. Se configuran suma y promedios en 
dichas tablas. Una vez concluido se aplica la evaluación final atendiendo a la rúbrica de evaluación y el logro esperado.

\section{Taller \# 7}

Título: Manejo de PowerPoint y Prezi.

Problema: Falta de aplicación de las TIC en el proceso de enseñanza-aprendizaje.

Objetivo: Fortalecer habilidades para manejo de las herramientas de PowerPoint y Prezi para la exposición de clases.

Introducción

Se realiza una dinámica, utilizando una aplicación (kahoot), en donde ellos contestan las siguientes preguntas:

¿Cuál es el PowerPoint y qué importancia tiene?

¿En qué se diferencia el PowerPoint y Prezi?

¿Qué importancia tiene este recurso para la labor del docente en el aula?

A partir de las interrogantes se provoca una interacción comunicativa participativa y flexible con los participantes a fin que expresen sus puntos de vista, sus necesidades y potencialidades en el uso y manejo de estos recursos con vista a que concientice el valor de su aplicación en la práctica pedagógica.

\section{Desarrollo}

Se explican los siguientes procedimientos:

Se explica el entorno de trabajo de PowerPoint. Entorno de trabajo. Herramientas: Agregar de diapositiva, transiciones, efectos, gráficos. SmartArt, Hipervínculo.

Prezi: Agregar objetos, animaciones.

Se procede a la orientación de los ejercicios que deberán desarrollar en el taller por el facilitador. Para ello se conforman los grupos y a cada uno se le asigna su tarea que luego expondrá al resto de sus compañeros:

Grupo

Grupo 1:

Grupo 2:

Grupo 3:

Grupo 4:

\section{Evaluación}

Cada grupo expone su producto. Se ofrece espacio para preguntas de los estudiantes, los miembros de cada grupo exponen y el facilitador refuerza.
Actividad

Presentación del entorno de trabajo de PowerPoint.

Presentación de herramientas: Agregar de diapositiva, transiciones.

Presentación de herramientas: gráficos. SmartArt.

Presentación de Prezi 
Como producto deberán diseñar una sesión de aprendizaje y crea presentaciones PPT y Prezi para dicha sesión, considerando, transiciones, efectos y gráficos. Una vez concluido se aplica la evaluación final atendiendo a la rúbrica de evaluación y el logro esperado

Taller \# 8

Título: Métodos y procedimientos de enseñanza - aprendizaje con el uso de las TIC Problema: Deficiencias en los conocimientos y uso de los métodos y procedimientos de la enseñanza- aprendizaje con el uso de las TIC

Objetivo: Profundizar los métodos y procedimientos de la enseñanza- aprendizaje con el uso de las TIC

Introducción

El facilitador comienza con las siguientes interrogantes para provocar el diálogo. ¿Cuáles son los métodos recomendados a utilizar en la enseñanza universitaria? ¿Qué es la enseñanza problémica?

¿En qué consiste el método investigativo pedagógico?

Después de las reflexiones y el diálogo se procede con la metodología de acuerdo con las etapas del taller.

\section{Desarrollo}

Se les orienta a los participantes aplicar la técnica del conteo del uno al cuatro y luego se reunirán en cada equipo y el facilitador les precisa el logro esperado.

Se le entregará a cada equipo el material didáctico por equipo t se les orienta que deben leer, analizar la información, debatirla y resumir las ideas relacionadas con el alcance para dirigir el proceso de enseñanza- aprendizaje.

Grupo

Grupo 1:

Grupo 2:

Grupo 3:

Grupo 4:

\section{Temática}

La enseñanza problémica.

El método pedagógico investigativo.

El método de proyecto.

El uso de las TIC en el proceso de enseñanzaaprendizaje.

Cada equipo realiza el trabajo y expone ante la plenaria y se somete .al debate para llegar a un consenso democrático relacionado con la superación permanente para tener un desempeño profesional exitoso.

Evaluación

Como producto deberán diseñar una sesión de clase atendiendo a la aplicación de uno de los métodos de enseñanza con la inclusión de las TIC 
Luego se propone la autoevaluación y la coevaluación por los participantes atendiendo a la rúbrica de evaluación y se otorga la evaluación que se corresponda con la calidad del trabajo presentado según la rúbrica de evaluación.

La efectividad de los talleres de capacitación docente se evaluará a través del impacto que se alcance en los resultados de la calidad del desempeño de los profesores al dirigir el I proceso de enseñanza - aprendizaje de las distintas asignaturas de las carreras de la Facultad de Contabilidad y Finanzas de la universidad.

Primera Etapa. Se propone analizar con los directivos de la Facultad de Contabilidad y Finanzas, la estructura de la estrategia de gestión modelada en cuanto a: misión, definición, alcance del objetivo, los lineamientos metodológicos establecidos sobre las acciones centrales de la propuesta: una orientada a profundizar en los fundamentos teóricos de las habilidades de informática en los docentes para su inclusión como recurso didáctico en la enseñanza- aprendizaje de las disciplinas curriculares que enseñan en la universidad..

Segunda Etapa. Participar en una reunión con el personal docente de la Facultad de Contabilidad y Finanzas para darle a conocer la problemática resultante del diagnóstico de campo de la investigación realizada. Se enfatizará en las fortalezas y limitaciones encontradas en el desarrollo de las habilidades de informática en los docentes para su inclusión en la enseñanza- aprendizaje a fin de estimular el aprendizaje en los estudiantes.

Se sugiere convocar al participante a debatir sobre el contenido del informe expuesto, intercambiar opiniones, ideas y hacer reflexiones sobre sus vivencias y necesidades pedagógicas personales. Se orientará el diálogo a la comprensión de la necesidad del cambio de manera gradual tanto en la superación teórica del docente como para su incorporación a la enseñanza- aprendizaje para lograr el desarrollo de un aprendizaje cualitativo superior en los estudiantes.

Tercera Etapa. El análisis realizado con los participantes tiene como objetivo sensibilizarlos en el compromiso a seguir como un reto la superación de las TIC permanente con su participación en los talleres de capación sobre las habilidades de informática. Con ello se aspira a provocar un cambio cualitativo superior en su haber como profesional y en su desempeño pedagógico en las clases a fin de estimular el rol protagónico del estudiantado en la producción del conocimiento y el desarrollo de las habilidades en un entorno comunicativo, académico, social y en sus actuar en los diversos contextos. Para ello se identificaron los aspectos teóricos, didácticos y prácticos a tener en cuenta en los talleres de superación 
Cuarta Etapa. Se enfatiza en la necesidad de conocer los documentos normativos de las carreras como el perfil del egresado, la ley universitaria y las disposiciones de la universidad a fin de establecer la coherencia lógica entre los elementos curriculares y las exigencias de las habilidades informática que desarrollarán los docentes en los talleres de capacitación.

En cada clase debe lograrse la correlación entre el contenido, los métodos, las habilidades, los recursos audiovisuales, la forma de evaluación a aplicar, los valores que el contenido de la clase permite reforzar a partir de un diseño de la actividad atendiendo a los niveles de asimilación del aprendizaje y el rol del estudiante estimulado por el uso de las TIC en el tratamiento de cada unidad de estudio programada y la sesión de aprendizaje con el objeto de elevar la calidad del aprendizaje integral de los estudiantes.

Quinta Etapa. La aplicación de la estrategia de gestión modelada se aplicará en la facultad de Economía de una universidad. Durante su puesta en práctica se realizará un control sistemático y cortes evaluativo-parciales para constatar el progreso en la gestión de las habilidades dificultades y hacer los reajustes adecuados y al final se realiza la evaluación conclusiva para medir el impacto en el proceso de enseñanza - aprendizaje.

Validación del impacto de los talleres dirigidos a fomentar el desarrollo de prácticas de gestión pedagógica para aportar al desarrollo de habilidades informáticas en los docentes universitarios de una universidad privada.

\section{Validación de la propuesta}

Para la validación teórica cualitativa de la estrategia diseñada dirigida a la solución del problema objeto de la investigación, se empleó el método de validación por juicio de expertos con la finalidad de valorar los aspectos internos y externos de la propuesta modelada.

De acuerdo con Escobar y Cuervo (2008), este método implica "una opinión informada de personas con trayectoria en el tema, que son reconocidas por otros como expertos cualificados en éste, y que pueden dar información, evidencia, juicios y valoraciones" (p. 29).

De esa forma, resulta trascendente la elección de los jueces, ya que es importante dilucidar si se trata de personas conocedoras de la temática por su formación académica o su experiencia laboral. Aunado a ello, cabe considerar sus ocupaciones y concertar los tiempos para la realización de la tarea de validación. Por otro lado, es necesario tomar en cuenta los diferentes requerimientos para su aplicación, por lo que se diseñaron dos fichas de valoración, una interna y otra externa.

Para la elección de los expertos se tuvo en consideración los siguientes criterios de 
selección: poseer grado académico de Maestro o Doctor en Educación; o título de post grado en la especialidad relacionada a la propuesta, tener más de 15 años de experiencia en la práctica docente o ejercer la dirección académica en una institución universitaria.

\section{Características de los expertos.}

Los expertos seleccionados para validar la propuesta modelada son docentes que cuentan con el grado académico y científico exigido, la experiencia en la práctica pedagógica y la autoridad para la valoración de la propuesta. En la tabla 9, se precisa los criterios tomados en cuenta para la selección de los expertos.

Tabla 3

Relación de expertos que validaron la propuesta.

\begin{tabular}{|c|c|c|c|c|}
\hline $\begin{array}{l}\text { Nombres y } \\
\text { apellidos }\end{array}$ & Grado académico & $\begin{array}{l}\text { Especialidad } \\
\text { profesional }\end{array}$ & Ocupación & $\begin{array}{c}\text { Años de } \\
\text { experiencia }\end{array}$ \\
\hline $\begin{array}{l}\text { Hernán Gerardo } \\
\text { Flores Valdiviezo }\end{array}$ & $\begin{array}{c}\text { Magister } \\
\text { Gerencia Social y } \\
\text { Administración }\end{array}$ & $\begin{array}{l}\text { Sociólogo / } \\
\text { Investigador }\end{array}$ & $\begin{array}{l}\text { Docente de la Escuela de } \\
\text { Post Grado Universidad } \\
\text { San Ignacio de Loyola }\end{array}$ & 40 años \\
\hline Goñi Cruz, Fernando & $\begin{array}{l}\text { Doctor Ciencias de } \\
\text { Educación }\end{array}$ & $\begin{array}{l}\text { Estadística e } \\
\text { interpretación } \\
\text { de datos } \\
\text { cualitativos }\end{array}$ & $\begin{array}{l}\text { Docente de la Escuela de } \\
\text { Post Grado Universidad } \\
\text { San Ignacio de Loyola }\end{array}$ & 25 años \\
\hline Mario León Moreno & $\begin{array}{c}\text { Magister en } \\
\text { Administración }\end{array}$ & $\begin{array}{l}\text { Ingeniero de } \\
\text { Sistemas }\end{array}$ & $\begin{array}{c}\text { Docente de la } \\
\text { Universidad Privada del } \\
\text { Norte }\end{array}$ & 17 años \\
\hline
\end{tabular}

Fuente: Elaboración propia (2019).

Validación interna y externa de la estrategia didáctica por criterio de expertos.

Para concebir la validación de la propuesta, se diseñaron dos fichas de evaluación, una para la validación interna referida al contenido y la otra para la validación externa referida a la forma que presenta la propuesta, con diez criterios de orden cualitativo y cuantitativo.

Desde el punto de vista cuantitativo los expertos determinaron su apreciación en cada uno de los criterios: deficiente (puntaje 1), bajo (puntaje 2), regular (puntaje 3), buena (puntaje 4) y muy bien (puntaje 5).

Tabla 4

Tabla de valoración de la validación

\begin{tabular}{ll}
\hline Nivel & Rango \\
\hline Deficiente & $0-25$ \\
Baja & $25-50$ \\
Regular & $51-70$ \\
Buena & $71-85$ \\
Muy Buena & $86-100$ \\
\hline
\end{tabular}

Fuente: Documentos de elaboración de tesis USIL (2018). 
De manera general en cada ficha se obtuvo un puntaje máximo de cincuenta puntos que sumados hacen un total de cien puntos.

Para analizar el aspecto cualitativo de la propuesta se pidió una apreciación crítica del objeto examinado considerando las siguientes dimensiones: positivos, negativos y sugerencias.

En la validación interna, el experto evalúa el contenido de la propuesta atendiendo a los indicadores : factibilidad de la aplicación del resultado que se presenta; claridad de la propuesta para ser aplicado por otros; posibilidad de la propuesta de extensión a otros contextos semejantes; correspondencia con las necesidades sociales e individuales actuales; (e) congruencia entre el resultado propuesto y el objetivo fijado; novedad en el uso de conceptos y procedimientos de la propuesta; la modelación contiene propósitos basados en los fundamentos educativos, curriculares y pedagógicos, detallado, preciso y efectivo; la propuesta está contextualizada a la realidad en estudio; presenta objetivos coherentes y posibles de alcanza; contiene un plan de acción de lo general a lo particular.

Para apreciar la validez interna se empleó una ficha en la que se presentan los indicadores, el puntaje según la escala de valoración correspondiente y los aspectos positivos, negativos y sugerencias pertinentes (Anexo 9) como: claridad; objetividad; actualidad; organización; suficiencia; intencionalidad; consistencia; coherencia; metodología; y pertinencia. Para valorar los criterios de validación externa se presenta los criterios, el puntaje a escala correspondiente y los aspectos positivos, negativos y sugerencias que amerite (Anexo 11).

Luego se llevó a cabo el sumatorio total de los resultados obtenidos por los expertos en la validación interna y externa del producto presentado.

Tabla 5

Resultados de la validación integral por de los especialistas

\begin{tabular}{lllll}
\hline Especialista & Grado académico & $\begin{array}{l}\text { Validación } \\
\text { interna }\end{array}$ & $\begin{array}{l}\text { Validación } \\
\text { externa }\end{array}$ & $\begin{array}{l}\text { Sumatoria } \\
\text { Valorativa }\end{array}$ \\
\hline $\begin{array}{l}\text { Hernán Gerardo } \\
\text { Flores Valdiviezo }\end{array}$ & $\begin{array}{l}\text { Magister } \\
\text { Gerencia Social y } \\
\text { Administración } \\
\text { Doctor Ciencias de }\end{array}$ & 46 & 46 & 92 \\
Goñi Cruz, Fernando & $\begin{array}{l}\text { Educación } \\
\text { Magister en } \\
\text { Administración }\end{array}$ & 47 & 42 & 87 \\
Mario León Moreno & atal & 48 & 95 \\
\hline
\end{tabular}

Fuente: Fichas de validación interna y externa USIL (2019). 


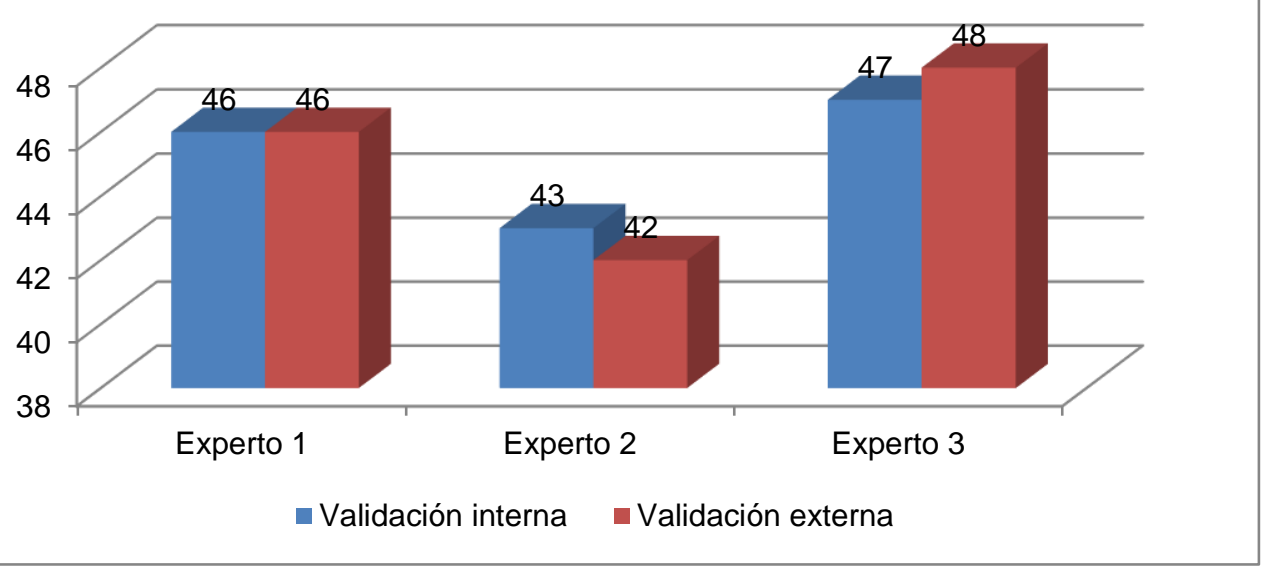

Figura 5. Resultados de la validación integral.

Fuente: Elaboración propia (2019).

Resultados finales del promedio de la valoración de los expertos son los siguientes: Tabla 5

Resultado de la valoración interna y externa por criterio de expertos

\begin{tabular}{ccc}
\hline Sumatoria de valoración total & Promedio de valoración & Valoración \\
\hline 274 & 91 & Muy buena
\end{tabular}

Fuente: Fichas de validación interna y externa USIL (2019).

La estrategia didáctica propuesta fue valorada de Muy Bien por los especialistas y añaden que según los fundamentos científicos, didácticos y práctica que sustentan el producto resultante del proceso investigativo, es novedoso, exigente y contribuye a desarrollar las habilidades informáticas en docentes de la carrera de contabilidad; además añaden que por la secuencia didáctica y los métodos de enseñanza que sostiene, puede ser aplicada a otras áreas curriculares de la carrera, a fin de potenciar el desarrollo de las habilidades informáticas por ser un aporte que enriquecerá la práctica pedagógica de los docentes de la especialidad.

\section{Conclusiones aproximativas}

En general, en el proceso de análisis seguido durante el proceso investigado permitió constatar que el nivel de los conocimientos y habilidades de los docentes para gestionar las herramientas tecnológicas se hayan por debajo del requerido para alcanzar una idónea práctica pedagógica. Entre las causas se halla el bajo dominio que tienen estos docentes en el uso de estas herramientas y el poco interés por generar a cuenta propia de mayor competencia, esperando que sea la institución donde labora la instancia que se la proporciones. La planificación pedagógica de por sí ya es deficiente e incluso nula, dado que no contempla la caracterización de los estudiantes para especificar objetivos de 
aprendizaje y llevar a cabo una planificación curricular acorde con sus necesidades, a lo que se suma la no inclusión de las TIC en este proceso. Otro aspecto es la falta de aplicación de las TIC en el proceso de enseñanza-aprendizaje, dado que no conoce la fundamentación teórica necesaria que le brinde base en su práctica. A ello se suma el reducido uso de estrategias y recursos didácticos, en menor media aún se encuentra la posibilidad de uso de las TIC en estas circunstancias.

Al tenerse en cuenta los resultados finales desde las sugerencias realizadas al producto presentado se realizó el análisis integral de la validación efectuadas por los expertos, se concluye que la estrategia de gestión modelada es válida y aplicable en la institución universitaria para la que se diseñó y dados sus fundamentos teóricos y curriculares integrales puede aplicarse a otras áreas disciplinares. Los expertos aseveran que el producto científico-pedagógico aportado por la investigación es una contribución a la práctica docente al preparar a los docentes en las habilidades de Informática y de esa manera perfeccionarán su desempeño al guiar el proceso de enseñanza-aprendizaje en la Facultad de Contabilidad de una universidad privada de Lima. 


\section{Conclusiones}

Al concluir el proceso investigativo mediante la sistematización de los referentes científicos, análisis de los resultados del diagnóstico de campo y modelar la estrategia de gestión para contribuir a la transformación del problema objeto de estudio, se arriba a las siguientes conclusiones:

Primera: Se cumplió con el objetivo general de la investigación al modelar la estrategia de gestión orientada a contribuir al desarrollo de las habilidades de informática en los docentes de la Facultad de Contabilidad con el fin de que las incorporen como recurso didáctico en el proceso de enseñanza- aprendizajea, a fin de lograr un aprendizaje cualitativamente superior en los estudiantes.

Segunda: Se cumplió la tarea científica relacionada con el marco teórico, al sistematizarse de forma holística e integral las categorías y subcategorías apriorísticas que sustentan el problema investigado. Ello fue posible considerando los distintos enfoques teóricos y didácticos de las habilidades de informática y su inclusión como recurso didáctico al proceso de enseñanza- aprendizaje, lo que permitió elaborar la matriz de categorización.

Tercera: El diagnóstico del trabajo de campo se cumplió a partir del diseño, validación y aplicación de diversas técnicas e instrumentos de recolección de datos, cuyo proceso permitió constatar el nivel del estado actual del objeto investigado, identificando las categorías emergentes generales que inciden en el problema y contrastándolas con las categorías apriorísticas sistematizadas en el marco teórico de la tesis.

Cuarta: La estrategia de gestión propuesta, es el resultado del cumplimiento de la tercera tarea científica y es congruente con los enfoques teóricos y didácticos para el desarrollo de las habilidades informáticas en los docentes; buscando su incorporación en el proceso de enseñanza- aprendizaje de las distintas disciplinas curriculares que tienen a su cargo como profesores universitarios. De esta manera, se pretende que asuman un rol mediador que guíe sus formas de pensar, sentir y hacer al desarrollar las actividades de aprendizaje.

Quinta: La quinta conclusión da cuenta de la evaluación otorgada por los expertos a la estrategia de gestión modelada como producto de la investigación. En su evaluación valoran la base teórica, metodológica y práctica de la propuesta, acredita su aplicación e 
incidencia en el desarrollo de las habilidades informáticas en los docentes y su incorporación en los procesos de enseñanza - aprendizaje, a fin de que se constituya en facilitador, guía y orientador de sus estudiantes, haciéndolos protagonistas de su propio aprendizaje. 


\section{Recomendaciones}

Primera: Dar a conocer la estrategia de gestión modelada a los directivos de la Facultad de Economía a fin de evaluar su implementación en la práctica pedagógica de las diversas asignaturas curriculares como una alternativa pedagógica innovadora que empodera al docente para desarrollar las habilidades de informáticas y su inclusión en la enseñanzaaprendizaje, la cual es vital en la sociedad del conocimiento que exige la educación actual.

Segunda: Evaluar la efectividad de la aplicación de la estrategia de gestión modelada en la práctica con el propósito de comprobar el impacto en el desarrollo de los conocimientos y las habilidades de informáticas en los docentes, su inclusión en aula y la eficiencia en la calidad del aprendizaje de los estudiantes universitarios.

Tercera: Presentar los resultados de la investigación en los distintos eventos científicos programados, a fin de dar a conocer sus resultados y continuar la investigación en otras aristas de la inclusión de las TIC en el proceso de enseñanza- aprendizaje como vía para continuar aportando a la calidad de la educación. 


\section{Referencias}

Addine, F. (2013). La didáctica general y su enseñanza en la educación superior pedagógica. La Habana: Pueblo y Educación.

Addine, F., Álvarez, L., Martínez, M., Parra, I., Sierra, R., Gutiérrez, M., Calzado, D. (2015). Didáctica de la pedagogía y la Psicología. La Habana, Cuba: Editorial Pueblo y Educación

Agudelo, E., Niebles, L. y Gallón, L. (2005). La gestión tecnológica como herramienta de planeación estratégica y operativa para las unidades de información. Rev. Interam. Bibliot. Medellín 28(2), 89-114.

Aguilera, E. y Ortiz, E. (2008). La caracterización de perfiles de estilos de aprendizaje y sus implicaciones didácticas en la educación superior. Revista de Pedagogía Universitaria, 13(5), 1-13.

Aguirre, P. (2018). Las TIC en la gestión del proceso de enseñanza-aprendizaje en el área Comunicación Organizacional: licenciatura en Ciencias de la Comunicación. Revista Iberoamericana para la Investigación y el Desarrollo Educativo, 8(16), 1-25.

Alonso, C., Gallego, D. y Honey, P. (1999). Los estilos de aprendizaje: procedimientos de diagnóstico y mejora. Bilbao: Mensajero.

Álvarez, C. (1999). La escuela en la vida. Didáctica. La Habana: Pueblo y Educación

Álvarez, M. (2011). Perfil del docente en el enfoque basado en competencias. Revista Electrónica Educare, XV (1), 99-107.

Arnaiz, P., Azorín, C. y García, M. (2015). Evaluación de planes de mejora en centros educativos de orientación inclusiva. Profesorado. Revista de Currículum y Formación de Profesorado, 19(3), 326-346.

Arnao, M., Aguilar, F. y Santisteban, K. (2013). Problemas para desarrollar la competencia comunicativo-investigativa en educación básica y superior UCV-Hacer. Revista de Investigación y Cultura, 2(2), 99-115.

Arriaga, M. (2015). El diagnóstico educativo, una importante herramienta para elevar la calidad de la educación en manos de los docentes. Atenas, 3(31), 63-74.

Ausubel, D. Novak, J. y Hanesian, H. (1983). Psicología educativa. Un punto de vista cognoscitivo. México. Editorial Trillas

Barrientos, A. (2016). Habilidades sociales y emocionales del profesorado de educación infantil relacionadas con la gestión del clima de aula (Tesis doctoral). Universidad Complutense de Madrid. Madrid: España. 
Batista, M. (2011). Significación de las habilidades comunicativas en el profesor universitario. Su importancia en la labor educativa y de superación. Cuadernos de Educación y Desarrollo, 3(24), 1-5.

Bernardo, M. (2007). Psicología de la personalidad: procesos. México. Ediciones Paraninfo.

Botero, C. (2009). Cinco tendencias de la gestión educativa. Revista Iberoamericana de Educación, 49(2), 1-11.

Bou, G., Trinidad, C. y Huguet (2003). E-learning. Madrid: Anaya Multimedia.

Brito H. y González, M. (1987). Psicología general para los Institutos Superiores Pedagógicos. La Habana: Editorial Pueblo y Educación.

Bruner, J. (1988). Desarrollo cognitivo y educación. Madrid: Morata.

Cabero, J.; otros (2006). Formación del profesorado universitario en estrategias metodológicas para la incorporación del aprendizaje en red en el EEES. Píxelbit. Revista de medios y educación, 27, 11-29.

Cañal, P. (2012). ¿Cómo evaluar la competencia científica? Investigación en la Escuela, 78, 5-17.

Cañedo, R., Ramos, R. y Guerrero, J. (2005). La Informática, la Computación y la Ciencia de la Información: una alianza para el desarrollo. Recuperado de http://scielo.sld.cu/pdf/aci/v13n5/aci07505.pdf

Cassany, D., Luna, M. y Sáenz, G (2009). Enseñar lengua (6ª Edición). Barcelona: Graó.

Castellanos, D., Reinoso, C. y García, S. (2007). Para Promover un Aprendizaje Desarrollador. Colección Proyectos. La Habana: Centro de Estudios Educacionales Instituto Superior Pedagógico Enrique José Varona.

Castillo, S. y Cabrerizo, J. (2006). Formación del profesorado en educación superior. Volumen II. Madrid: Mc Graw-Hill

Chávez, R. (2002). Material Didáctico Labarrere. Instituto Central de Ciencias Pedagógicas. La Habana: Editorial Pueblo y Educación.

Chumpitaz, L. y Rivero, C. (2012). Uso cotidiano y pedagógico de las TIC por profesores de una universidad privada de Lima. Educación, XXI (41), 81-100

Cisterna, F. (2005) Categorización y triangulación como procesos de validación del conocimiento en investigación cualitativa. Theoria, 14(1), 61-71

Coll, C. (2004). Psicología de la educación y prácticas educativas mediadas por las tecnologías de la información la comunicación. Una mirada constructivista. Sinéctica, 25, 1-24.

Coll, C., Pozo, J., Sarabia, B. y Valls, E. (1995). Los contenidos en la reforma en la reforma enseñanza y aprendizaje de conceptos, procedimientos y actividades. Madrid: Santillana 
Collazo, B. y Puentes, M. (2001). La orientación en la actividad pedagógica: el maestro, un orientador. La Habana: Pueblo y Educación.

Comisión mixta CRUE-TIC y REBIUN (2009). Competencias informáticas e informacionales en los estudios de grado. Recuperado de: https://www.uv.es/websbd/formacio/ci2.pdf

Consejo Nacional de Ciencia y Tecnología (2006). Plan Nacional Estratégico de Ciencia, Tecnología e Innovación para la Competitividad y el Desarrollo Humano 2006 2021. Lima: CONCYTEC.

Consejo Nacional de Educación (2006). Proyecto Educativo Nacional al 2021. Lima: CNE. Coronado, J. (2015). Uso de las TIC y su relación con las competencias digitales de los docentes en la Institución Educativa No 5128 de Ventanilla - Callao (Tesis de Maestría). Universidad Nacional de Educación Enrique Guzmán y Valle. Lima.

Crispín, M., Caudillo L., Doria C., y Esquivel M. (2011). Aprendizaje Autónomo, orientaciones para la docencia, Aprendizaje Autónomo. México D. F., México: Universidad Iberoamericana.

Cubillos, J. y Díaz, O. (2012). Estrategia de gestión mediada por las tecnologías de la información y la comunicación, para el fortalecimiento de la comunicación organizacional en el Colegio General Santander I.E.D. Bogotá: Universidad Libre.

Díaz, F. y Hernández, G. (2010). Estrategias docentes para un aprendizaje significativo. Bogotá; Mc Graw Hill.

Díaz, I. (2009). Las competencias TIC y la integración de las tecnologías de la información y comunicación de los docentes de la Universidad Católica del Maule (Tesis de Maestría). Universidad de Chile. Santiago, Chile.

Duart, J.; Lupiáñez, F. (2005). Estrategias en la introducción y uso de las TIC en la universidad. Revista de Universidad y Sociedad del conocimiento, v. 2, n.1, 5-31.

Escobar, J. y Cuervo, Á. (2008). Validez de contenido y juicio de expertos: una aproximación a su utilización. Avances en Medición, 6(1), 27-36. http://www.humanas.unal.edu.co/psicometria/files/7113/8574/5708/27-36.pdf

Feo, R. (2010). Orientaciones básicas para el diseño de estrategias didácticas. Tendencias pedagógicas, 16, 220-236.

Fremio, J. y Andrade, E. (2017). Nivel de conocimiento de las tecnologías de la información y comunicación en los docentes de educación superior. Innova ResearchJournal, 2(12), 59-74.

Froufe, M. (2011). Psicología del aprendizaje. Principios y aplicaciones conductuales. Madrid: Paraninfo.

Gagné, R. (1965). Condiciones del aprendizaje. Madrid: Editorial Aguilar. 
García, V. (1999). La educación personalizada en la universidad. Madrid: RIALP, S.A.

García-Valcárcel, A. (2007). Herramientas tecnológicas para mejorar la docencia universitaria. Una reflexión desde la experiencia y la investigación. RIED, 10(2), 125-148.

Ginoris, O. (2011). Didáctica desarrolladora: teoría y práctica de la escuela cubana. La Habana: Juan Marianello.

Gonzales, M. (2015). Eficacia del uso de herramientas informáticas básicas en el aprendizaje significativo de estudiantes del programa de estudios básicos de la Universidad Ricardo Palma en el año 2014 (Tesis de Maestría). Universidad de San Martin de Porres. Lima, Perú.

Gonzales, W. (2016). La modelación como competencia en la formación del profesional informático. Revista digital de investigación en docencia universitaria, 10(2), 59-71.

González, F. (2003). Sujeto y subjetividad: una aproximación histórica cultural. México: Ediciones Paraninfo.

González, V. (2008). Estrategias de enseñanza y aprendizaje. México: Editorial Paz.

Gonzáles, A. (1997). Ideas del pedagogo Alfredo Miguel Aguayo acerca del aprendizaje. ¿Aportes a la Didáctica? (Tesis de Maestría). Instituto Superior Pedagógico Enrique José Varona. La Habana.

Gonzalvez, C., Vicent, M., San martin, R. y Martínez, M. (2018). Evaluación del dominio de las habilidades comunicativas interpersonales en docentes en formación. En Roigm R. El compromiso académico y social a través de la investigación e innovación educativas en la Enseñanza Superior (940-950). Barcelona: Octaedro.

Hannan, A. y Silver, H. (2005). La innovación en la enseñanza superior. Madrid: Narcea.

Hernández, Z. (2012). Métodos de análisis de datos. Logroño: Servicio de Publicaciones de la Universidad de La Rioja

Hilgard, E. (1979). Teorías del Aprendizaje. México: Trillas.

Illán, N. y Molina, J. (2011). Integración Curricular: respuesta al reto de educar en y desde la diversidad. Educar em Revista, 41, 17-40.

Jarvis, P. (2006). Universidades corporativas. Nuevos modelos de aprendizaje en la sociedad global. Madrid: Narcea S.A.

Kehm, B. y Wit, H. (2005). Internationalisation in highereducation. Amsterdam: European

Lanuza, F., Rizo, M. y Saavedra, L. (2018). Uso y aplicación de las TIC en el proceso de enseñanza- aprendizaje. Revista Cientifica de FAREM-Esteli, 7(25). Recuperado de https://www.lamjol.info/index.php/FAREM/article/view/5667/5380.

Leiva, J. (2006). Introducción a la informática. Zaragoza: Escuela Universitaria Politécnica de La Almunia.http://www.lcc.uma.es/ jlleivao/introduccion/disenotema1.pdf. 
Leontiev, A. (1989). Actividad, conciencia, personalidad. La Habana: Pueblo y Educación. López, M. (2017). La Gestión pedagógica. Apuntes para un estudio necesario. Dominio de las ciencias, 3, 201-215.

Lugo, M. (2010). Las políticas TIC en la educación de América Latina. Tendencias y experiencias. Revista Fuentes, (10), 52-68.

Maldonado, M. (2006). Las competencias, su método y su genealogía. Bogotá: Ecoe Ediciones.

Marqués, P. (1999). Programari educatiu català sobre la Comunitat Europea com a instrument de recerca i mitjà didàctic per als alumnes de l'etapa dotze-setze anys. Butlletí de la Societat Catalana de Pedagogía, 4, 65 - 78

Martí, E. (2003). Las tecnologías de la información y de la comunicación. En Representar el mundo externamente (213-269). Madrid: Aprendizaje

Martínez, F. (2009). Mitología de las TIC en la sociedad y la enseñanza. Educativo Siglo $X X I, 27(2), 33-42$

Martínez, M. (2004). Ciencia y arte de la metodología cualitativa. México: Editorial Trillas.

Mas, O. (2011). El profesor universitario: sus competencias y formación. Profesorado. Revista de curriculum y formación del profesorado, 15(3), 195-211.

Meléndez, S. y Gómez, L. (2008). La planificación curricular en el aula. Un modelo de enseñanza por competencias. Laurus, 14(26), 367-392.

Mora, F. (2017). Solo se puede aprender aquello que se ama. Neuroeducación. Barcelona: Alianza.

Mora, M. (2014). Habilidades en el uso de herramientas informáticas en la investigación: estrategia didáctica para la unidad curricular proyecto el PNF en mecánica (Tesis doctoral). Universidad Central "Marta Abreu" de las Villas. Santa Clara, Cuba.

Moreno W. y Velázquez, M. (2017) Estrategia didáctica para desarrollar el pensamiento crítico. Revista Iberoamericana sobre Calidad, Eficacia y Cambio en Educación REICE, 5(2), 53-73.

Moreno, W. y Paredes, N. (2014). La gestión de las TIC y la calidad de la educación, medida por los resultados de las evaluaciones estandarizadas. Libre Empresa, 23, 137-163.

Morin, E. (2011). La vía para el futuro de la humanidad. Barcelona: Paidós

Moyá, M. (2016). Habilidades comunicativas y comunicación política (Tesis doctoral). Universidad Miguel Hernández. España.

Navío, A. (2005). Las competencias profesionales del formador. Una visión desde la formación continua. Barcelona: Octaedro-EUB. 
Oltolina, M. (2015). La formación de competencias digitales de estudiantes de profesorados universitarios: La estrategia de e-actividades en un modelo de aula extendida (Tesis de Maestría). Universidad Nacional de La Plata. La Plata, Argentina.

Organización de las Naciones Unidas para la Educación, la Ciencia y la Cultura (Unesco, 2013). Enfoques estratégicos sobre las TICS en educación en América Latina y el Caribe. Santiago: Orealc/Unesco

Ortiz, A. (2015). Como trabaja el cerebro humano y como deberían enseñar los docentes. Neuroeducación. Barcelona: Ediciones la U.

Paquay, L. (2005). La formación profesional del maestro. Estrategias y competencias. México: Fondo de cultura económica.

Parra, A. (2006). El modelo educativo por competencias centrado en el aprendizaje y sus implicaciones en la formación integral del estudiante. 6to. Congreso Internacional, Retos y Expectativas de la Universidad Chihuahua, México.

Peñaloza, W. (2003). Los propósitos de la educación. Lima: Pedagógico San Marcos.

Perera, V. y Torres, J. (2005). Una aproximación al estado actual de las investigaciones sobre la comunicación mediada por ordenador en el ámbito educativo. V Congreso Internacional Virtual de Educación, 7-27 de Febrero de 2005. España

Pérez, M., Enrique, J., Carbó, J. y González, M. (2017). La evaluación formativa en el proceso enseñanza aprendizaje. Edumecentro, 9(3), 263-283.

Pérez, R., Mercado, P., Martínez, M. y Mena, E. (2018). La sociedad del conocimiento y la sociedad de la información como la piedra angular en la innovación tecnológica educativa. Revista Iberoamericana para la investigación y el desarrollo educativo, 8(16). DOI: 10.23913/ride.v8i16.371.

Piaget, J. (1981). Seis estudios de Psicología. Barcelona: Barral.

Pimienta, J. (2012). Estrategias de enseñanza aprendizaje. Docencia universitaria basada en competencias. México: Pearson Educación.

Pino, C. (2012). Acciones y habilidades. Algunas discrepancias entre psicólogos y didactas. Ciencias Holguín, 18(1). http://www.ciencias.holguin.cu/index.php/cienciasholguin/article/view/640/670

Pupo, R. (2006). El hombre, la actividad humana, la cultura y sus mediaciones fundamentales. La Habana.

Reyes, D. y García, Y. (2014). Desarrollo de habilidades científicas en la formación inicial de profesores de ciencias y matemática. Educ. Educ. 17 (2), 271-285. Doi. 10.5294/edu.2014.17.2.4

Rico, P., Santos, E. y Martín, M. (2013). Proceso de enseñanza-aprendizaje desarrollador en la escuela Primaria. La Habana: Pueblo y Educación. 
Rodríguez, A. y Pérez, A. (2017). Métodos científicos de indagación y de construcción del conocimiento. Rev. esc.adm.neg. 82, 179-200

Rodríguez, A. y Pérez, A. (2017). Métodos científicos de indagación y de construcción del conocimiento. Revista EAN, 82,179-200.

Rodríguez, E. (2005). Metodología de la investigación. México: Universidad Juárez Autónoma de Tabasco.

Romero, V. (2006). Implicaciones pedagógicas del diagnóstico de la habilidad informática. Revista Graffylia, 4(6), 136-142.

Sáez, C. (2014). Neuroeducación o cómo educar con el cerebro. Evaluación de los aprendizajes y el talento humano. Usil. Edu, 63-69

Salcedo, H. (2011). Los objetivos y su importancia para el proceso de enseñanzaaprendizaje. Revista de Pedagogía, XXXII (91), 113-130.

Salgueiro, A. (2001) Indicadores de gestión y cuadro de mando. Madrid: Díaz de Santos.

Salinas, J. (2004): Cambios metodológicos con las TIC. Estrategias didácticas y entornos virtuales de enseñanza-aprendizaje. Bordón, 56 (3 y 4), 469-481.

Santiesteban, A. y Molina, V. (2018). Importancia del conocimiento y las habilidades en informática e inglés para el desempeño científico profesional. Revista Electrónica Dr. Zoilo E. Marinello Vidaurreta, 43(2), Recuperado de: http://www.revzoilomarinello.sld.cu/index.php/zmv/article/view/1251.

Silvestre, M. y Zilberstein, J. (2002). Hacia una didáctica desarrolladora. La Habana: Pueblo y Educación. Ciudad de.

Solórzano F. y García, A. (2013). Fundamentos del aprendizaje en red desde el conectivismo y la teoría de la actividad. Revista Cubana de Educación Superior, 35(3), 98-112.

Tapia, C. y Cubo, S (2017). Habilidades sociales relevantes: percepciones de múltiples actores educativos. MAGIS, Revista Internacional de Investigación en Educación, 9 (19), 133-148. doi: 10.11144/Javeriana.m9-19.hsrp

Terrazas, R. y Silva, R. (2013). La educación y la sociedad del conocimiento. Perspectivas, $32,145-168$

Tobón, S. (2013). Formación basada en competencia: Pensamiento complejo, diseño curricular y didáctica. Bogotá: Ecoe Ediciones

Tobón, S. (2013). Los proyectos formativos: transversalidad y desarrollo de competencias para la sociedad del conocimiento. México. CIFE.

Uribe, A. (2008). Acceso, conocimiento y uso de Internet en la universidad. Modelo de diagnóstico y caracterización: Caso Universidad de Antioquia. Colombia: Universidad de Antioquia. 
Uribe-Tirado, A. (2010). La Alfabetización Informacional en la Universidad. Descripción y Categorización según los Niveles de Integración de ALFIN. Caso Universidad de Antioquia. Revista Internamericana de Bibliotecología, 33(1), 31-83.

Valencia, T., Serna, A., Ochoa, S., Caicedo, A., Montes, J. y Chávez, J. (2016). Competencias y estándares TIC desde la dimensión pedagógica: Una perspectiva desde los niveles de apropiación de las TIC en la práctica educativa docente. Cali: Universidad Javeriana-Unesco.

Valle, A. (2007). Algunos modelos importantes en la investigación pedagógica. La Habana: Instituto Central de Ciencias Pedagógicas.

Vega, C. (2017). Uso de las TICS y su influencia con la enseñanza- aprendizaje del idioma inglés en los estudiantes del l y ll ciclo de la Escuela Académico Profesional de la Facultad de Educación Unmsm-Lima (Tesis de Maestría). Universidad Nacional Mayor de San Marcos. Perú.

Villasana, N. y Dorrego, E. (2007). Habilidades sociales en entornos virtuales de trabajo colaborativo. RIED. Revista Iberoamericana de Educación a Distancia, 10(2), 4574.

Vygotsky, L. (1987). Historia del desarrollo de las funciones psíquicas superiores. La Habana: Editorial Científico Técnica.

Zegarra, R. y Velázquez, M. (2016). El coaching: una forma para fortalecer el profesionalismo del docente en el aula. Páginas de Educación, 9(2), 156-183. 


\section{Anexos}

\section{Anexo 1. Encuesta a estudiantes}

Objetivo. Constatar los gustos y preferencias de los estudiantes por el proceso enseñanza aprendizaje empleando las TIC.

Participantes: Docentes de la facultad de contabilidad

Fecha:

\section{Instrucciones}

Con motivo de realizarse una investigación sobre el uso de las TIC en la enseñanzaaprendizaje, te solicitamos tu valiosa colaboración al responder la presente encuesta.

Lee detenidamente cada uno de los ítems y responde con sinceridad según el indicador que consideres. Recuerda que no hay respuesta buenas ni malas.

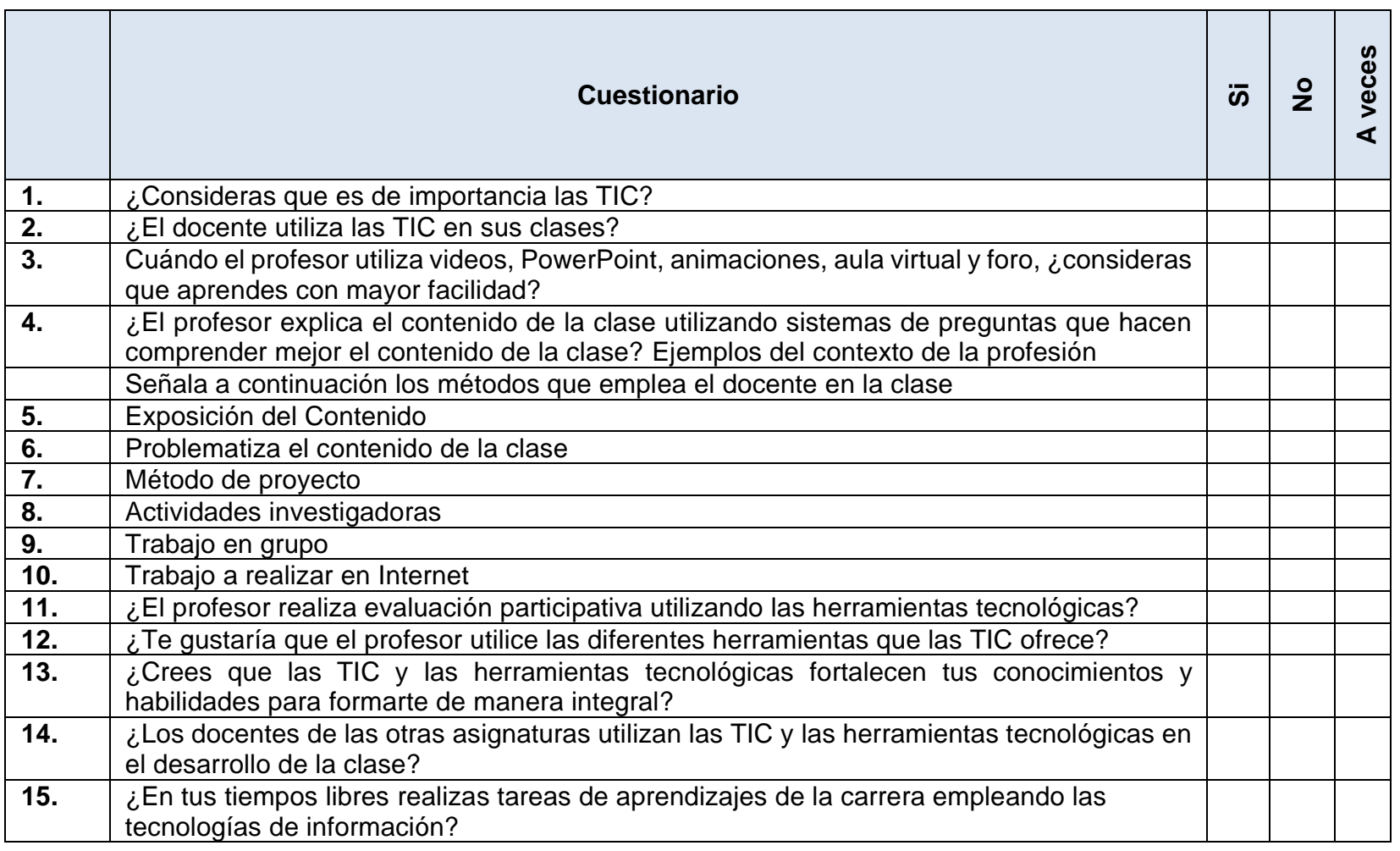




\section{Anexo 2. Observación a clases a docentes}

Objetivo. Comprobar los conocimientos teóricos y didácticos que poseen los docentes sobre las habilidades y uso de las TIC al dirigir el proceso de enseñanza- aprendizaje en las distintas asignaturas de la Facultad de Contabilidad de una Universidad Privada de Lima.

Datos generales.

Docentes de la asignatura:

Fecha: Hora: Asistencia:

Tema de la clase:

\begin{tabular}{|c|c|c|c|}
\hline & Aspectos a observar: & SI & NO \\
\hline & I. Motivación y orientación hacia los objetivos. & & \\
\hline 1 & El procedimiento con el que inicia la clase atrae la atención de los estudiantes. & & \\
\hline 2 & $\begin{array}{l}\text { Establece un adecuado diálogo para explorar los conocimientos previos que tienen los } \\
\text { estudiantes con lo nuevo. }\end{array}$ & & \\
\hline \multirow[t]{2}{*}{3} & Informa a los estudiantes sobre los objetivos de la clase. & & \\
\hline & II. Desarrollo del proceso de enseñanza-aprendizaje. & & \\
\hline \multirow[t]{2}{*}{4} & $\begin{array}{l}\text { El docente explica el contenido de su clase, apoyándose en las TIC demostrando cómo } \\
\text { proceder a través de varios ejemplos, revelando seguridad y dominio del contenido en } \\
\text { su tratamiento didáctico. }\end{array}$ & & \\
\hline & $\begin{array}{l}\text { Establece un sistema de preguntas dialógicas a partir de la observación de las TIC, } \\
\text { permitiendo la participación de los educandos y el uso de la informática al explicar el } \\
\text { contenido de la enseñanza. }\end{array}$ & & \\
\hline 5 & $\begin{array}{l}\text { Presenta varios ejemplos donde modela cómo proceder al emplear las TIC y las } \\
\text { habilidades comunicativas para estimular el pensamiento y la libre expresión de los } \\
\text { estudiantes. }\end{array}$ & & \\
\hline 6 & Orienta el desarrollo de actividades de aprendizaje en forma individual, grupal o virtual. & & \\
\hline 7 & $\begin{array}{l}\text { Explica detalladamente las acciones que los estudiantes deberán realizar; para luego } \\
\text { exponer en plenaria y realizar la heteroevaluación y autoevaluación }\end{array}$ & & \\
\hline 8 & $\begin{array}{l}\text { Entrega a los equipos una guía donde se les precisa las acciones que deben realizar, } \\
\text { cuál es el producto a entregar, cuales son los indicadores de evaluación y que } \\
\text { orientaciones deben seguir para exponer la propuesta. }\end{array}$ & & \\
\hline 9 & $\begin{array}{l}\text { Las tareas de aprendizaje son variadas, diferenciadas y exigen niveles crecientes de } \\
\text { asimilación con el uso de las TIC como medio de enseñanza. }\end{array}$ & & \\
\hline 10 & $\begin{array}{l}\text { Se utilizan métodos y procedimientos TIC que promueven la búsqueda reflexiva, } \\
\text { valorativa e independiente del conocimiento por los estudiantes. }\end{array}$ & & \\
\hline 11 & $\begin{array}{l}\text { El docente promueve el debate, el intercambio y la socialización de la actividad en los } \\
\text { equipos. }\end{array}$ & & \\
\hline 12 & $\begin{array}{l}\text { El docente emplea las TIC como medios de enseñanza y argumenta los sustentos } \\
\text { teóricos de estas herramientas, resaltando los beneficios para el aprendizaje en los } \\
\text { estudiantes. }\end{array}$ & & \\
\hline \multirow[t]{2}{*}{13} & $\begin{array}{l}\text { Aprovecha las potencialidades del contenido expuesto para que los estudiantes valoren } \\
\text { el uso de las TIC al realizar sus actividades de aprendizaje. }\end{array}$ & & \\
\hline & III. Conclusiones de la clase & & \\
\hline 14 & $\begin{array}{l}\text { Se utilizan formas (individuales y colectivas) de control, valoración y evaluación del } \\
\text { proceso y el resultado de las tareas de aprendizaje de forma que promuevan la } \\
\text { autorregulación de los estudiantes. }\end{array}$ & & \\
\hline 15 & Los equipos exponen a considerando los indicadores y las orientaciones del docente. & & \\
\hline 16 & $\begin{array}{l}\text { El docente solicita al equipo y luego al resto de los estudiantes que evalúen al final de } \\
\text { la exposición lo que se ha presentado. }\end{array}$ & & \\
\hline 17 & $\begin{array}{l}\text { El profesor destaca lo positivo y negativo de cada equipo e integrante del producto } \\
\text { presentado. }\end{array}$ & & \\
\hline
\end{tabular}




\section{Anexo 3. Entrevista semiestructurada a docentes}

Objetivo. Comprobar los conocimientos teóricos y didácticos que tienen los docentes sobre las TIC y su empleo en la enseñanza- aprendizaje en las distintas asignaturas de la Facultad de Contabilidad de una Universidad Privada de Lima

Datos generales.

Fecha: Hora:

Asistencia:

Entrevistados: Docentes de distintas asignaturas.

Estimado(a) profesor(a), con motivo de realizar una investigación sobre el manejo y uso de las TIC en la enseñanza- aprendizaje y conociendo de su experiencia como docentes, queremos conversar con ustedes al respecto y de antemano le agradecemos su colaboración. Sus opiniones y puntos de vistas, serán de gran utilidad para el proceso investigativo Muchas gracias por su ayuda.

\section{HABILIDADES INFORMATICAS}

1. ¿Cómo podría definir las TIC y qué importancia le confiere? ¿Qué términos se le vienen a la mente para describirla?

2. ¿Cómo usted define las habilidades informáticas? ¿Es necesario saber redactar para dominar esta habilidad? ¿Por qué?

3. ¿Ha recibido capacitación metodológica para lograr el desarrollo de las habilidades informáticas y su uso en la clase? ¿Cree que mejoraría sus recursos expositivos en clase?

4. ¿Considera usted que domina o tiene habilidades en el uso de las TIC? ¿Estas habilidades facilitan la explicación de la ciencia?

5. ¿Considera que las TIC le ayudan a diseñar las actividades de enseñanza y de aprendizaje en su asignatura?

6. ¿Cree que las TIC fortalecen su capacidad profesional y su actitud en el uso del conocimiento sobre distintos temas y explicarlos con rigor? Explique

7. ¿Cómo es la participación de sus estudiantes en la clase cuando usa las TIC?

8. ¿Cómo se siente cuando intercambia conocimientos, opiniones, creencias y puntos de vistas con otras personas a través de alguna TIC?

9. ¿Cómo hace para desarrollar los conocimientos y comportamientos positivos en sus estudiantes al usar las TIC?

\section{ESTRATEGIAS DE GESTIÓN}

1. ¿Qué actividades realizas en el aula para conocer las fortalezas y debilidades de los estudiantes? 
2. ¿Logra caracterizar la realidad educativa de sus estudiantes? Describa sus hallazgos

3. ¿En su planificación pedagógica, formula objetivos a corto, mediano y largo plazo? Explica cómo.

4. ¿Conoce los principios y enfoques teóricos sobre el uso de las TIC en la enseñanza- aprendizaje? Describa la que conoce.

5. ¿Qué herramientas de las TIC usas en la clase para contribuir al desarrollo del aprendizaje de tus estudiantes?

6. ¿Qué métodos o estrategias de enseñanza aplicas en la clase para contribuir al desarrollo del aprendizaje de tus estudiantes?

7. ¿Qué condiciones es necesario crear para la aplicación de estrategias TIC? Explique

8. ¿Observa que el uso estrategias de gestión TIC transforma el desempeño del docente? Explique

9. ¿Observa que el uso estrategias de gestión TIC provoca cambios en la enseñanza- aprendizaje? Explique 
Anexo 4. Fichas de validación

\section{FICHA DE VALIDACIÓN DE LA PROPUESTA METODOLÓGICA}

\section{Datos generales.}

1.1. Apellidos y nombres de especialista: .....HERAAN GERARDO FloRES V

\subsection{Grado de estudios alcanzado} ....... AGISTER

\subsection{Resultado científico en valoración:}

\subsection{Autor del resultado científico:}

\section{Aspectos a observar}

\section{VALIDACIÓN INTERNA}

\begin{tabular}{|c|c|c|c|c|c|c|c|c|}
\hline \multirow[t]{3}{*}{ indicadores } & \multirow{2}{*}{\multicolumn{5}{|c|}{$\begin{array}{l}\text { Escala de } \\
\text { valoración }\end{array}$}} & \multicolumn{3}{|l|}{ Aspectos } \\
\hline & & & & & & \multirow[t]{2}{*}{ Positivos } & \multirow{2}{*}{ Negativos } & \multirow[t]{2}{*}{ Sugerencias } \\
\hline & 1 & 2 & 3 & 4 & 5 & & & \\
\hline $\begin{array}{l}\text { Factibilidad de aplicación del resultado que se } \\
\text { presenta. }\end{array}$ & & & & & $x$ & & & \\
\hline $\begin{array}{l}\text { Claridad de la propuesta para ser aplicado } \\
\text { por otros. }\end{array}$ & & & & f & & & & \\
\hline $\begin{array}{l}\text { Posibilidad de la propuesta de extensión a } \\
\text { otros contextos semejantes. }\end{array}$ & & & & & $x$ & & & \\
\hline $\begin{array}{l}\text { Correspondencia con las necesidades } \\
\text { sociales e individuales actuales. }\end{array}$ & & & & & 4 & & & \\
\hline $\begin{array}{l}\text { Congruencia entre el resultado propuesto y el } \\
\text { objetivo fijado. }\end{array}$ & & & & & $\mathcal{L}$ & & & \\
\hline $\begin{array}{l}\text { Novedad en el uso de conceptos y } \\
\text { procedimientos de la propuesta. }\end{array}$ & & & & j. & & & & \\
\hline $\begin{array}{l}\text { La modelación contiene propósitos basados } \\
\text { en los fundamentos educativos, curriculares y } \\
\text { pedagógicos. detallado, preciso y efectivo }\end{array}$ & & & & $\dot{x}$ & & & & \\
\hline $\begin{array}{l}\text { La propuesta está contextualizada a la } \\
\text { realidad en estudio. }\end{array}$ & & & & & $\chi$. & & & \\
\hline $\begin{array}{l}\text { Presenta objetivos claros, coherentes y } \\
\text { posibles de alcanzar }\end{array}$ & & & & $=$ & & & & \\
\hline $\begin{array}{l}\text { Contiene un plan de acción de lo general a lo } \\
\text { particular. }\end{array}$ & & & & & $t$ & & & \\
\hline
\end{tabular}


FICHA DE VALIDACIÓN EXTERNA (FORMA)

\begin{tabular}{|c|c|c|c|c|c|c|c|}
\hline \multirow{2}{*}{\multicolumn{2}{|c|}{ Indicadores }} & \multirow{2}{*}{\multicolumn{3}{|c|}{$\begin{array}{c}\text { Escala de } \\
\text { valoración }\end{array}$}} & \multirow{2}{*}{\multicolumn{3}{|c|}{ Aspectos }} \\
\hline & & & & & & & \\
\hline & & 12 & 3 & \begin{tabular}{l|l}
4 & 5 \\
\end{tabular} & Positivos & Negativos & Sugerencias \\
\hline Claridad & $\begin{array}{l}\text { Es formulado con lenguàje } \\
\text { apropiado. }\end{array}$ & & & K & & & \\
\hline Objetividad & $\begin{array}{l}\text { Esta expresado en } \\
\text { conductas observables }\end{array}$ & & & & & & \\
\hline Actuàiidàd & $\begin{array}{l}\text { Adecuado àl avance de là } \\
\text { ciencia pedagógica. }\end{array}$ & & & 久 & & & \\
\hline Organización & $\begin{array}{l}\text { Existe una organización } \\
\text { lógica. }\end{array}$ & & & r & & & \\
\hline Suficiencià & $\begin{array}{l}\text { Comprende los àspectos } \\
\text { de cantidad y calidad. }\end{array}$ & & & & & & \\
\hline Intencionalidad & $\begin{array}{l}\text { Adecuado para valorar los } \\
\text { aspectos de las categorías } \\
\text { y subcategorías. }\end{array}$ & & & X & & & \\
\hline Consistencia & $\begin{array}{l}\text { Basado en aspectos } \\
\text { teóricos científicos de la } \\
\text { Psicología. }\end{array}$ & & & 久 & & & \\
\hline Coherencia & $\begin{array}{l}\text { Entre las categorías, } \\
\text { subcategorías e } \\
\text { indicadores. }\end{array}$ & & & 1 & & & \\
\hline Metodología & $\begin{array}{l}\text { La estrategia responde al } \\
\text { propósito del diagnóstico. }\end{array}$ & & & & 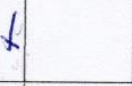 & & \\
\hline Pertinencia & $\begin{array}{l}\text { Es útil y adecuado para la } \\
\text { investigación. }\end{array}$ & & & & & & \\
\hline
\end{tabular}

OPINIÓN DE APLICABILIDAD:

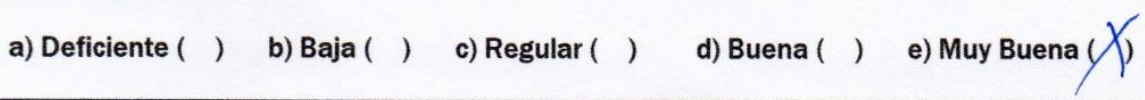

\begin{tabular}{|c|c|c|c|}
\hline Nombres y Apellidos & HZKWAD $6=12 A R D$ Floces V. & DNI N ${ }^{\mathrm{a}}$ & 06055101 \\
\hline Dirección domiciliaria & Hos cabulís 159 (2011 & Teléfono / Celular & 990461104 \\
\hline $\begin{array}{l}\text { Título profesional/ } \\
\text { Especialidad }\end{array}$ & 50 cabloso & & \\
\hline Grado Académico & Masister & & \\
\hline Mención & eral & & \\
\hline
\end{tabular}

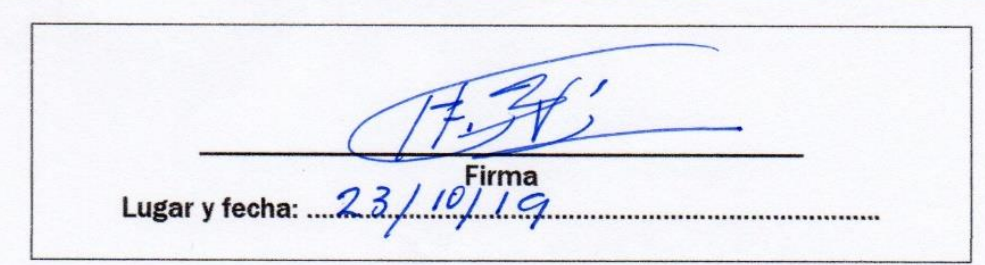




\section{FICHA DE VALIDACIÓN DE LA PROPUESTA METODOLÓGICA}

\section{Datos generales.}

1.1. Apellidos y nombres de especialista:

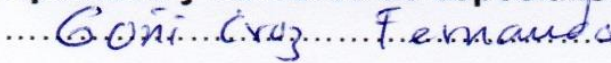

1.2. Grado de estudios alcanzado

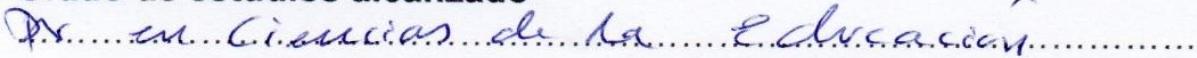

1.3. Resultado científico en valoración:

1.4. Autor del resultado científico:

\section{Aspectos a observar}

\section{VALIDACIÓN INTERNA}

\begin{tabular}{|c|c|c|c|c|c|c|c|}
\hline \multirow[t]{3}{*}{ indicadores } & \multirow{2}{*}{\multicolumn{4}{|c|}{$\begin{array}{l}\text { Escala de } \\
\text { valoración }\end{array}$}} & \multicolumn{3}{|l|}{ Aspectos } \\
\hline & & & & & \multirow[t]{2}{*}{ Positivos } & \multirow[t]{2}{*}{ Negativos } & \multirow[t]{2}{*}{ Sugerencias } \\
\hline & \begin{tabular}{l|l}
12 \\
\end{tabular} & \begin{tabular}{l|l}
2 & 3 \\
\end{tabular} & 4 & 5 & & & \\
\hline $\begin{array}{l}\text { Factibilidad de aplicación del resultado que se } \\
\text { presenta. }\end{array}$ & & & & $x$ & & & \\
\hline $\begin{array}{l}\text { Claridad de la propuesta para ser aplicado } \\
\text { por otros. }\end{array}$ & & & $x$ & & & & \\
\hline $\begin{array}{l}\text { Posibilidad de la propuesta de extensión a } \\
\text { otros contextos semejantes. }\end{array}$ & & & & $x$ & & & \\
\hline $\begin{array}{l}\text { Correspondencia con las necesidades } \\
\text { sociales e individuales actuales. }\end{array}$ & & & $x$ & & & & \\
\hline $\begin{array}{l}\text { Congruencia entre el resultado propuesto y el } \\
\text { objetivo fijado. }\end{array}$ & & & $x$ & & & & \\
\hline $\begin{array}{l}\text { Novedad en el uso de conceptos y } \\
\text { procedimientos de la propuesta. }\end{array}$ & & & $x$ & & & & \\
\hline $\begin{array}{l}\text { La modelación contiene propósitos basados } \\
\text { en los fundamentos educativos, curriculares y } \\
\text { pedagógicos. detallado, preciso y efectivo }\end{array}$ & & & & $x$ & & & \\
\hline $\begin{array}{l}\text { La propuesta está contextualizada a la } \\
\text { realidad en estudio. }\end{array}$ & & & $\varnothing$ & & & & \\
\hline $\begin{array}{l}\text { Presenta objetivos claros, coherentes y } \\
\text { posibles de alcanzar }\end{array}$ & & & $x$ & & & & \\
\hline $\begin{array}{l}\text { Contiene un plan de acción de lo general a lo } \\
\text { particular. }\end{array}$ & & & $\infty$ & & & & \\
\hline
\end{tabular}


FICHA DE VALIDACIÓN EXTERNA (FORMA)

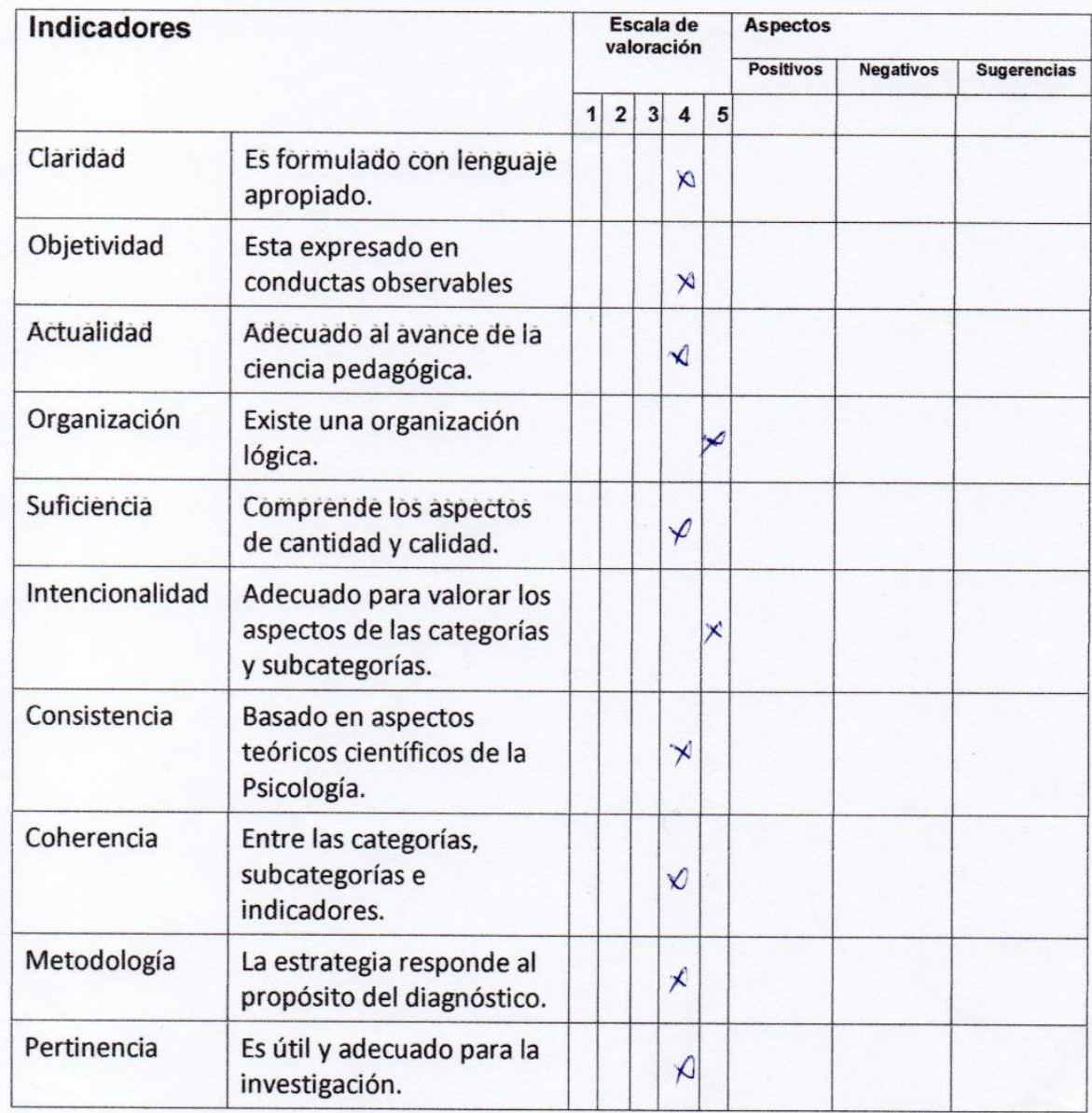

OPINIÓN DE APLICABILIDAD:

a) Deficiente ( ) b) Baja ( ) c) Regular ( ) d) Buena ( ) e) Muy Buena ( )

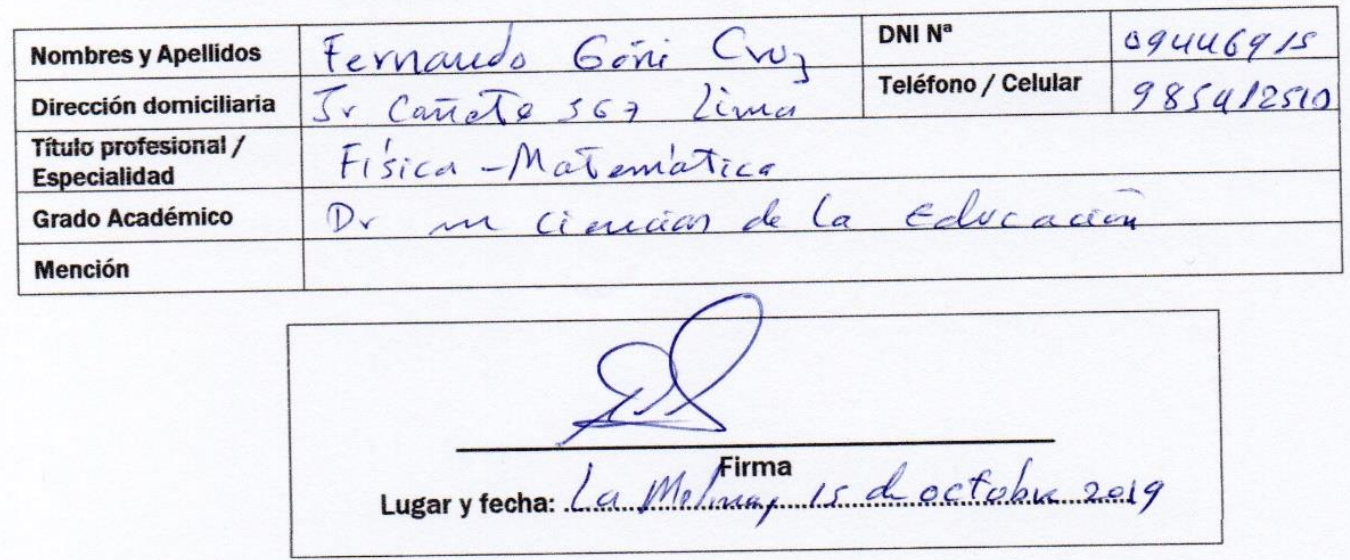




\section{Datos generales.}

1.1. Apellidos y nombres de especialista:

MarióléLón Moreno

\subsection{Grado de estudios alcanzado} Magister

\subsection{Resultado científico en valoración:}

\subsection{Autor del resultado científico:}

\section{Aspectos a observar}

\section{VALIDACIÓN INTERNA}

\begin{tabular}{|c|c|c|c|c|c|c|c|c|}
\hline \multirow[t]{3}{*}{ indicadores } & \multirow{2}{*}{\multicolumn{5}{|c|}{$\begin{array}{l}\text { Escala de } \\
\text { valoración }\end{array}$}} & \multicolumn{3}{|l|}{ Aspectos } \\
\hline & & & & & & \multirow[t]{2}{*}{ Positivos } & \multirow[t]{2}{*}{ Negativos } & \multirow[t]{2}{*}{ Sugerencias } \\
\hline & 1 & 2 & 3 & 4 & 5 & & & \\
\hline $\begin{array}{l}\text { Factibilidad de aplicación del resultado que se } \\
\text { presenta. }\end{array}$ & & & & & $x$ & & & \\
\hline $\begin{array}{l}\text { Claridad de la propuesta para ser aplicado } \\
\text { por otros. }\end{array}$ & & & & $x$ & & & & \\
\hline $\begin{array}{l}\text { Posibilidad de la propuesta de extensión a } \\
\text { otros contextos semejantes. }\end{array}$ & & & & & $\mathrm{x}$ & & & \\
\hline $\begin{array}{l}\text { Correspondencia con las necesidades } \\
\text { sociales e individuales actuales. }\end{array}$ & & & & & $\mathrm{x}$ & & & \\
\hline $\begin{array}{l}\text { Congruencia entre el resultado propuesto y el } \\
\text { objetivo fijado. }\end{array}$ & & & & & $\mathrm{x}$ & & & \\
\hline $\begin{array}{l}\text { Novedad en el uso de conceptos y } \\
\text { procedimientos de la propuesta. }\end{array}$ & & & & $\mathrm{x}$ & & & & \\
\hline $\begin{array}{l}\text { La modelación contiene propósitos basados } \\
\text { en los fundamentos educativos, curriculares y } \\
\text { pedagógicos. detallado, preciso y efectivo }\end{array}$ & & & & & $\mathrm{x}$ & & & \\
\hline $\begin{array}{l}\text { La propuesta está contextualizada a la } \\
\text { realidad en estudio. }\end{array}$ & & & & & $x$ & & & \\
\hline $\begin{array}{l}\text { Presenta objetivos claros, coherentes y } \\
\text { posibles de alcanzar }\end{array}$ & & & & & $x$ & & & \\
\hline $\begin{array}{l}\text { Contiene un plan de acción de lo general a lo } \\
\text { particular. }\end{array}$ & & & & $\mathrm{x}$ & & & & \\
\hline
\end{tabular}


FICHA DE VALIDACIÓN EXTERNA (FORMA)

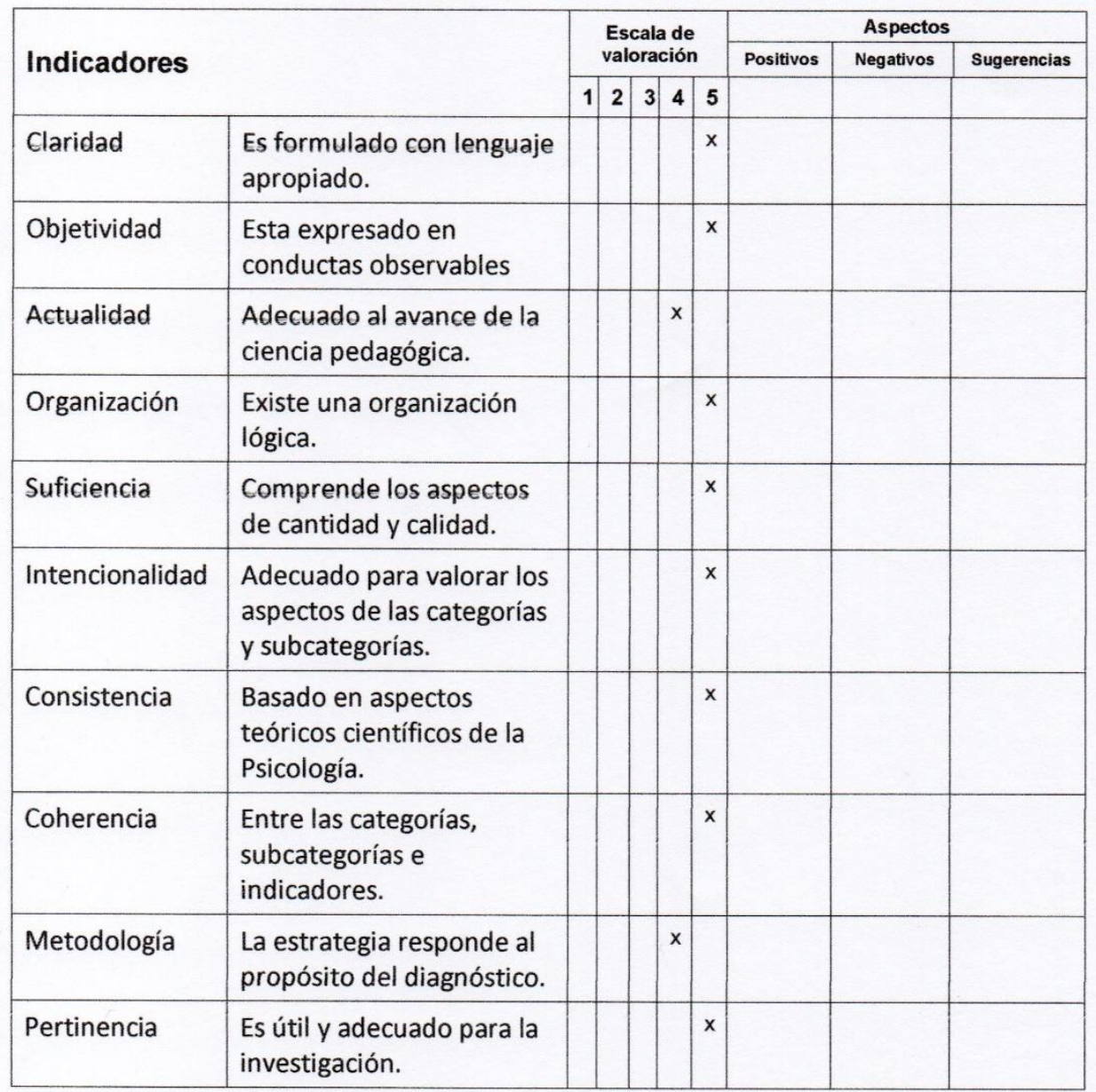

OPINIÓN DE APLICABILIDAD:
a) Deficiente ( )
b) Baja ( )
c) Regular ( )
d) Buena ( )
e) Muy Buena ( )

\begin{tabular}{|l|l|l|l|}
\hline Nombres y Apellidos & MARIO LEÓN MORENO & DNI N & 16783926 \\
\hline Dirección domiciliaria & Del Parque Norte 289 San Isidro & Teléfono / Celular & 987211380 \\
\hline $\begin{array}{l}\text { Título profesional / } \\
\text { Especialidad }\end{array}$ & Ingeniero de Sistemas & \\
\hline Grado Académico & Magister en Administración / Bachiller en Ingeniería de Sistemas \\
\hline Mención & Dirección General & \\
\hline
\end{tabular}

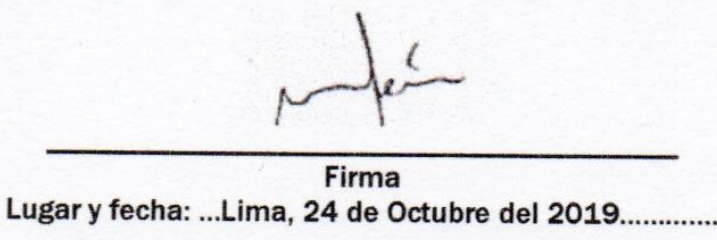


Anexo 5. Matriz de categorización

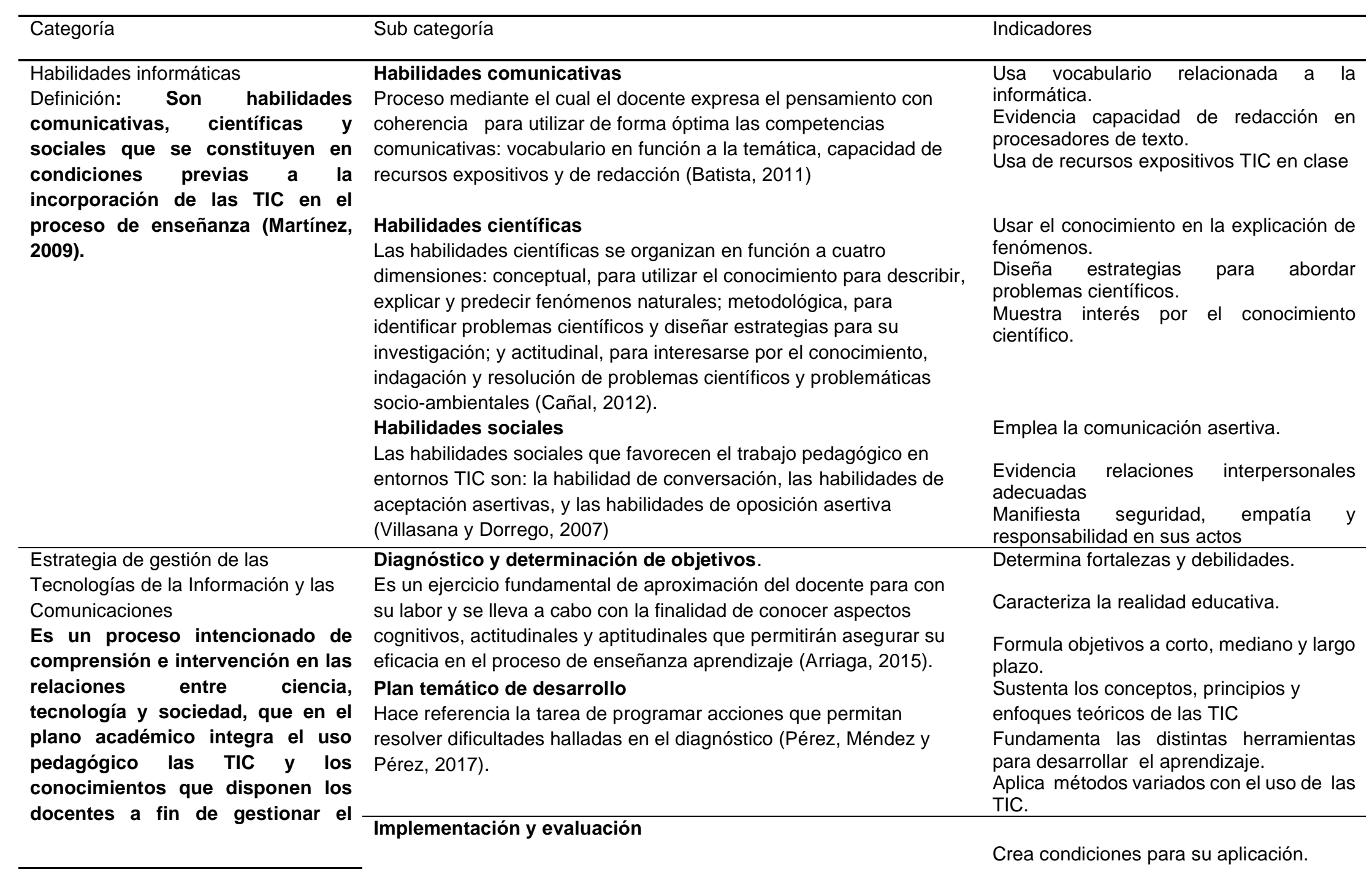


conocimiento (Moreno y Paredes,

$$
\text { 2014). }
$$

marcha de las actividades planificadas y su consecuente evaluación, bajo una perspectiva de calidad a través de la mejoría continua. Se desarrollan acciones que conducen a la optimización de aspectos susceptibles a cambio. Por otro lado, la evaluación supone el trazo de una línea de orientación en base a indicadores que permita saber el nivel de cumplimiento de

actividades así como de los resultados obtenidos,, lo que deviene en un nuevo diagnóstico y por tanto un nuevo plan (Arnaiz, Azorín y

García, 2015)
Transforma el desempeño del docente.

Provoca cambios en la enseñanzaaprendizaje 


\section{Anexo 6. Codificación y categorización de las entrevistas}

\section{Codificación y categorización de las entrevistas}

\begin{tabular}{|c|c|c|c|c|}
\hline 1.Hugo & $\begin{array}{l}\text { Las Pregunta y las Respuestas } \\
\text { HABILIDADES INFORMATICAS }\end{array}$ & Frases codificadas & Categorías y subcategorías & Cód. \\
\hline 10. & $\begin{array}{l}\text { ¿Cómo podría definir las TIC y qué importancia le confiere? ¿Qué } \\
\text { términos se le vienen a la mente para describirla? } \\
\text { Las tecnologías de la información y la comunicación son el uso de las } \\
\text { técnicas de la informática para el uso de varias actividades diarias como } \\
\text { estudiar, comunicarse, divertirse entre otras. Realmente se revisten de } \\
\text { gran importancia porque han cambiado muchas de las formas de vida } \\
\text { cotidiana de las personas en la actualidad. Los términos que vendrían a } \\
\text { mi mente serían informáticos, computación, computadores, internet, } \\
\text { celulares, entre otros. }\end{array}$ & $\begin{array}{l}\text { son el uso de las técnicas de la } \\
\text { informática para el uso de varias } \\
\text { actividades diarias como estudiar, } \\
\text { comunicarse, divertirse entre otras }\end{array}$ & Uso de las TIC & 1 \\
\hline 11. & $\begin{array}{l}\text { ¿Cómo usted define las habilidades informáticas? ¿Es necesario saber } \\
\text { redactar para dominar esta habilidad? ¿Por qué? } \\
\text { Las habilidades informáticas con las competencias que tienen las } \\
\text { personas más jóvenes para dominar y manejar las técnicas de las } \\
\text { tecnologías de la información y la comunicación, estos jóvenes son } \\
\text { incluso llamados internautas, naturales en el manejo de estas } \\
\text { herramientas, la gran mayoría han nacido con estas tecnologías en sus } \\
\text { manos. No es necesario saber redactar para manejar un Word o } \\
\text { procesador de textos por el contrario estas personas cada vez manejan } \\
\text { menos el idioma de castilla, no saben redactar es más cuando se les } \\
\text { pide escriban en una hoja y lapicero cometen toda clase de errores } \\
\text { ortográficos, aún estén acabando una carrera profesional. }\end{array}$ & $\begin{array}{l}\text { las competencias que tienen las } \\
\text { personas más jóvenes para dominar } \\
\text { y manejar las técnicas de las } \\
\text { tecnologías de la información y la } \\
\text { comunicación. }\end{array}$ & Dominio de la informática & 2 \\
\hline 12. & $\begin{array}{l}\text { ¿Ha recibido capacitación metodológica para lograr el desarrollo de las } \\
\text { habilidades informáticas y su uso en la clase? ¿Cree que mejoraría sus } \\
\text { recursos expositivos en clase? } \\
\text { Se me ha invitado muchas veces a capacitaciones de la UPN para el } \\
\text { manejo de las habilidades informáticas en mis clases, pero por mi calidad } \\
\text { de docente a tiempo parcial, dichas invitaciones se me cruzan en todos } \\
\text { los casos con las actividades en otras casas de estudio. En definitiva, los } \\
\text { recursos informáticos mejorarían tremendamente las estrategias } \\
\text { expositivas en nuestras clases, pero lo limitado de nuestro tiempo por } \\
\text { deber cumplir una serie de actividades es una gran limitante para recibir } \\
\text { capacitaciones en las TICs. }\end{array}$ & $\begin{array}{l}\text { los recursos informáticos mejorarían } \\
\text { tremendamente las estrategias } \\
\text { expositivas en nuestras clases }\end{array}$ & $\begin{array}{l}\text { Las TIC como recurso } \\
\text { expositivo }\end{array}$ & 3 \\
\hline 13. & $\begin{array}{l}\text { ¿Considera usted que domina o tiene habilidades en el uso de las TIC? } \\
\text { ¿Estas habilidades facilitan la explicación de la ciencia? }\end{array}$ & $\begin{array}{l}\text { estas habilidades son de gran } \\
\text { utilidad para explicar de mucha } \\
\text { mejor forma las ciencias porque }\end{array}$ & $\begin{array}{l}\text { Recurso grafico para explicar } \\
\text { contenidos }\end{array}$ & 4 \\
\hline
\end{tabular}


Considero tener habilidades limitadas en el uso de Word, Excel (por la

misma carrera de contabilidad) y Power Point por la misma necesidad de tener que utilizarlas para las exposiciones de mis clases, considero tene habilidades en forma intermedia para nada avanzadas como algunos de mis alumnos. En definitiva, estas habilidades son de gran utilidad para explicar de mucha mejor forma las ciencias porque facilitan una serie de usos de imágenes, videos y audio.

14. ¿Considera que las TIC le ayudan a diseñar las actividades de enseñanza y de aprendizaje en su asignatura?

Si considero que las TIC serían de gran ayuda para diseñar actividades de enseñanza-aprendizaje porque potencian la exposición de las clases al ofrecer el uso de imágenes, videos y audio, muchas veces nuestros alumnos han mostrado en sus trabajos de exposición tener un gran dominio de estas técnicas tecnológicas, donde sus presentaciones presentan de mejor forma que nosotros los docentes el uso de estas TIC como un famoso PREZZI.

15. ¿Cree que las TIC fortalecen su capacidad profesional y su actitud en el uso del conocimiento sobre distintos temas y explicarlos con rigor? Explique

Estoy seguro que el manejo de las TICs serían de gran utilidad para fortalecer nuestras capacidades profesionales y ayudarnos a explicar de una forma más grafica los temas que desarrollamos en las clases que presentamos a nuestros estudiantes, temas que responden a un silabo del curso y las exigencias del mercado laboral, se les mostraría a los alumnos formas más cercanas a la realidad que les espera en el trabajo, existe un curso de sistemas contables donde se les enseña a los jóvenes CONCAR, SISCONT en un laboratorio de computadoras y cada alumno en su propia máquina, estos programas permiten manejar la contabilidad computarizada para las MYPES.

16. ¿Cómo es la participación de sus estudiantes en la clase cuando usa las TIC?

Cuando utilizo el Power Point observo a mis estudiantes más interesados y absortos en aquello que se les pueda presentar en las diapositivas, como dice la frase: "una imagen vale más que mil palabras", asimismo cuando sus compañeros exponen usando videos y otras técnicas de internet se puede observar a una clase más conectada con los temas de los expositores, en ese sentido reconozco la gran utilidad de las TIC en la mejora de las clases.

17. ¿Cómo se siente cuando intercambia conocimientos, opiniones, creencias y puntos de vistas con otras personas a través de alguna TIC? facilitan una serie de usos de

imágenes, videos y audio

Si considero que las TIC serían de gran ayuda para diseñar actividades de enseñanza-aprendizaje porque potencian la exposición de las clase al ofrecer el uso de imágenes. videos y audio

serían de gran utilidad para fortalecer nuestras capacidades profesionales y ayudarnos a explicar de una forma más grafica los temas que desarrollamos en las clases que presentamos a nuestros estudiantes

observo a mis estudiantes más interesados y absortos en aquello que se les pueda presentar en las diapositivas,

se puede observar a una clase más conectada con los temas de los

expositores

por este medio nos comunicaban cosas importantes en tiempo real
Las TIC como recurso expositivo

Recurso grafico para explicar
Motivación y actitud positiva para el aprendizaje 
Una de las TIC más usadas son el WhatsApp por intermedio del celular,

yo creía que esto solo servía para que los jóvenes lo usarán como chismógrafo; pero debo reconocer su gran utilidad cuando algunos coordinadores académicos nos ingresaron al WhatsApp y por este medio nos comunicaban cosas importantes en tiempo real, además con mis clientes de contabilidad también lo hemos empleado para intercambiar información importante para coordinaciones y mantener actualizas su contabilidad.

18. ¿Cómo hace para desarrollar los conocimientos y comportamientos positivos en sus estudiantes al usar las TIC?

En realidad, como mi manejo de las TICs no es muy bueno que digamos, suelo usar muy poco el reforzamiento de los conocimientos y comportamientos positivos de mis estudiantes, a diferencia cuando ellos presentan sus trabajos expositivos donde demuestran gran manejo de

las TIC, entonces reciben los elogios de mi parte por los buenos trabajos presentados, en estos momentos se podría decir reciben

retroalimentación positiva de mi parte.

\section{ESTRATEGIAS DE GESTIÓN}

10. ¿Qué actividades realizas en el aula para conocer las fortalezas y debilidades de los estudiantes?

En los primeros momentos de las clases se emplean las técnicas de recojo de saberes previos en esta etapa se puede observar las fortalezas y debilidades de los estudiantes, otro momento se presenta cuando deben desarrollar los casos prácticos contables, entonces se puede observar las fortalezas y las debilidades de los estudiantes; una de las más representativas es cuando el alumno no sabe emplear la calculadora o aplicar el porcentaje.

11. ¿Logra caracterizar la realidad educativa de sus estudiantes? Describa sus hallazgos

Las características de nuestros estudiantes se muestran por su pobre manejo del idioma castellano, lo difícil que les resulta poder redactar incluso en el procesador de palabras. Otro aspecto es la dificultad en el manejo de las matemáticas por lo difícil que se les hace manejarse en las fórmulas matemáticas. Otro de los puntos de gran dificultad para ellos es el exponer en forma adecuada mostrando gran nerviosismo para salir habla y al mismo momento de exponer. El aspecto positivo para rescatar es el uso de las TIC donde se desempeñan mostrando gran manejo y dominio.

12. ¿En su planificación pedagógica, formula objetivos a corto, mediano y largo plazo? Explica cómo.

reciben los elogios de mi parte por los buenos trabajos presentados, en estos momentos se podría decir

reciben retroalimentación positiva de mi parte.

se emplean las técnicas del recojo de saberes previos en esta etapa se puede observar las fortalezas y debilidades de los estudiantes

Las características de nuestros estudiantes se muestran por su pobre manejo del idioma castellano, lo difícil que les resulta poder redactar incluso en el procesador de palabras [...]manejo de las matemáticas [...] nerviosismo para salir hablar y al mismo momento de exponer

En mi planificación pedagógica preparo los objetivos correspondientes al curso a mi cargo
Facilita la comunicación y la retroalimentación

Métodos de enseñanza-

aprendizaje 
En mi planificación pedagógica preparo los objetivos correspondientes al curso a mi cargo, por ejemplo, Contabilidad Financiera I que trata de los temas de finanzas, mercados financieros, el valor del dinero en el tiempo, generación de valor de la empresa, entre otros; ellos exigen objetivos a corto plazo como el aprendizaje de cada tema que implica sus propios subtemas, los objetivos a mediano plazo se encuentran determinados por las unidades en que se divide el curso. Para finalizar con los objetivos a largo plazo que muestran que todos esos temas deben ser de dominio de un gerente y que como contadores de un microempresario están en la obligación no solo de llevar su contabilidad, liquidar sus impuestos, sino además de fungir como asesores financieros para ayudar crecer a su cliente.

13. ¿Conoce los principios y enfoques teóricos sobre el uso de las TIC en la enseñanza- aprendizaje? Describa la que conoce.

Bueno conozco como indique anteriormente el procesador de textos Word, la hoja de cálculo Excel y el presentador de diapositivas Power Point, siendo sus principios el del Word de servir para escribir cartas, solicitudes, texto, monografías, entre otros; el Excel me sirve para desarrollar una serie de hojas de cálculo como los estados financieros con sus notas, hojas de costos, presupuestos, liquidación de impuestos, entre otros.

14. ¿Qué herramientas de las TIC usas en la clase para contribuir al desarrollo del aprendizaje de tus estudiantes?

Las herramientas que suelo usar en mis clases para contribuir al desarrollo del aprendizaje de mis estudiantes es la hoja de cálculo Excel para desarrollar casos prácticos relacionados a los costos, estados financieros, entre otros; además el presentador de diapositivas Power Point para presentar la teoría de mis cursos en forma más rápida que tener que escribirlo en la pizarra y que mis alumnos estén escribiendo en sus cuadernos, además como exige la institución educativa colgar dichas diapositivas en la plataforma de la universidad.

15. ¿Qué métodos o estrategias de enseñanza aplicas en la clase para contribuir al desarrollo del aprendizaje de tus estudiantes?

Los métodos o estrategias que aplico en mis clases son las expositivas para enseñar la teoría y los procedimientos prácticos de los casos contables. Otra técnica muy utilizada es la práctica dirigida en forma grupal donde los estudiantes emplean la educación entre pares además de ser apoyados por mi persona. Otra técnica que empleo con gran frecuencia en las expositivas para de esa forma desarrollar en mis estudiantes esta habilidad que es muy carente entre ellos. Otro método es la tarea grupal para ser presentada en la siguiente semana o [...]ellos exigen objetivos a corto

plazo como el aprendizaje de cada tema [...]los objetivos a mediano plazo se encuentran determinados por las unidades en que se divide el curso. Para finalizar con los objetivos a largo plazo que muestran que todos esos temas deben ser de dominio de un gerente y que como contadores de un microempresario

Bueno conozco como indique anteriormente el procesador de textos Word, la hoja de cálculo Excel y el presentador de diapositivas Power Point

Las herramientas que suelo usar en mis clases para contribuir al desarrollo del aprendizaje de mis estudiantes es la hoja de cálculo Excel para desarrollar casos prácticos relacionados a los costos, estados financieros, entre otros además el presentador de diapositivas Power Point para presentar la teoría de mis cursos Los métodos o estrategias que aplico en mis clases son las expositivas[...]Otra técnica muy utilizada es la práctica

dirigida[...]Otro método es la tarea grupa
Conocimiento y uso de 
semanas posteriores para que desarrollen las habilidades de trabajo en

equipo, coordinación, liderazgo, respeto por las opiniones de los demás, entre otras.

16. ¿Qué condiciones es necesario crear para la aplicación de estrategias TIC? Explique

Es necesario utilizar las destrezas en habilidades tecnológicas que tienen nuestros estudiantes para potenciar las exposiciones del trabajo final de varias semanas, donde demostraran el manejo que tienen de las TIC, en definitiva, para los docentes deben ser las capacitaciones en las TIC,

pero es necesario considerar los diversos horarios de los docentes a

tiempo parcial, en ese sentido, las capacitaciones deberían ser en su

mayor número virtuales en lugar de presenciales.

17. ¿Observa que el uso estrategias de gestión TIC transforma e desempeño del docente? Explique

Es muy cierto, antes de emplear el Word, Excel y Power Point no

entendía para que servían hasta el momento que tenía la necesidad por

mi carrera de contador a emplear el Excel y reconocí la gran utilidad para mis cálculos contables que potenciaron tremendamente mi laboral

contable. Los otros como el Word y Power Point se revistieron de gran

importancia y necesidad cuando estudie mi maestría porque me ayudo

18. ¿Observa que el uso estrategias de gestión TIC provoca cambios en la ¿Observa que el uso estrategias de

En definitiva, estoy totalmente seguro de que las TIC provocará y está provocando grandes cambios en el proceso enseñanza-aprendizaje como en su momento estos los aplicativos Word, Excel y Power Point cambiaron tremendamente nuestra forma de estudiar, aprender e incluso de trabajar. En ese sentido, es muy importante manejar las TIC para potenciar el proceso enseñanza-aprendizaje en favor de nuestros estudiantes que se verán beneficiado su aprendizaje en los nuevos conceptos de la carrera elegida para luego ponerlos en práctica en su trabajo.

Es necesario utilizar las destrezas en habilidades tecnológicas que tienen nuestros estudiantes para potenciar las exposiciones del trabajo final [...]las capacitaciones deberían ser en su mayor número virtuales en lugar de presenciales.

Es muy cierto, antes de emplear e Word, Excel y Power Point no

entendía para que servían hasta el momento que tenía la necesidad por mi carrera de contador a emplear e Excel y reconocí la gran utilidad para mis cálculos contables que

potenciaron tremendamente mi

laboral contable.

es muy importante manejar las TIC para potenciar el proceso

enseñanza-aprendizaje en favor de nuestros estudiantes que se verán beneficiado su aprendizaje en los nuevos conceptos de la carrera elegida para luego ponerlos en práctica en su trabajo.
Entornos TIC facilitadoras de as habilidades de los estudiantes

Conocimiento y uso de

la enseñanzas aprendizaje

Entornos TIC facilitadoras de las habilidades de los estudiantes 


\begin{tabular}{|c|c|c|c|c|}
\hline 2.Edgardo & $\begin{array}{l}\text { Las Pregunta y las Respuestas } \\
\text { HABILIDADES INFORMATICAS }\end{array}$ & Frases codificadas & Categorías y subcategorías & Cód. \\
\hline 1. & $\begin{array}{l}\text { ¿Cómo podría definir las TIC y qué importancia le confiere? ¿Qué } \\
\text { términos se le vienen a la mente para describirla? } \\
\text { Tengo entendido que las TIC's son las Tecnologías en Información y } \\
\text { Comunicación y pienso que son muy importantes en el proceso de } \\
\text { enseñanza aprendizaje, pues facilitan el intercambio de información y } \\
\text { el acceso a una mayor posibilidad de encontrar herramientas que } \\
\text { permitan lograr y alcanzar aprendizajes significativos dentro de la } \\
\text { educación en todos sus niveles, tales como la educación primaria, } \\
\text { secundaria y superior universitaria y no universitaria. }\end{array}$ & $\begin{array}{l}\text { facilitan el intercambio de } \\
\text { información y el acceso a una } \\
\text { mayor posibilidad de encontrar } \\
\text { herramientas que permitan lograr y } \\
\text { alcanzar aprendizajes significativos } \\
\text { dentro de la educación en todos sus } \\
\text { niveles }\end{array}$ & $\begin{array}{l}\text { Acceso a la información para } \\
\text { alcanzar aprendizajes } \\
\text { significativos }\end{array}$ & 19 \\
\hline 2. & $\begin{array}{l}\text { ¿Cómo usted define las habilidades informáticas? ¿Es necesario } \\
\text { saber redactar para dominar esta habilidad? ¿Por qué? } \\
\text { Entiendo que las habilidades informáticas se refieren a la } \\
\text { capacidad que tienen determinadas personas para manejar y } \\
\text { gestionar herramientas tecnológicas para diversos fines, como } \\
\text { por ejemplo en la educación dentro del proceso de enseñanza } \\
\text { aprendizaje. } \\
\text { Por otro lado, pienso que el saber redactar no necesariamente } \\
\text { asegura o garantiza que las personas puedan dominar éstas } \\
\text { habilidades informáticas, puesto que no necesariamente una } \\
\text { cosa tiene que ver con la otra. }\end{array}$ & $\begin{array}{l}\text { Entiendo que las habilidades } \\
\text { informáticas se refieren a la } \\
\text { capacidad que tienen determinadas } \\
\text { personas para manejar y gestionar } \\
\text { herramientas tecnológicas para } \\
\text { diversos fines }\end{array}$ & $\begin{array}{l}\text { Capacidad para manejar y } \\
\text { gestionar herramientas } \\
\text { tecnológicas }\end{array}$ & 20 \\
\hline 3. & $\begin{array}{l}\text { ¿Ha recibido capacitación metodológica para lograr el desarrollo de } \\
\text { las habilidades informáticas y su uso en la clase? ¿Cree que } \\
\text { mejoraría sus recursos expositivos en clase? } \\
\text { En mi caso particular, he recibido capacitación relacionada con } \\
\text { herramientas de enseñanza aprendizaje y metodologías } \\
\text { pedagógicas y andragógicas, pero no necesariamente } \\
\text { relacionadas con el desarrollo de habilidades informáticas. } \\
\text { Así mismo, pienso que una capacitación adecuada en el } \\
\text { desarrollo de éstas habilidades informáticas sí mejoraría mis } \\
\text { recursos expositivos en clase. }\end{array}$ & $\begin{array}{l}\text { Así mismo, pienso que una } \\
\text { capacitación adecuada en el } \\
\text { desarrollo de éstas habilidades } \\
\text { informáticas sí mejoraría mis } \\
\text { recursos expositivos en clase }\end{array}$ & $\begin{array}{l}\text { Las TIC como recurso } \\
\text { expositivo }\end{array}$ & 21 \\
\hline 4. & $\begin{array}{l}\text { ¿Considera usted que domina o tiene habilidades en el uso de las } \\
\text { TIC? ¿Estas habilidades facilitan la explicación de la ciencia? }\end{array}$ & $\begin{array}{l}\text { considero que al dominar éstas } \\
\text { habilidades, esto facilitaría el }\end{array}$ & $\begin{array}{l}\text { Motivación y actitud positiva } \\
\text { para el aprendizaje }\end{array}$ & 22 \\
\hline
\end{tabular}


Considero que aún no domino las habilidades necesarias que se requieren para el uso de las TIC's y particularmente pienso que tener estas habilidades si facilitarían el desarrollo y la explicación de las clases y de la ciencia.

Por otro lado, considero que, al dominar éstas habilidades, esto facilitaría el proceso de enseñanza-aprendizaje dentro del aula, lo que motivaría y despertaría el interés de los estudiantes para aprender y para aplicar los conocimientos recibidos.

¿Considera que las TIC le ayudan a diseñar las actividades de enseñanza y de aprendizaje en su asignatura?

Sí considero que las TIC me ayudarían a diseñar las actividades de enseñanza y de aprendizaje en mis asignaturas y esto me permitiría fomentar y despertar el interés de mis estudiantes en e proceso de enseñanza y aprendizaje de todas mis asignaturas.

¿Cree que las TIC fortalecen su capacidad profesional y su actitud en el uso del conocimiento sobre distintos temas y explicarlos con rigor? Explique

Pienso que el dominar las TIC's le daría un valor agregado a mi capacidad profesional, y por consiguiente, mejoraría mi actitud en el uso del conocimiento sobre distintos temas, lo que me permitiría una mayor solidez para explicar todos los temas con rigor.

¿Cómo es la participación de sus estudiantes en la clase cuando usa las TIC?

Si usara con frecuencia las TIC's, pienso que la participación de mis estudiantes en las clases sería mucho más activa y

despertaría el interés y la motivación por aprender más y en

mejores condiciones, pues las tecnologías de información y comunicación permiten realizar clases más dinámicas con la activa participación de todos los estudiantes. proceso de enseñanza-aprendizaje

dentro del aula, lo que motivaría y

despertaría el interés de los

estudiantes para aprender y para

aplicar los conocimientos recibidos

permitiría fomentar y despertar el nterés de mis estudiantes en el

proceso de enseñanza y

aprendizaje de todas mis

asignaturas

las TIC's mejoraría mi actitud en el uso del conocimiento sobre

distintos temas, lo que me permitiría

una mayor solidez para explicar

todos los temas con rigor

las TIC's, [...] clases sería mucho más activa y despertaría el interés y la motivación [...] permiten realizar clases más dinámicas con la activa participación de todos los

estudiantes.
Las TIC como facilitadores de la enseñanza aprendizaje

Motivación y actitud positiva para el aprendizaje

Motivación y actitud positiva
Motivación y actitud
para el aprendizaje 
8.

¿Cómo se siente cuando intercambia conocimientos, opiniones, creencias y puntos de vistas con otras personas a través de alguna TIC?

Pienso que me sentiría bastante bien y satisfecho pues el uso de las TIC's permite el intercambio de todo tipo de información, en todos los niveles, en todas las áreas y en todos los estratos socioeconómicos.

¿Cómo hace para desarrollar los conocimientos y comportamientos positivos en sus estudiantes al usar las TIC?

Pienso que al usar las TIC's podría fomentar el desarrollo de los conocimientos y comportamientos positivos en mis estudiantes, pues está comprobado que el uso de las TIC's potencia el

proceso de enseñanza-aprendizaje y el desarrollo de habilidades informáticas en los estudiantes.

19.

\section{ESTRATEGIAS DE GESTIÓN}

¿Qué actividades realizas en el aula para conocer las fortalezas y debilidades de los estudiantes?

Sinceramente, con las justas me alcanza el tiempo para desarrollar los temas de mis clases, por lo que me sería

imposible poder realizar actividades que me permitan conocer las fortalezas y debilidades de cada uno de mis estudiantes.

20.

¿Logra caracterizar la realidad educativa de sus estudiantes? Describa sus hallazgos

Sinceramente no entiendo esta pregunta, no sé qué significa "caracterizar la realidad educativa" de los estudiantes, por lo que no estoy en condiciones de responder esta pregunta.

21

¿En su planificación pedagógica, formula objetivos a corto, mediano y largo plazo? Explica cómo.

La planificación pedagógica para formular objetivos a corto, mediano y largo plazo la realizan los responsables de desarrollar las TIC's permiten el intercambio de

todo tipo de información, en todos

los niveles

el uso de las TIC's potencia el proceso de enseñanza-aprendizaje

y el desarrollo de habilidades

informáticas

me sería imposible poder realizar actividades que me permitan

conocer las fortalezas y debilidades

de cada uno de mis estudiantes

no sé qué significa

"caracterizar la realidad

educativa" de los estudiantes,

por lo que no estoy en

condiciones de responder esta

pregunta.

objetivos a corto, mediano y largo plazo la realizan los responsables de desarrollar los sílabos y las mallas

curriculares
Facilita la comunicación y la

retroalimentación

la enseñanza aprendizaje

Caracterización de la realidad académica

\section{Caracterización dela realidad}

académica

\section{Niveles de planificación}

pedagógica 
los sílabos y las mallas curriculares de cada una de las materias

que se desarrollan en las diversas carreras que se imparten en la

universidad, por lo que no soy la persona indicada para

responder esta pregunta.

22.

¿Conoce los principios y enfoques teóricos sobre el uso de las TIC en la enseñanza- aprendizaje? Describa la que conoce.

Sinceramente, no conozco ninguno de los principios y enfoques teóricos sobre el uso de las TIC's en el proceso de enseñanzaaprendizaje, por lo que no estoy en condiciones de responder esta pregunta.

23.

¿Qué herramientas de las TIC usas en la clase para contribuir a desarrollo del aprendizaje de tus estudiantes?

Con cierta frecuencia, utilizo Microsoft Excel para desarrollar los casos prácticos en los diversos cursos que tengo a mi cargo,

pero no me queda claro si el Excel puede ser considerado como una herramienta de las TIC's, pero pienso que sí contribuye al desarrollo del aprendizaje de mis estudiantes.

24.

¿Qué métodos o estrategias de enseñanza aplicas en la clase para contribuir al desarrollo del aprendizaje de tus estudiantes?

Con mucha frecuencia aplico el Método de Casos y el de Resolución de Problemas para contribuir al desarrollo del aprendizaje de mis estudiantes.

25.

¿Qué condiciones es necesario crear para la aplicación de estrategias TIC? Explique

Pienso que lo primero que se tiene que tener en cuenta para la aplicación de estrategias TIC, es si se cuenta con toda la

infraestructura necesaria para su aplicación y desarrollo, aparte

de una capacitación metodológica adecuada que permita contar no conozco ninguno de los principios y enfoques teóricos sobre el uso de

as TIC's en el proceso de

enseñanza-aprendizaje

\section{utilizo Microsoft Excel para}

desarrollar los casos prácticos en

los diversos cursos que tengo a mi

cargo [...]pienso que sí contribuye

al desarrollo del aprendizaje de mis estudiantes

aplico el Método de Casos y el de Resolución de Problemas para contribuir al desarrollo de

aprendizaje de mis estudiantes

infraestructura necesaria para su aplicación y desarrollo, aparte de una capacitación metodológica

adecuada que permita contar con las habilidades informáticas

necesarias para poder aplicar dichas estrategias
Conocimiento y uso de herramientas informáticas para

la enseñanzas aprendizaje

Conocimiento y uso de

la enseñanzas aprendizaje

Métodos de enseñanzaaprendizaje 
¿Observa que el uso estrategias de gestión TIC transforma el desempeño del docente? Explique

Pienso que el uso de estrategias de gestión en TIC's si transforma el desempeño del docente, puesto que está

comprobado que estas estrategias y herramientas facilitan el

proceso de enseñanza-aprendizaje dentro del aula.

27.

¿Observa que el uso estrategias de gestión TIC provoca cambios en la enseñanza- aprendizaje? Explique

Tal como se menciona en la respuesta a la pregunta que antecede, pienso que el uso de estrategias de gestión en TIC's si transforma el desempeño del docente, puesto que está

comprobado que estas estrategias y herramientas facilitan el proceso de enseñanza-aprendizaje dentro del aula. está comprobado que estas estrategias y herramientas facilitan el proceso de enseñanza-

aprendizaje dentro del aula
Conocimiento y uso de herramientas informáticas para la enseñanzas aprendizaje en TIC's si transforma el desempeño del docente, puesto que está

comprobado que estas estrategias y

herramientas facilitan el proceso de

enseñanza-aprendizaje dentro del

aula.
Estrategias de gestión de la TIC facilitadoras del aprendizaje

\begin{tabular}{|c|c|c|c|c|}
\hline Pedro & $\begin{array}{l}\text { Las Pregunta y las Respuestas } \\
\text { HABILIDADES INFORMATICAS }\end{array}$ & Frases codificadas & Categorías y subcategorías & Cód. \\
\hline 1. & $\begin{array}{l}\text { ¿Cómo podría definir las TIC y qué importancia le confiere? ¿Qué } \\
\text { términos se le vienen a la mente para describirla? } \\
\text { EL concepto de las TIC creo que es el uso de las tecnologías como } \\
\text { herramientas adicionales en el desarrollo de una clase, el termino que } \\
\text { me viene a la mente es tecnología, somos conscientes del avance de la } \\
\text { tecnología en todos los ámbitos profesionales, en la educación también } \\
\text { existe, el problema es que no estamos actualizados, existe una gran } \\
\text { diferencia en el uso de estrategias de enseñanza, porque falta capación } \\
\text { en los docentes. }\end{array}$ & $\begin{array}{l}\text { TIC creo que es el uso de las } \\
\text { tecnologías [...] el problema es que } \\
\text { no estamos actualizados, existe una } \\
\text { gran diferencia en el uso de } \\
\text { estrategias de enseñanza, porque } \\
\text { falta capación en los docentes. }\end{array}$ & $\begin{array}{l}\text { Las TIC como facilitadores de la } \\
\text { enseñanza aprendizaje }\end{array}$ & 37 \\
\hline 2. & $\begin{array}{l}\text { ¿Cómo usted define las habilidades informáticas? ¿Es necesario } \\
\text { saber redactar para dominar esta habilidad? ¿Por qué? }\end{array}$ & $\begin{array}{l}\text { Habilidad informática es la destreza } \\
\text { que tiene un usuario para usar los } \\
\text { programas informáticos en la } \\
\text { computadora, de acuerdo con sus } \\
\text { necesidades }\end{array}$ & Dominio de la informática & 38 \\
\hline
\end{tabular}


Habilidad informática es la destreza que tiene un usuario para usar los programas informáticos en la computadora, de acuerdo con sus necesidades.

La redacción en la actualidad es más fácil, porque el Word tiene un corrector ortográfico, el problema es cuando queremos enlazar oraciones, si no se tiene facilidad de palabra se nos complica, nos lleva un tiempo adicional, esto se evidencia cuando queremos hacer un manual de algún curso, muchos nos limitamos a copiar y pegar. las habilidades informáticas y su uso en la clase? ¿Cree que mejoraría sus recursos expositivos en clase?

Las capacitaciones no, la dificultad es el horario y la universidad no quiere invertir, otros casos es que los docentes trabajos por hora, se complica para darnos un tiempo y podernos capacitar, solo algunas veces lo hago por medio del internet, en algunos casos me ha permitido ampliar el conocimiento de un curso. Los días ideales para una capacitación seria los fines de semana de esta manera podríamos participar y estar actualizados.

¿Considera usted que domina o tiene habilidades en el uso de las TIC? ¿Estas habilidades facilitan la explicación de la ciencia?

No considero que dominio las Tic, tengo conocimientos básicos, solo uso internet para buscar información de los temas a desarrollar y el Power Point como una ayuda visual, con textos e imágenes.

Estas habilidades para usarla y aplicarla correctamente se de actualizar con las nuevas tecnologías, orientadas a mejorar la educación en la actualidad, para aprovechar sus ventajas que ofrece en la actualidad.

¿Considera que las TIC le ayudan a diseñar las actividades de enseñanza y de aprendizaje en su asignatura?

Si considero que me ayudarían, por el momento no lo utilizo por no dominar los TICs, además de no tener el tiempo necesario para
Las capacitaciones no, la dificultad es el horario y la universidad no quiere invertir, otros casos es que los docentes trabajos por hora, se complica para darnos un tiempo y podernos capacitar

No considero que dominio las Tic, tengo conocimientos básicos, solo uso internet para buscar

información

no lo utilizo por no dominar los

TICs, además de no tener el tiempo

Dominio de la informática
Capacidad para manejar y gestionar herramientas tecnológicas

Acceso a la información para alcanzar aprendizajes significativos 
preparar mis clases, además de incluir los tics en proceso de enseñanza debemos dominar las TICs para sentirnor seguros, esto motivara a diseñar nuestras actividades incluyendo las TICs de acuerdo al tema, contexto, objetivo de la clase, basado en el estudiante.

¿Cree que las TIC fortalecen su capacidad profesional y su actitud en el uso del conocimiento sobre distintos temas y explicarlos con rigor? Explique

Las TICs si fortalecerían mi capacidad profesional, el docente cuanto más metodologías y estrategias usa en el desarrollo de sus clases es mejor.

Por comentario de algunos colegas las TICs son flexibles, se adapta a las diferentes asignaturas, sirve como material de apoyo en el desarrollo de la clase. Además, por la facilidad en la actualidad para acceder a la tecnología.

¿Cómo es la participación de sus estudiantes en la clase cuando usa las TIC?

No he usado

¿Cómo se siente cuando intercambia conocimientos, opiniones, creencias y puntos de vistas con otras personas a través de alguna TIC?

No he tenido la oportunidad

9

¿Cómo hace para desarrollar los conocimientos y

comportamientos positivos en sus estudiantes al usar las TIC? dominar las TICs para sentirnor

seguros

las TICs son flexibles, se adapta a las diferentes asignaturas, sirve como material de apoyo en el

desarrollo de la clase
Las TIC como facilitadores de

la enseñanza aprendizaje

No he podido evidenciar

\section{ESTRATEGIAS DE GESTIÓN}

1.

¿Qué actividades realizas en debilidades de los estudiantes? 
- Al inicio de cada clase, por medio de preguntas, me permite obtener los conocimientos previos de los estudiantes, po medio de lluvias de ideas o preguntas. Me permite conocer cuánto saben del tema y su habilidad para transmitirla.

- Participación de los estudiantes durante el desarrollo de las clases, por medio de preguntas para evidenciar el aprendizaje, para que ellos participen en su aprendizaje.

- Al final de las clases el reforzamiento del tema tratado, con la participación de ellos.

- En estos tres momentos podemos conocer las fortalezas y debilidades de nuestros estudiantes.

¿Logra caracterizar la realidad educativa de sus estudiantes? Describa sus hallazgos

- Cada estudiante es único, que con formaciones educaciones distintas y educación particular en sus hogares, cuando están en aula de clases tenemos un grupo heterogéneo, con grandes capacidades, muchos de ellos no lo ponen en práctica, por falta de confianza y motivación.

Algunos estudiantes manejan bien la motivación intrínseca

- A otros estuantes se les tienen que ser motivados para el aprendizaje, es muy importante en ellos enfatizar el objetivo de la clase.

¿En su planificación pedagógica, formula objetivos a corto, mediano y largo plazo? Explica cómo.

Corto: Con una buena planificación de clases usando estrategias y metodologías se lograr el objetivo de la clase

Mediano: Son los objetivos de las unidades y del curso al desarrollar las actividades en orden coherente con estrategias y metodologías logramos lo planificado.

Largo: Ser parte de la formación del estudiante de la carrera que

está orientado al perfil del estudiante.

Participación de los estudiantes

durante el desarrollo de las clases,

por medio de preguntas

Cada estudiante es único, que con formaciones educaciones distintas y educación particular en sus

hogares, cuando están en aula de

clases tenemos un grupo

heterogéneo

usando estrategias y metodologías se logra el objetivo de la clase

Mediano: Son los objetivos de las

unidades y del curso al desarrollar

las actividades en orden coherente

Largo: Ser parte de la formación del

estudiante de la carrera que está

orientado al perfil del estudiante
Caracterización dela realidad académica

Niveles de planificación 
¿Qué herramientas de las TIC usas en la clase para contribuir al desarrollo del aprendizaje de tus estudiantes?

El Power Point, con imágenes y texto de la clase, además me sirve para la secuencia de los temas actividades del curso que estoy desarrollando, además les sirve a los estudiantes como material de apoyo para reforzar su aprendizaje, algunas veces utilizo el Word para hacer pequeñas guías de los temas un poco complicado, con imágenes o procesos de actividades, por ejemplo, el desarrollo de una planilla.

6.

¿Qué métodos o estrategias de enseñanza aplicas en la clase para contribuir al desarrollo del aprendizaje de tus estudiantes?

Utilizo las estrategias de expositivas para temas teóricos, experiencia figurada y demostración sobre actividades que realizaran a futuro, por ejemplo, la elaboración de una Planilla de Sueldos y salarios, teniendo en cuenta los beneficios de acuerdo a ley que les corresponde a los trabajadores en las empresas. La metodología interrogativa, participativa y activa durante las clases, donde el estudiante es participe de su aprendizaje.

7. ¿Qué condiciones es necesario crear para la aplicación de estrategias TIC? Explique

Conocer las TICs y dominar el su uso para un correcto uso además de poder aprovechar su flexibilidad de adaptación para cualquier curso y tema.
El Power Point, con imágenes y texto de la clase, además me sirve para la secuencia de los temas actividades del curso que estoy desarrollando, además les sirve a los estudiantes como material de apoyo para reforzar su aprendizaje algunas veces utilizo el Word

Utilizo las estrategias de expositivas para temas teóricos, experiencia figurada y demostración sobre actividades que realizaran a futuro La metodología interrogativa, participativa y activa durante las clases, donde el estudiante es participe de su aprendizaje.

[condiciones] Conocer las TICs y dominar el su uso [...]dominar el tema a desarrollar [...] capacitación
Conocimiento y uso de herramientas informáticas para la enseñanzas aprendizaje

Métodos de enseñanzaaprendizaje 
También debe dominar el tema a desarrollar para poder aplicar

correctamente las TICs que se debe haber capacitado en su uso y

aplicación.

Sin capacitación es limitado su uso y los resultados no serán

óptimos además será trabajoso y tedioso para el docente la

planificación de la clase

8.

¿Observa que el uso estrategias de gestión TIC transforma el

desempeño del docente? Explique

No he aplicado

9. ¿ ¿Observa que el uso estrategias de gestión TIC provoca cambios en la enseñanza- aprendizaje? Explique

No he aplicado

\section{Guillermo Las Pregunta y las Respuestas}

\section{Frases codificadas}

\section{HABILIDADES INFORMATICAS}

1.

$$
\text { términos se le vienen a la mente para describirla? }
$$

La tecnología de la información resulta ser herramientas de informática moderna que en distintos medios empresariales sobre todo pedagógicos se usan cada vez con mayor énfasis. Resulta relevante para el docente que conozca y domine estas herramientas como una forma de transmitir conocimiento a los alumnos, así como de facilitar el trabajo docente y presentar estrategias modernas a los estudiantes de acuerdo a las exigencias del entorno.
Resulta relevante para el docente que conozca y domine estas herramientas como una forma de transmitir conocimiento a los alumnos así como de facilitar e trabajo docente y presentar estrategias modernas a los estudiantes de acuerdo a las exigencias del entorno

\section{Categorías y subcategorías}

Las TIC como facilitadores de la enseñanza aprendizaje 
de un determinado problema. La redacción se vuelve necesario según

el tipo de herramienta como es el caso de un procesador de

texto(Word), sin embargo, los procesadores de texto dentro de su

configuración tienen programas de corrección en la escritura.

21. ¿Ha recibido capacitación metodológica para lograr el desarrollo de las habilidades informáticas y su uso en la clase? ¿Cree que mejoraría sus recursos expositivos en clase?

No he recibido, y las veces que se han programado algunas no he podido asistir por temas de cruce de horarios. Es evidente que el desempeño docente mejoraría sustantivamente con el uso de las diversas TIC.

22. ¿Considera usted que domina o tiene habilidades en el uso de las TIC? ¿Estas habilidades facilitan la explicación de la ciencia?

No, el dominio de las Tic se logra con la práctica, pero

previamente se debe capacitar en el uso de las mismas. La

explicación de la ciencia depende del campo científico y de ello

depende el tipo de tecnología a usar.

23. ¿Considera que las TIC le ayudan a diseñar las actividades de enseñanza y de aprendizaje en su asignatura?

Definitivamente, las TICs propondrían rediseñar las actividades de enseñanza de los cursos. Así mismo estas se constituyen en

importantes estrategias pedagógicas que el docente tiene para

lograr un aprendizaje significativo y lograr las competencias en el

estudiante que se encuentran diseñadas en el silabo del curso. el desempeño docente mejoraría sustantivamente con el uso de las diversas TIC.

lominio de las TIC se logra con la práctica, pero previamente se debe capacitar en el uso de las mismas

Así mismo estas se constituyen en importantes estrategias pedagógicas que el docente tiene para lograr un aprendizaje significativo y lograr las competencias en el estudiante
Las TIC como recurso

expositivo 
6.

24. ¿Cree que las TIC fortalecen su capacidad profesional y su

actitud en el uso del conocimiento sobre distintos temas y

explicarlos con rigor? Explique

Completamente de acuerdo. Los docentes deben ir en

concordancia con el desarrollo tecnológico y el uso de TICs

resulta relevante para el docente porque le dota de mayor

argumento y fortaleza profesional. Con ello logra mejores

resultados en sus estudiantes a la par que las clases se hacen

más dinámicas.

25. ¿Cómo es la participación de sus estudiantes en la clase cuando usa las TIC?

En relación a ello, como no uso frecuentemente las TICs, no he podido constatar la participación dinámica de los estudiantes. Sin embargo, debo manifestar que en el caso de uso de las TICs en un aula de clase los alumnos participarían activamente. Sobre

todo, mostrarían mucho interés en aplicar las TICs en la solución

de los casos planteados.

8.

26. ¿Cómo se siente cuando intercambia conocimientos, opiniones, creencias y puntos de vistas con otras personas a través de alguna TIC?

Considerando que se intercambia opiniones entre un docente que no tiene buen nivel de conocimiento de las TICs con otro docente que, si tiene buen dominio de las TICs, resultaría frustrante para el docente sin conocimiento de estas TICs. Pero también motivaría a capacitarse y ajustarse a las exigencias pedagógicas actuales.
Los docentes deben ir en

concordancia con el desarrollo

tecnológico y el uso de TICs resulta

relevante para el docente porque le

dota de mayor argumento y

fortaleza profesional

debo manifestar que en el caso de uso de las TICs en un aula de clase los alumnos participarían

activamente. Sobre todo mostrarían mucho interés

Considerando que se intercambia opiniones entre un docente que no tiene buen nivel de conocimiento de las TICs con otro docente que si tiene buen dominio de las TICs, resultaría frustrante para el docente sin conocimiento de estas TICs

Primero se debe capacitar al docente en el uso de las TIC, Hecho ello, el docente debe ajustar su material pedagógico (teórico y práctico) para que el estudiante pueda participar activamente
Capacidad para manejar $y$

gestionar herramientas

tecnológicas 
planteados. Como las hojas de cálculo, Los procesadores de textos, administradores de base de datos, Páginas WEB, etc.

\section{ESTRATEGIAS DE GESTIÓN}

10. 28. ¿Qué actividades realizas en el aula para conocer las fortalezas y debilidades de los estudiantes?

- Lluvia de ideas

Listas de cotejo

Desarrollo de casos

- Estrategias de preguntas y respuestas

11.

29. ¿Logra caracterizar la realidad educativa de sus estudiantes? Describa sus hallazgos

Los alumnos presentas las siguientes características:

- Alumnos con poca motivación

- $\quad$ Alumnos Con poca disposición horaria para sus estudios

Alumnos Con responsabilidad familiar

- Alumnos con poco conocimiento de las TICs.

12.

30. ¿En su planificación pedagógica, formula objetivos a corto, mediano y largo plazo? Explica cómo.

Los Objetivos que el docente se patea en el aula debe ir en concordancia con el perfil profesional planteado por la

universidad. Pero cada sesión de clase busca un logro en el estudiante y ello corresponde a las capacidades que se debe lograr en el estudiante para que pueda insertarse en el mundo laborar y ser competente.

13.

31. ¿Conoce los principios y enfoques teóricos sobre el uso de las TIC en la enseñanza- aprendizaje? Describa la que conoce. No los conozco. mediante el uso de estas nuevas tecnologías en la solución de los problemas planteados

Lluvia de ideas

Listas de cotejo

Desarrollo de casos

Estrategias de preguntas y

respuestas

Los alumnos presentas las siguientes características:

Alumnos con poca motivación

Alumnos Con poca disposición

horaria para sus estudios

Alumnos Con responsabilidad

familiar

Alumnos con poco conocimiento de

las TICs.

Los Objetivos que el docente se patea en el aula debe ir en concordancia con el perfil

profesional planteado por la

universidad. Pero cada sesión de

clase busca un logro en el

estudiante
Métodos de enseñanza-

aprendizaje

Caracterización dela realidad académica

Niveles de planificación pedagógica 
14. 32. ¿Qué herramientas de las TIC usas en la clase para contribuir al desarrollo del aprendizaje de tus estudiantes?

Por desconocimiento no uso las TICs, sin embargo, espero

capacitación continua para lograr este conocimiento y lo traslade

a los estudiantes.

15.

33. ¿Qué métodos o estrategias de enseñanza aplicas en la clase para contribuir al desarrollo del aprendizaje de tus estudiantes? Estudio de casos,

Realidad problemática,

desarrollo de ejercicios,

Trabajos grupales

Exposiciones

16. 34. ¿Qué condiciones es necesario crear para la aplicación de estrategias TIC? Explique

Es necesario contar con aulas condicionadas tecnológicamente para ello: digamos computadora, proyector, conexión a internet. Implementación de laboratorios con tecnología moderna con instalación de computadoras individuales según el número de estudiantes. El laboratorio debe contar con conexión a internet y tener instalado programas de uso del docente según la exigencia del curso.

17. 35. ¿Observa que el uso estrategias de gestión TIC transforma el desempeño del docente? Explique

Considero que el uso de los TICs si debe generar un cambio significativo en el desempeño del docente. Primero le dota de nuevos conocimientos, segundo le dota de nuevas estrategias pedagógicas, tercero le facilita el trabajo en el aula y cuarto hace que se logren los objetivos en el aula y sea una clase más significativa.

18.

36. ¿Observa que el uso estrategias de gestión TIC provoca cambios en la enseñanza- aprendizaje? Explique

Considero que si generaría cambios significativos en el estudiante y en el docente por cuanto que el uso de las TICs facilita el espero capacitación continua para

lograr este conocimiento y lo

traslade a los estudiantes

Estudio de casos,

Realidad problemática,

desarrollo de ejercicios

Trabajos grupales

Exposiciones

Es necesario contar con aulas

condicionadas tecnológicamente

Considero que el uso de los TICs si debe generar un cambio

significativo en el desempeño del docente.

Considero que si generaría cambios significativos en el estudiante y en

Entornos TIC facilitadoras de

las habilidades de los

el docente por cuanto que el uso de

estudiantes
Conocimiento y uso de

herramientas informáticas para

la enseñanzas aprendizaje

Entornos TIC facilitadoras de

las habilidades de los

estudiantes

68

cimiento y uso de

herramientas informáticas para

la enseñanzas aprendizaje 


\begin{tabular}{|c|c|c|}
\hline & $\begin{array}{l}\text { trabajo docente en el aula a la vez que en el estudiante le } \\
\text { proporciona innumerable información que se encuentra en la } \\
\text { WEB. }\end{array}$ & $\begin{array}{l}\text { en el aula a la vez que en el } \\
\text { estudiante le proporciona } \\
\text { innumerable información que se } \\
\text { encuentra en la WEB. }\end{array}$ \\
\hline
\end{tabular}

\section{Anexo 4. Proceso de Comparación, relación y clasificación de las entrevistas}

\begin{tabular}{|c|c|c|c|c|c|c|}
\hline Entrevista D. 1 & Entrevista D. 2 & Entrevista D. 3 & Entrevista D. 4 & Categorías & $\begin{array}{l}\text { Conjunto de } \\
\text { códigos }\end{array}$ & Comentario \\
\hline \multicolumn{7}{|l|}{ HABILIDADES INFORMATICAS } \\
\hline \multirow[t]{2}{*}{$\begin{array}{l}\text { son el uso de las técnicas de la } \\
\text { informática para el uso de varias } \\
\text { actividades diarias como } \\
\text { estudiar, comunicarse, divertirse } \\
\text { entre otras. }\end{array}$} & $\begin{array}{l}\text { Entiendo que las habilidades } \\
\text { informáticas se refieren a la } \\
\text { capacidad que tienen } \\
\text { determinadas personas para } \\
\text { manejar y gestionar } \\
\text { herramientas tecnológicas } \\
\text { para diversos fines }\end{array}$ & $\begin{array}{l}\text { Las capacitaciones no, la } \\
\text { dificultad es el horario y } \\
\text { la universidad no quiere } \\
\text { invertir, otros casos es } \\
\text { que los docentes trabajos } \\
\text { por hora, se complica } \\
\text { para darnos un tiempo y } \\
\text { podernos capacitar, }\end{array}$ & $\begin{array}{l}\text { Los docentes deben ir } \\
\text { en concordancia con el } \\
\text { desarrollo tecnológico y } \\
\text { el uso de TICs resulta } \\
\text { relevante para el } \\
\text { docente porque le dota } \\
\text { de mayor argumento y } \\
\text { fortaleza profesional }\end{array}$ & $\begin{array}{l}\text { Capacidad para } \\
\text { manejar y } \\
\text { gestionar } \\
\text { herramientas } \\
\text { tecnológicas }\end{array}$ & $1,20,39,60,63$ & \\
\hline & & & $\begin{array}{l}\text { Primero se debe } \\
\text { capacitar al docente en } \\
\text { el uso de las TIC, } \\
\text { Hecho ello, el docente } \\
\text { debe ajustar su } \\
\text { material pedagógico } \\
\text { (teórico y práctico) para } \\
\text { que el estudiante } \\
\text { pueda participar } \\
\text { activamente mediante } \\
\text { el uso de estas nuevas } \\
\text { tecnologías en la } \\
\text { solución de los } \\
\text { problemas planteados }\end{array}$ & & & \\
\hline $\begin{array}{l}\text { las competencias que tienen las } \\
\text { personas más jóvenes para }\end{array}$ & & $\begin{array}{l}\text { Habilidad informática es } \\
\text { la destreza que tiene un }\end{array}$ & $\begin{array}{l}\text { no lo utilizo por no } \\
\text { dominar los TICs, }\end{array}$ & $\begin{array}{l}\text { Dominio de la } \\
\text { informática }\end{array}$ & $\begin{array}{l}2,38,41,56 \\
58,62\end{array}$ & \\
\hline
\end{tabular}




\begin{tabular}{|c|c|c|c|c|c|}
\hline $\begin{array}{l}\text { dominar y manejar las técnicas } \\
\text { de las tecnologías de la } \\
\text { información y la comunicación }\end{array}$ & & $\begin{array}{l}\text { usuario para usar los } \\
\text { programas informáticos } \\
\text { en la computadora, de } \\
\text { acuerdo con sus } \\
\text { necesidades }\end{array}$ & $\begin{array}{l}\text { además de no tener el } \\
\text { tiempo necesario para } \\
\text { preparar mis clases, } \\
\text { además de incluir los } \\
\text { tics en proceso de } \\
\text { enseñanza debemos } \\
\text { dominar las TICs para } \\
\text { sentirnos seguros }\end{array}$ & & \\
\hline & & & $\begin{array}{l}\text { En cuanto a la } \\
\text { informática, es la } \\
\text { capacidad o dominio } \\
\text { que el docente o } \\
\text { estudiante tiene para } \\
\text { aplicarlo en la solución } \\
\text { de un determinado } \\
\text { problema }\end{array}$ & & \\
\hline & & & $\begin{array}{l}\text { el dominio de las TIC } \\
\text { se logra con la práctica, } \\
\text { pero previamente se } \\
\text { debe capacitar en el } \\
\text { uso de las mismas }\end{array}$ & & \\
\hline & & & $\begin{array}{l}\text { Considerando que se } \\
\text { intercambia opiniones } \\
\text { entre un docente que } \\
\text { no tiene buen nivel de } \\
\text { conocimiento de las } \\
\text { TICs con otro docente } \\
\text { que, si tiene buen } \\
\text { dominio de las TICs, } \\
\text { resultaría frustrante } \\
\text { para el docente sin } \\
\text { conocimiento de estas } \\
\text { TICs }\end{array}$ & & \\
\hline $\begin{array}{l}\text { los recursos informáticos } \\
\text { mejorarían tremendamente las }\end{array}$ & $\begin{array}{l}\text { Así mismo, pienso que una } \\
\text { capacitación adecuada en el } \\
\text { desarrollo de éstas } \\
\text { habilidades informáticas sí }\end{array}$ & & $\begin{array}{l}\text { El desempeño docente } \\
\text { mejoraría } \\
\text { sustantivamente con el }\end{array}$ & $\begin{array}{l}\text { Las TIC como } \\
\text { recurso expositivo }\end{array}$ & $\begin{array}{l}3,4,5,6,21 \\
57\end{array}$ \\
\hline
\end{tabular}




\begin{tabular}{|c|c|c|c|c|}
\hline $\begin{array}{l}\text { estrategias expositivas en } \\
\text { nuestras clases } \\
\text { estas habilidades son de gran } \\
\text { utilidad para explicar de mucha } \\
\text { mejor forma las ciencias porque } \\
\text { facilitan una serie de usos de } \\
\text { imágenes, videos y audio }\end{array}$ & $\begin{array}{l}\text { mejoraría mis recursos } \\
\text { expositivos en clase }\end{array}$ & $\begin{array}{l}\text { uso de las diversas } \\
\text { TIC. }\end{array}$ & & \\
\hline $\begin{array}{l}\text { Si considero que las TIC serían } \\
\text { de gran ayuda para diseñar } \\
\text { actividades de enseñanza- } \\
\text { aprendizaje porque potencian la } \\
\text { exposición de las clases al } \\
\text { ofrecer el uso de imágenes, } \\
\text { videos y audio. } \\
\text { serían de gran utilidad para } \\
\text { fortalecer nuestras capacidades } \\
\text { profesionales y ayudarnos a } \\
\text { explicar de una forma más } \\
\text { grafica los temas que } \\
\text { desarrollamos en las clases que } \\
\text { presentamos a nuestros } \\
\text { estudiantes a }\end{array}$ & & & & \\
\hline $\begin{array}{l}\text { observo a mis estudiantes más } \\
\text { interesados y absortos en } \\
\text { aquello que se les pueda } \\
\text { presentar en las diapositivas, } \\
\text { se puede observar a una clase } \\
\text { más conectada con los temas } \\
\text { de los expositores }\end{array}$ & $\begin{array}{l}\text { considero que, al dominar } \\
\text { éstas habilidades, esto } \\
\text { facilitaría el proceso de } \\
\text { enseñanza-aprendizaje } \\
\text { dentro del aula, lo que } \\
\text { motivaría y despertaría el } \\
\text { interés de los estudiantes } \\
\text { para aprender y para aplicar } \\
\text { los conocimientos recibidos } \\
\text { las TIC's mejoraría mi } \\
\text { actitud en el uso del } \\
\text { conocimiento sobre } \\
\text { distintos temas, lo que me } \\
\text { permitiría una mayor solidez } \\
\text { para explicar todos los } \\
\text { temas con rigor }\end{array}$ & $\begin{array}{l}\text { debo manifestar que } \\
\text { en el caso de uso de } \\
\text { las TICs en un aula de } \\
\text { clase los alumnos } \\
\text { participarían } \\
\text { activamente. Sobre } \\
\text { todo mostrarían } \\
\text { mucho interés }\end{array}$ & $\begin{array}{l}\text { Motivación y } \\
\text { actitud positiva } \\
\text { para el } \\
\text { aprendizaje }\end{array}$ & $\begin{array}{l}7,22,24,25 \\
61\end{array}$ \\
\hline
\end{tabular}


por este medio nos comunicaban cosas importantes en tiem

reciben los elogios de mi parte

las TIC's permiten el

intercambio de todo tipo de

información, en todos los

niveles

por los buenos trabajos
presentados, en estos

$\begin{array}{lll}\text { presentados, en estos } & \text { en } \\ \text { momentos se podría decir }\end{array}$

reciben retroalimentación

positiva de mi parte.

Facilita la

comunicación y la

retroalimentación

No considero que

dominio las Tic, tengo

conocimientos básicos,

solo uso internet para

buscar información permitan lograr y alcanzar aprendizajes significativos dentro de la educación en todos sus niveles

permitiría fomentar y

despertar el interés de mis

estudiantes en el proceso de

enseñanza y aprendizaje de

todas mis asignaturas el uso de las TIC's

potencia el proceso de

enseñanza-aprendizaje y

el desarrollo de

habilidades informáticas
TIC creo que es el uso de las tecnologías [...] el problema es que no estamos actualizados,

existe una gran

diferencia en el uso de estrategias de

enseñanza, porque

falta capación en los

docentes.

las TICs son flexibles,

se adapta a las

diferentes asignaturas, sirve como material de apoyo en el desarrollo

de la clase

Resulta relevante para

el docente que conozca y domine estas

herramientas como una

forma de transmiti

conocimiento a los
Acceso a la

información para

alcanzar

aprendizajes

significativos

Las TIC como

facilitadores de

enseñanza

aprendizaje

$23,27,37,42$

55,59 ,
19, 40,
$8,9,26$ 
alumnos, así como de

facilitar el trabajo

docente y presentar

estrategias modernas a

los estudiantes de

acuerdo a las

exigencias del entorno

Así mismo estas se

constituyen en

importantes estrategias

pedagógicas que el

docente tiene para

lograr un aprendizaje

significativo y lograr las

competencias en e

estudiante

\section{ESTRATEGIAS DE GESTION}

Las características de nuestros me sería imposible poder por medio de preguntas

estudiantes se muestran por su realizar actividades que me me permite obtener los

pobre manejo del idioma permitan conocer las

castellano, lo difícil que les fortalezas y debilidades de

resulta poder redactar incluso en cada uno de mis estudiantes

el procesador de palabras

Participación de los

desarrollo de las clases,

[..]manejo de las matemáticas

[...] nerviosismo para salir hablar

por medio de preguntas

Cada estudiante es único,

que con formaciones

educaciones distintas y

educación particular en

sus hogares, cuando

están en aula de clases

tenemos un grupo

heterogéneo

Los alumnos presentas

las siguientes

características:

Alumnos con poca

motivación

Caracterización $\quad 11,28,29,45$,

dela realidad $\quad 47,65$

47, 65 , 


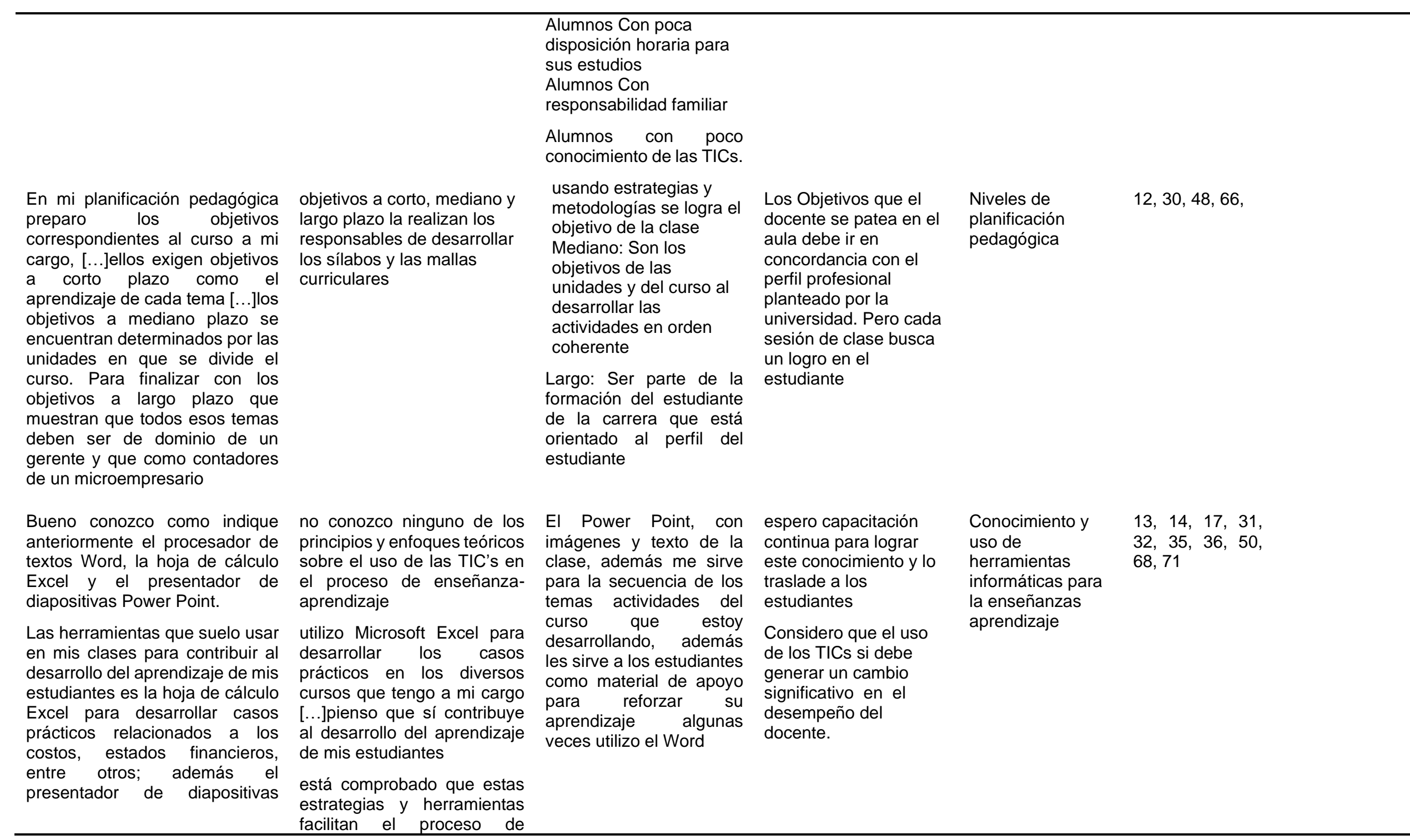




\begin{tabular}{|c|c|c|c|c|c|}
\hline $\begin{array}{l}\text { Power Point para presentar la } \\
\text { teoría de mis cursos. }\end{array}$ & $\begin{array}{l}\text { enseñanza-aprendizaje } \\
\text { dentro del aula }\end{array}$ & & & & \\
\hline $\begin{array}{l}\text { Es muy cierto, antes de emplear } \\
\text { el Word, Excel y Power Point no } \\
\text { entendía para que servían hasta } \\
\text { el momento que tenía la } \\
\text { necesidad por mi carrera de } \\
\text { contador a emplear el Excel y } \\
\text { reconocí la gran utilidad para mis } \\
\text { cálculos contables que } \\
\text { potenciaron tremendamente mi } \\
\text { laboral contable. }\end{array}$ & $\begin{array}{l}\text { en TIC's si transforma el } \\
\text { desempeño del docente, } \\
\text { puesto que está comprobado } \\
\text { que estas estrategias y } \\
\text { herramientas facilitan el } \\
\text { proceso de enseñanza- } \\
\text { aprendizaje dentro del aula. }\end{array}$ & & & & \\
\hline $\begin{array}{l}\text { se emplean las técnicas del } \\
\text { recojo de saberes previos en } \\
\text { esta etapa se puede observar las } \\
\text { fortalezas y debilidades de los } \\
\text { estudiantes }\end{array}$ & $\begin{array}{l}\text { aplico el Método de Casos y } \\
\text { el de Resolución de } \\
\text { Problemas para contribuir al } \\
\text { desarrollo del aprendizaje de } \\
\text { mis estudiantes }\end{array}$ & $\begin{array}{l}\text { Utilizo las estrategias de } \\
\text { expositivas para temas } \\
\text { teóricos, experiencia } \\
\text { figurada y demostración } \\
\text { sobre actividades que } \\
\text { realizaran a futuro }\end{array}$ & & $\begin{array}{l}\text { Métodos de } \\
\text { enseñanza- } \\
\text { aprendizaje }\end{array}$ & $\begin{array}{l}10,15,33,51 \\
64,69\end{array}$ \\
\hline $\begin{array}{l}\text { Los métodos o estrategias que } \\
\text { aplico en mis clases son las } \\
\text { expositivas[...]Otra técnica muy } \\
\text { utilizada es la práctica } \\
\text { dirigida[...]Otro método es la } \\
\text { tarea grupal }\end{array}$ & & $\begin{array}{l}\text { La metodología } \\
\text { interrogativa, } \\
\text { participativa y activa } \\
\text { durante las clases, } \\
\text { donde el estudiante es } \\
\text { participe de su } \\
\text { aprendizaje. } \\
\text { Lluvia de ideas, Listas de } \\
\text { cotejo, Desarrollo de } \\
\text { casos, Estrategias de } \\
\text { preguntas y respuestas } \\
\text { Estudio de casos, } \\
\text { Realidad problemática, } \\
\text { desarrollo de ejercicios, } \\
\text { Trabajos grupales } \\
\text { Exposiciones }\end{array}$ & & & \\
\hline $\begin{array}{l}\text { Es necesario utilizar las } \\
\text { destrezas en habilidades } \\
\text { tecnológicas que tienen nuestros }\end{array}$ & $\begin{array}{l}\text { infraestructura necesaria } \\
\text { para su aplicación y } \\
\text { desarrollo, aparte de una }\end{array}$ & $\begin{array}{l}\text { [condiciones] Conocer las } \\
\text { TICs y dominar el su uso } \\
\text { [...]dominar el tema a }\end{array}$ & $\begin{array}{l}\text { Es necesario contar } \\
\text { con aulas }\end{array}$ & $\begin{array}{l}\text { Entornos TIC } \\
\text { facilitadoras de }\end{array}$ & $\begin{array}{l}16,18,34,52 \\
72\end{array}$ \\
\hline
\end{tabular}




\begin{tabular}{|c|c|c|c|c|c|}
\hline $\begin{array}{l}\text { estudiantes para potenciar las } \\
\text { exposiciones del trabajo final } \\
\text { [...]las capacitaciones deberían } \\
\text { ser en su mayor número virtuales } \\
\text { en lugar de presenciales. } \\
\text { es muy importante manejar las } \\
\text { TIC para potenciar el proceso } \\
\text { enseñanza-aprendizaje en favor } \\
\text { de nuestros estudiantes que se } \\
\text { verán beneficiado su aprendizaje } \\
\text { en los nuevos conceptos de la } \\
\text { carrera elegida para luego } \\
\text { ponerlos en práctica en su } \\
\text { trabajo }\end{array}$ & $\begin{array}{l}\text { capacitación metodológica } \\
\text { adecuada que permita contar } \\
\text { con las habilidades } \\
\text { informáticas necesarias para } \\
\text { poder aplicar dichas } \\
\text { estrategias }\end{array}$ & $\begin{array}{l}\text { desarrollar } \\
\text { capacitación }\end{array}$ & {$[\ldots]$} & $\begin{array}{l}\text { condicionadas } \\
\text { tecnológicamente } \\
\text { Considero que si } \\
\text { generaría cambios } \\
\text { significativos en el } \\
\text { estudiante y en el } \\
\text { docente por cuanto } \\
\text { que el uso de las TICs } \\
\text { facilita el trabajo } \\
\text { docente en el aula a la } \\
\text { vez que en el } \\
\text { estudiante le } \\
\text { proporciona } \\
\text { innumerable } \\
\text { información que se } \\
\text { encuentra en la WEB. }\end{array}$ & $\begin{array}{l}\text { las habilidades de } \\
\text { los estudiantes }\end{array}$ \\
\hline
\end{tabular}




\section{Anexo 7. Ficha de validación de la propuesta metodológica}

\section{Datos generales.}

1.1. Apellidos y nombres del especialista

1.2. Grado de estudios alcanzado

1.3. Resultado científico en valoración:

1.4. Autor del resultado científico:

II. Aspectos a observar

VALIDACIÓN INTERNA

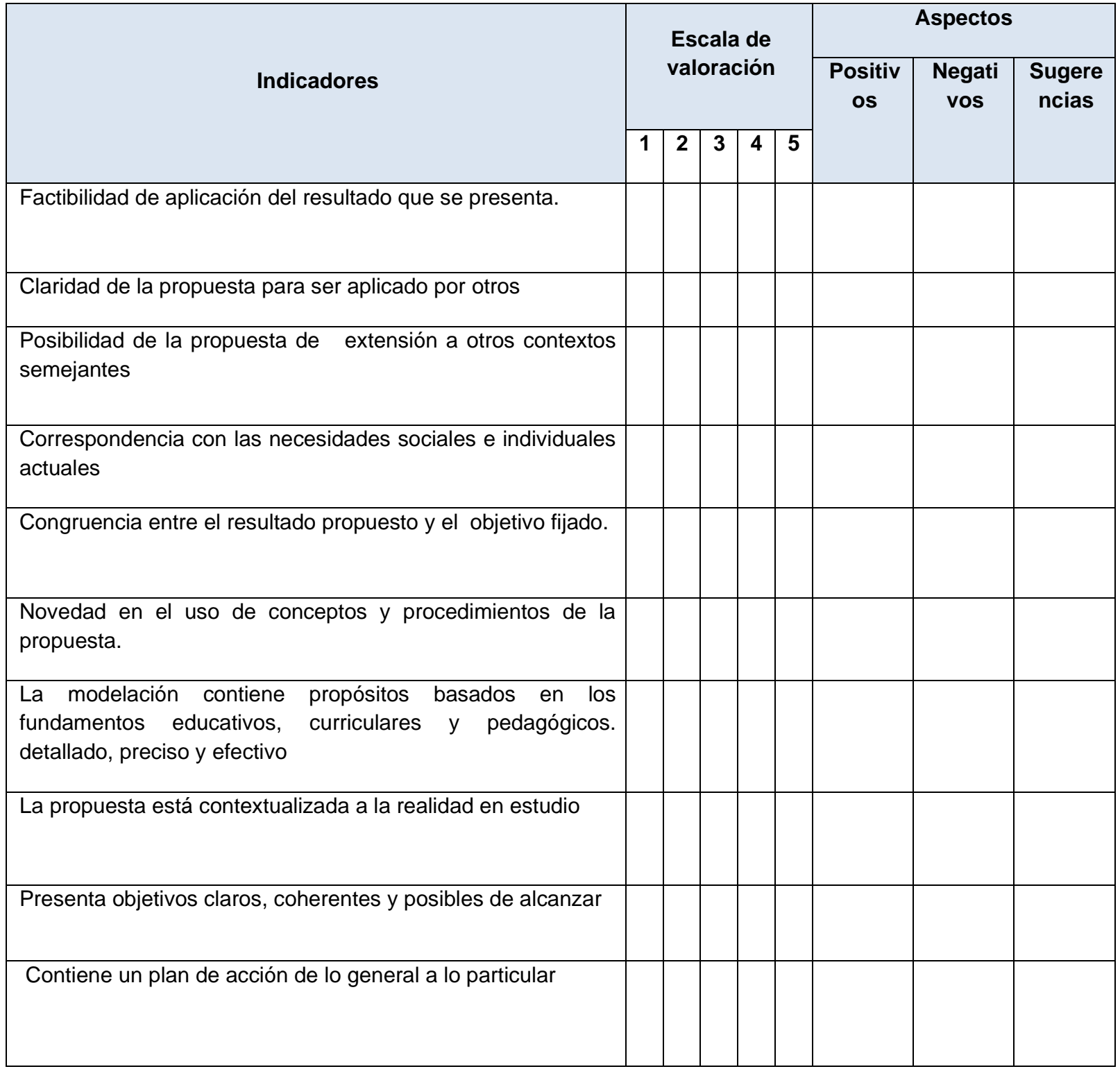


FICHA DE VALIDACIÓN EXTERNA (FORMA)

\begin{tabular}{|c|c|c|c|c|c|c|c|c|c|}
\hline & \multirow{3}{*}{ Indicadores } & \multirow{2}{*}{\multicolumn{5}{|c|}{$\begin{array}{l}\text { Escala de } \\
\text { valoración }\end{array}$}} & \multicolumn{3}{|c|}{ Aspectos } \\
\hline & & & & & & & \multirow{2}{*}{$\begin{array}{c}\text { Positivo } \\
\mathbf{s}\end{array}$} & \multirow{2}{*}{$\begin{array}{l}\text { Negativ } \\
\text { os }\end{array}$} & \multirow{2}{*}{$\begin{array}{c}\text { Sugere } \\
\text { ncias }\end{array}$} \\
\hline & & 1 & 2 & 3 & 4 & 5 & & & \\
\hline Claridad & $\begin{array}{l}\text { Es formulado con lenguaje } \\
\text { apropiado }\end{array}$ & & & & & & & & \\
\hline Objetividad & $\begin{array}{l}\text { Esta expresado en conductas } \\
\text { observables }\end{array}$ & & & & & & & & \\
\hline Actualidad & $\begin{array}{l}\text { Adecuado al avance de la ciencia } \\
\text { pedagógica }\end{array}$ & & & & & & & & \\
\hline Organización & Existe una organización lógica & & & & & & & & \\
\hline Suficiencia & $\begin{array}{l}\text { Comprende los aspectos de } \\
\text { cantidad y calidad }\end{array}$ & & & & & & & & \\
\hline Intencionalidad & $\begin{array}{lccc}\text { Adecuado para valorar los } \\
\text { aspectos de la(s) variable(s) }\end{array}$ & & & & & & & & \\
\hline Consistencia & $\begin{array}{l}\text { Basado en aspectos teóricos } \\
\text { científicos de la Psicología }\end{array}$ & & & & & & & & \\
\hline Coherencia & $\begin{array}{l}\text { Entre los índices, indicadores y las } \\
\text { dimensiones }\end{array}$ & & & & & & & & \\
\hline Metodología & $\begin{array}{l}\text { La estrategia responde al } \\
\text { propósito del diagnóstico }\end{array}$ & & & & & & & & \\
\hline Pertinencia & $\begin{array}{l}\text { Es útil y adecuado para la } \\
\text { investigación }\end{array}$ & & & & & & & & \\
\hline
\end{tabular}

\section{Aportes o sugerencias para el perfeccionamiento del resultado científico:}

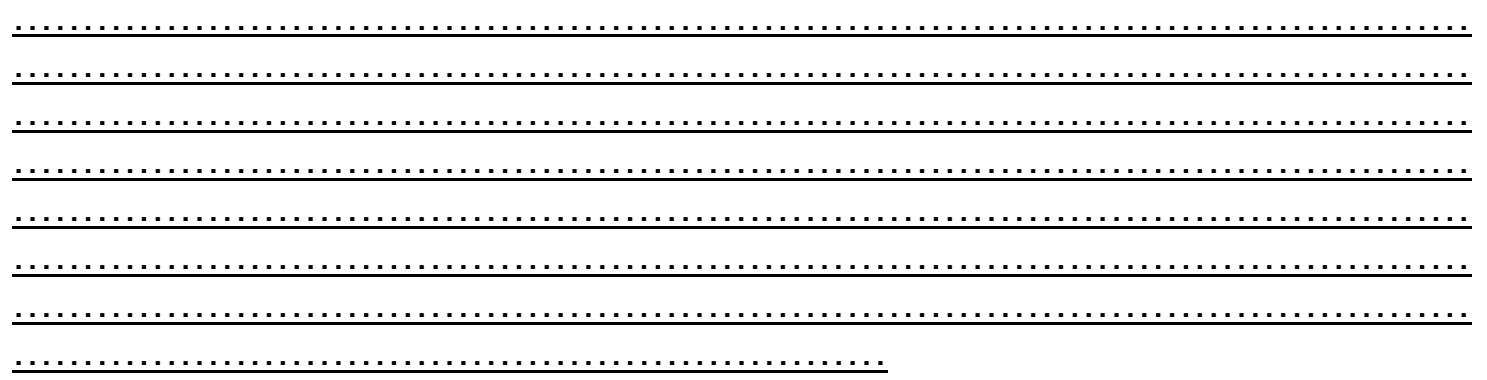

II. Opinión de aplicabilidad.

III. RESULTADOS

PROMEDIO DE VALORACIÓN INTERNA: VALORACIÓN EXTERNA: _ (50\%) (50\%) + PUNTAJE DE RESULTADO DE VALORACIÓN: 
Tabla de Valoración

\begin{tabular}{ll}
\hline Deficiente & $0-25$ \\
Baja & $25-50$ \\
Regular & $51-70$ \\
Buena & $71-85$ \\
Muy Buena & $86-100$ \\
\hline
\end{tabular}

1. Deficiente ( )

2. Baja

3. Regular

4. Buena

5. Muy buena ( )

OPINIÓN DE APLICABILIDAD:
a) Deficiente ( )
b) Baja ( )
c) Regular ( )
d) Buena ( )
e) Muy Buena ( )

Nombres y Apellidos

Dirección domiciliaria

Título profesional /

Especialidad

Grado Académico

Mención

\section{DNI N ${ }^{\mathrm{a}}$}

Teléfono / Celular
Firma

Lugar y fecha: 
Anexo 8. Análisis estadístico de la encuesta a estudiantes

1. ¿Consideras que es de importancia las TIC?

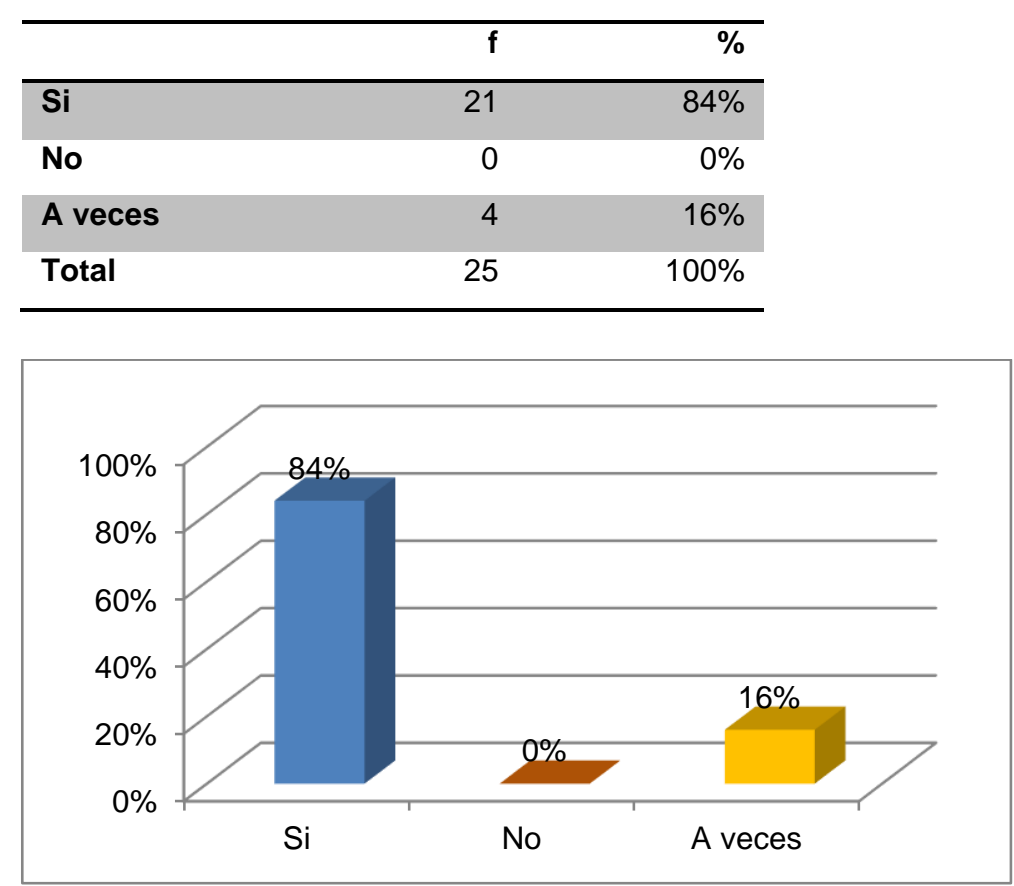

2. ¿El docente utiliza las TIC en sus clases?

\begin{tabular}{lrr}
\hline & $\mathbf{f}$ & $\%$ \\
\hline Si & 14 & $56 \%$ \\
No & 3 & $12 \%$ \\
A veces & 8 & $32 \%$ \\
Total & 25 & $100 \%$ \\
\hline
\end{tabular}

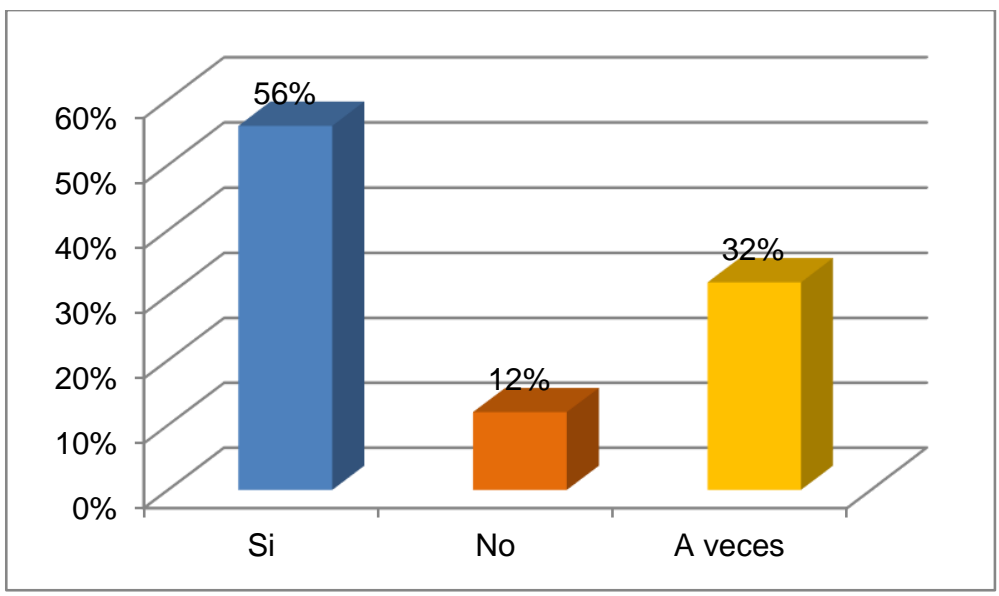


3. ¿Cuándo el profesor utiliza videos, PowerPoint, animaciones, aula virtual y foro, ¿consideras que aprendes con mayor facilidad?

\begin{tabular}{lrr}
\hline & $\mathbf{f}$ & $\%$ \\
\hline Si & 25 & $100 \%$ \\
No & 0 & $0 \%$ \\
A veces & 0 & $0 \%$ \\
Total & 25 & $100 \%$ \\
\hline
\end{tabular}

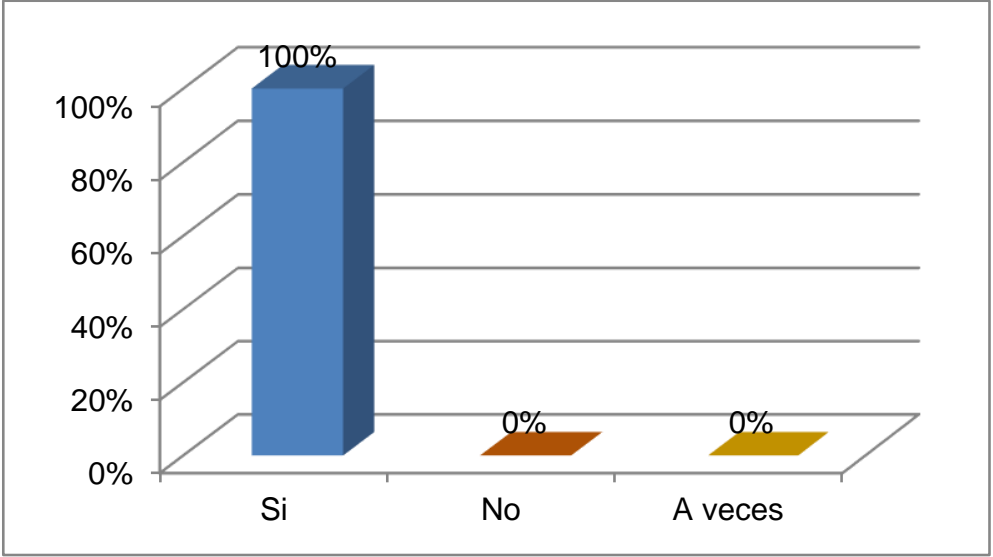

4. ¿El profesor explica el contenido de la clase utilizando sistemas de preguntas que hacen comprender mejor el contenido de la clase? ¿Ejemplos del contexto de la profesión?

\begin{tabular}{lrr}
\hline & $\mathbf{f}$ & \multicolumn{2}{c}{$\%$} \\
\hline Si & 14 & $56 \%$ \\
No & 3 & $12 \%$ \\
A veces & 8 & $32 \%$ \\
Total & 25 & $100 \%$ \\
\hline
\end{tabular}

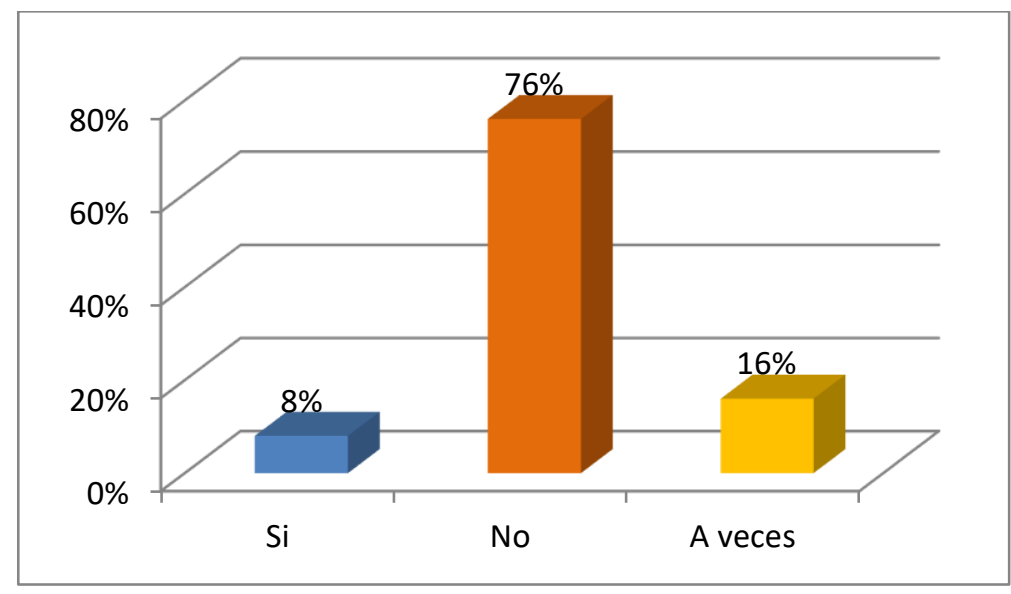


Señala a continuación los métodos que emplea el docente en la clase

\section{Exposición del Contenido}

\begin{tabular}{lrr}
\hline & $\mathbf{f}$ & $\%$ \\
\hline Si & 25 & $100 \%$ \\
No & 0 & $0 \%$ \\
A veces & 0 & $0 \%$ \\
Total & 25 & $100 \%$ \\
\hline
\end{tabular}

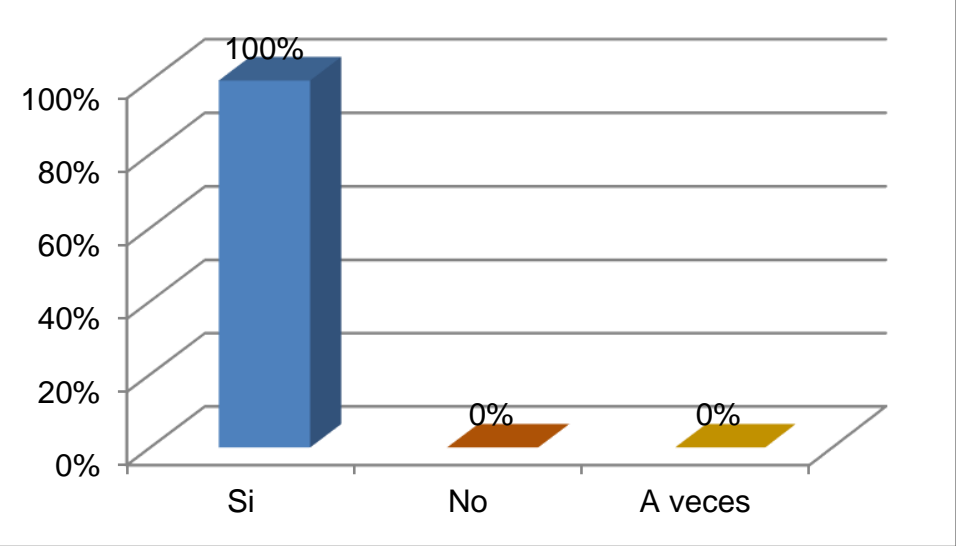

\section{Problematiza el contenido de la clase}

\begin{tabular}{lrr}
\hline & $\mathbf{f}$ & $\%$ \\
\hline Si & 1 & $4 \%$ \\
No & 15 & $60 \%$ \\
A veces & 9 & $36 \%$ \\
Total & 25 & $100 \%$ \\
\hline
\end{tabular}

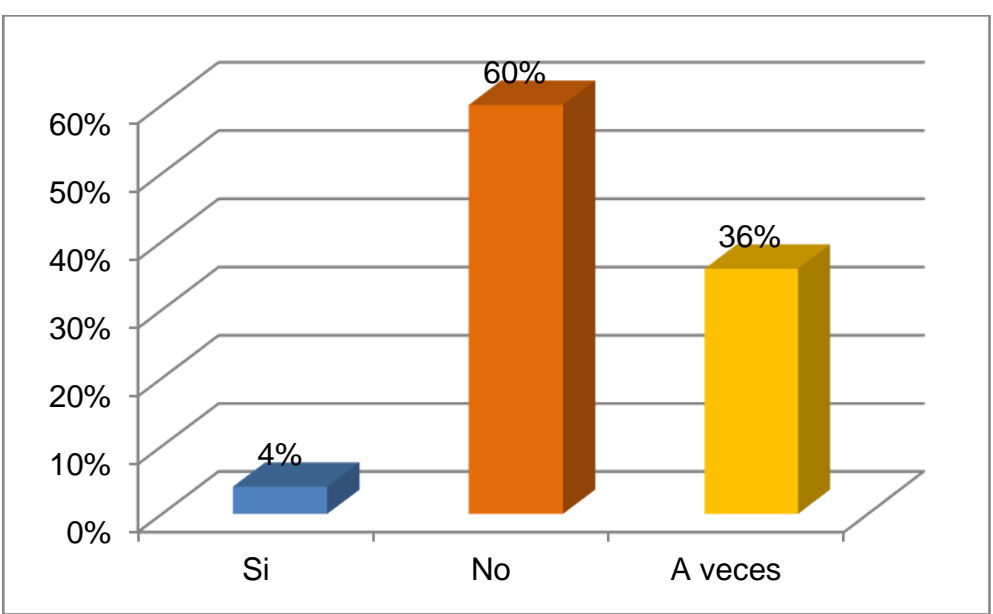




\section{Método de proyecto}

\begin{tabular}{lrr}
\hline & $\mathbf{f}$ & $\%$ \\
\hline Si & 0 & $0 \%$ \\
No & 25 & $100 \%$ \\
A veces & 0 & $0 \%$ \\
Total & 25 & $100 \%$ \\
\hline
\end{tabular}

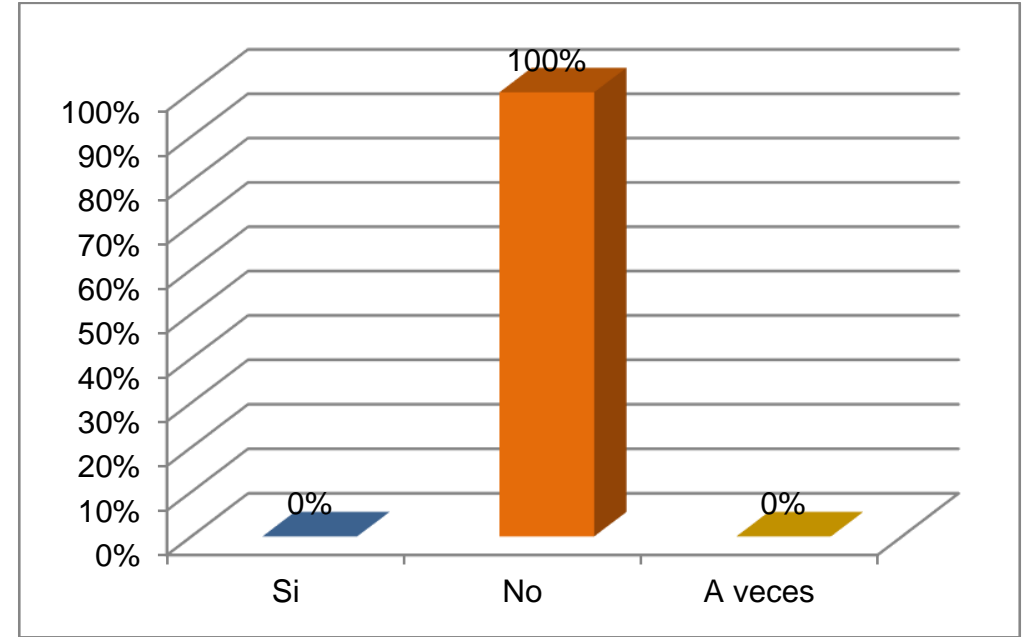

\section{Actividades investigadoras}

\begin{tabular}{lrr}
\hline & $\mathbf{f}$ & $\%$ \\
\hline Si & 10 & $40 \%$ \\
No & 9 & $36 \%$ \\
A veces & 6 & $24 \%$ \\
Total & 25 & $100 \%$ \\
\hline
\end{tabular}

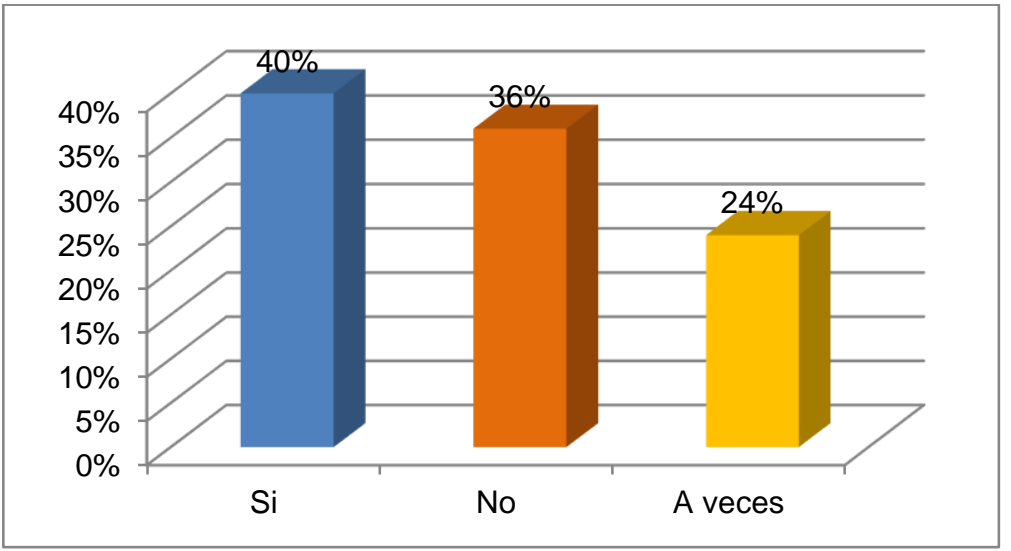




\section{Trabajo en grupo}

\begin{tabular}{lrr}
\hline & $\mathbf{f}$ & $\%$ \\
\hline Si & 14 & $56 \%$ \\
No & 8 & $32 \%$ \\
A veces & 3 & $12 \%$ \\
Total & 25 & $100 \%$ \\
\hline
\end{tabular}

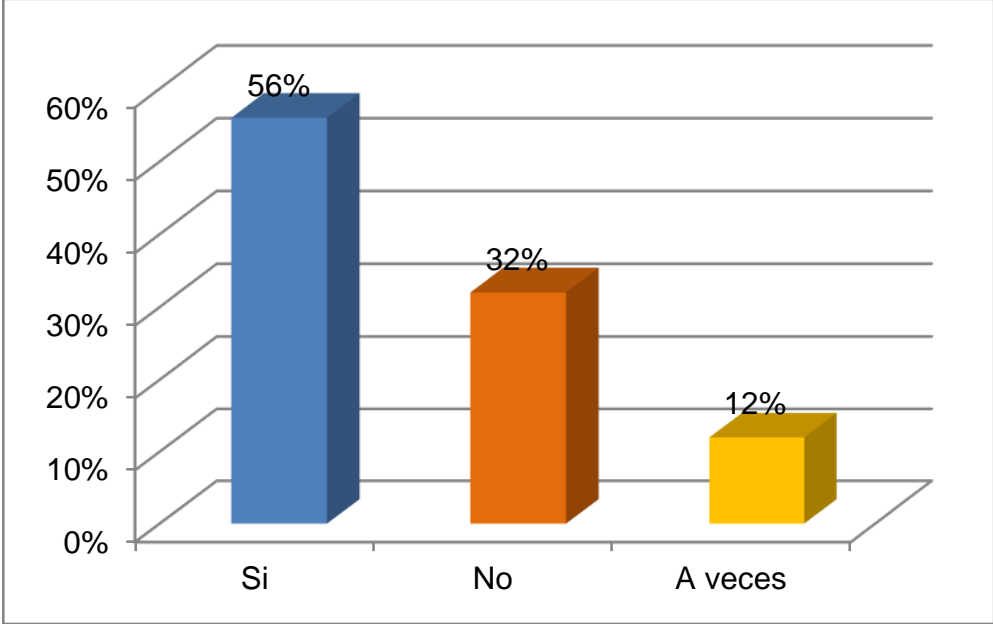

10. Trabajo a realizar en Internet

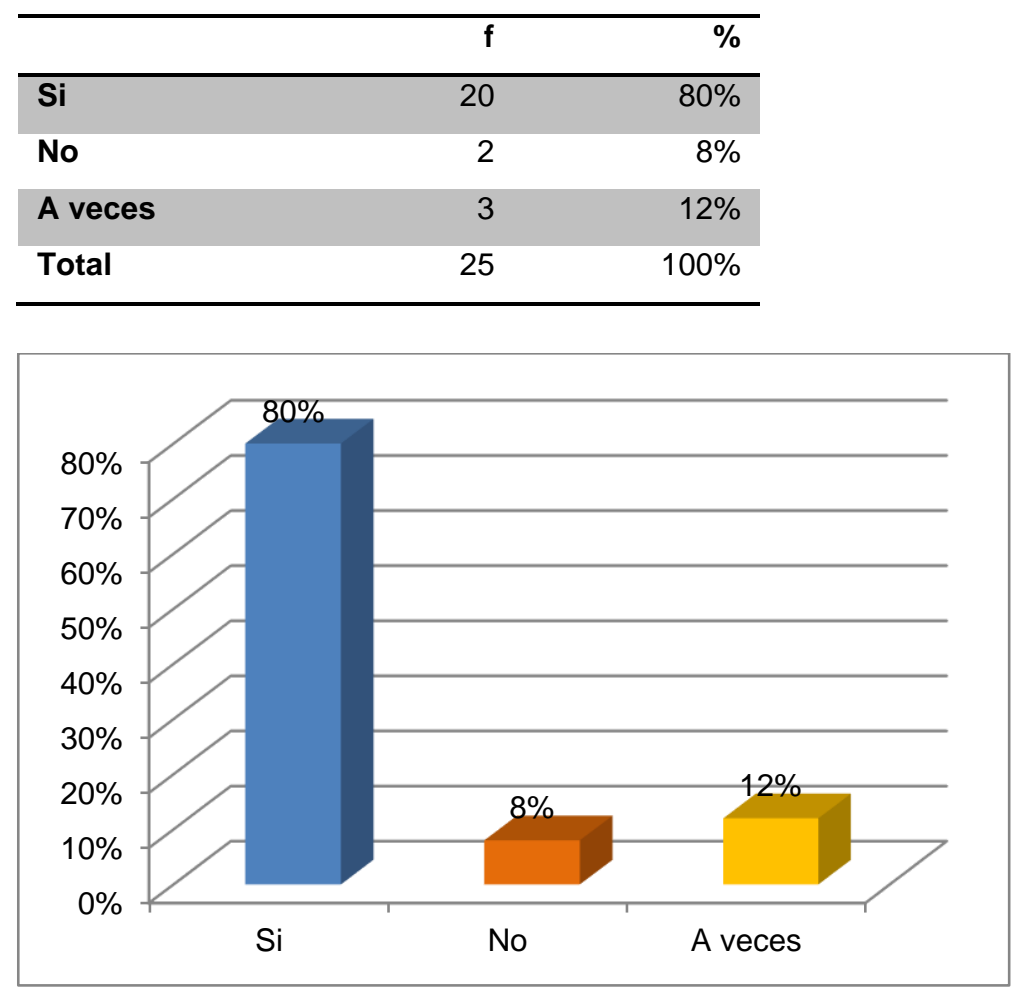


11. ¿EI profesor realiza evaluación participativa utilizando las herramientas tecnológicas?

\begin{tabular}{lrr}
\hline & $\mathbf{f}$ & $\%$ \\
\hline Si & 1 & $4 \%$ \\
No & 18 & $72 \%$ \\
A veces & 6 & $24 \%$ \\
Total & 25 & $100 \%$ \\
\hline
\end{tabular}

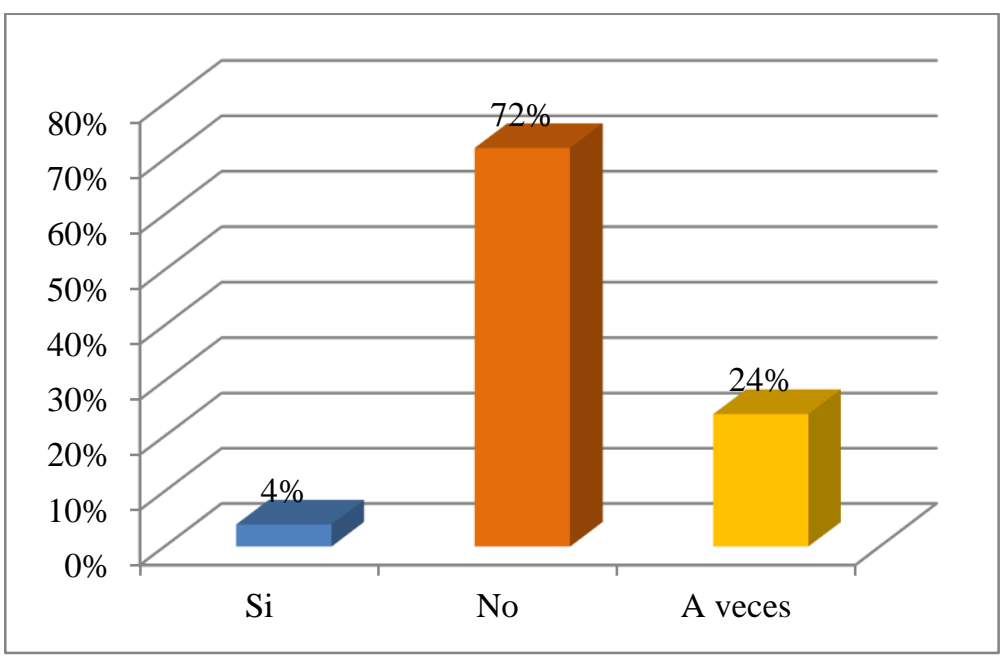

12. ¿Te gustaría que el profesor utilice las diferentes herramientas que las TIC ofrece?

\begin{tabular}{lrr}
\hline & $\mathbf{f}$ & $\%$ \\
\hline Si & 25 & $100 \%$ \\
No & 0 & $0 \%$ \\
A veces & 0 & $0 \%$ \\
Total & 25 & $100 \%$ \\
\hline
\end{tabular}

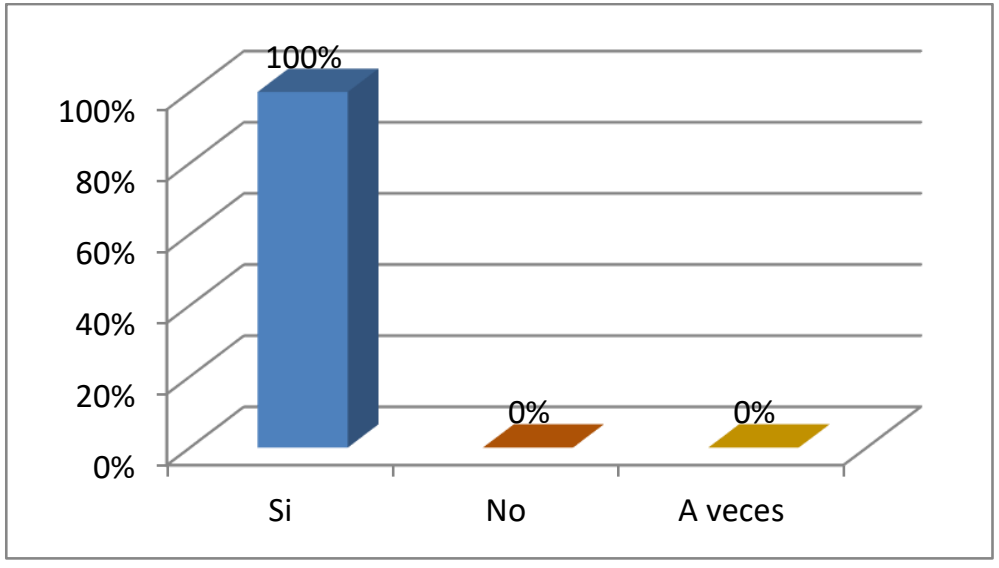


13. ¿Crees que las TIC y las herramientas tecnológicas fortalecen tus conocimientos y habilidades para formarte de manera integral?

\begin{tabular}{lrr}
\hline & $\mathbf{f}$ & $\%$ \\
\hline Si & 25 & $100 \%$ \\
No & 0 & $0 \%$ \\
A veces & 0 & $0 \%$ \\
Total & 25 & $100 \%$ \\
\hline
\end{tabular}

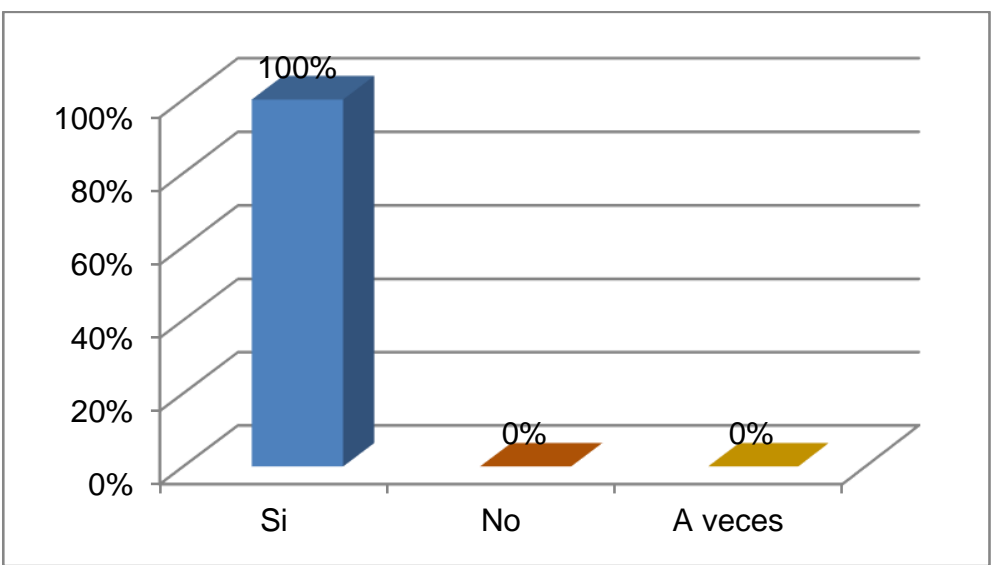

14. ¿Los docentes de las otras asignaturas utilizan las TIC y las herramientas tecnológicas en el desarrollo de la clase?

\begin{tabular}{lrr}
\hline & $\mathbf{f}$ & $\%$ \\
\hline Si & 17 & $68 \%$ \\
No & 0 & $0 \%$ \\
A veces & 8 & $32 \%$ \\
Total & 25 & $100 \%$ \\
\hline
\end{tabular}

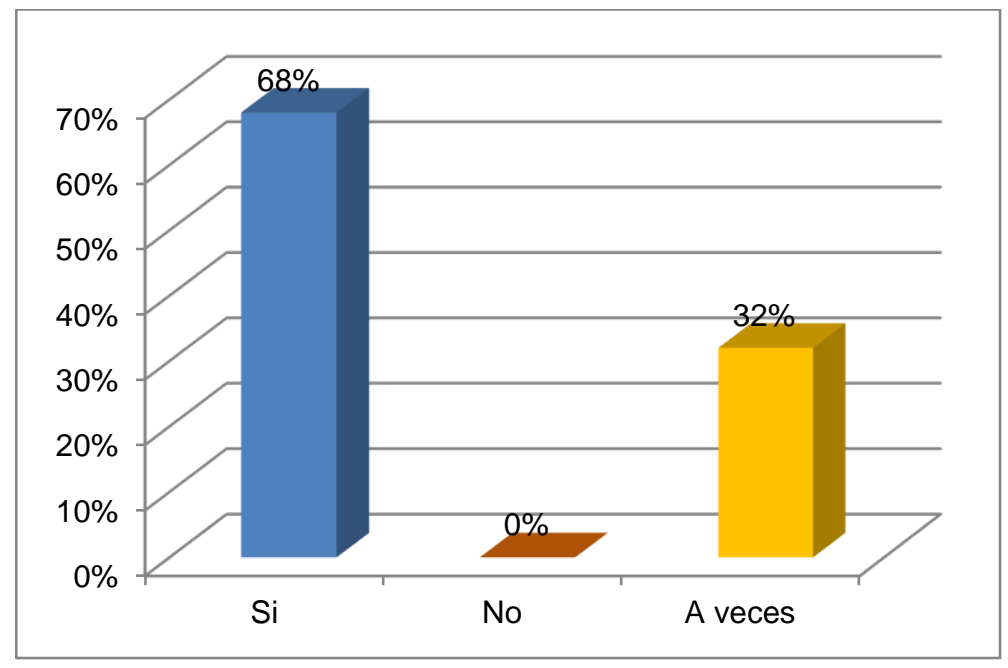


15. ¿En tus tiempos libres realizas tareas de aprendizajes de la carrera empleando las tecnologías de información?

\begin{tabular}{lrr}
\hline & $\mathbf{f}$ & $\%$ \\
\hline Si & 25 & $100 \%$ \\
No & 0 & $0 \%$ \\
A veces & 0 & $0 \%$ \\
Total & 25 & $100 \%$ \\
\hline
\end{tabular}

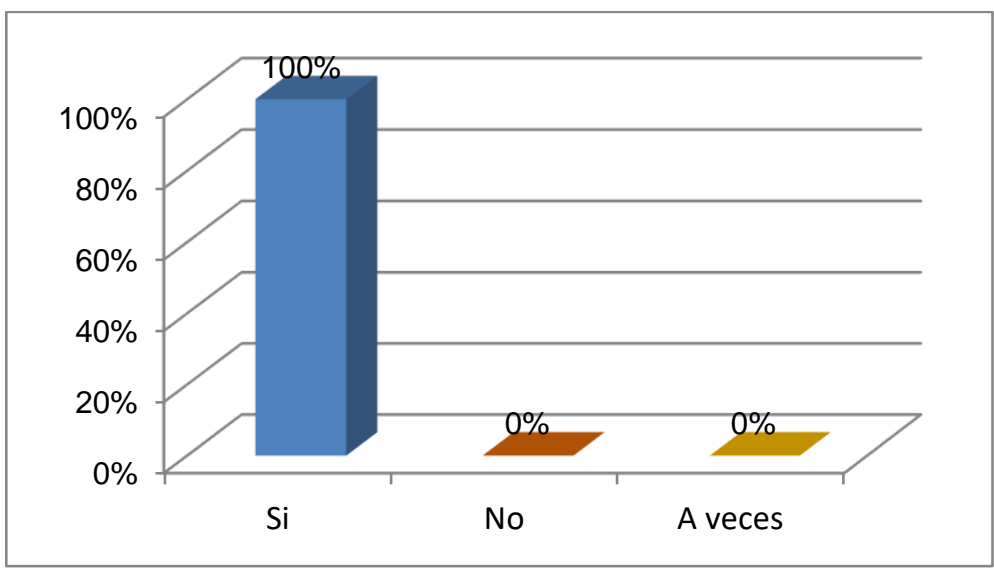

